\title{
Gender sensitivity in health care practices : from awareness to action
}

Citation for published version (APA):

Çelik, H. (2009). Gender sensitivity in health care practices : from awareness to action. [Doctoral Thesis, Maastricht University]. Datawyse / Universitaire Pers Maastricht. https://doi.org/10.26481/dis.20091120hc

Document status and date:

Published: 01/01/2009

DOI:

10.26481/dis.20091120hc

Document Version:

Publisher's PDF, also known as Version of record

\section{Please check the document version of this publication:}

- A submitted manuscript is the version of the article upon submission and before peer-review. There can be important differences between the submitted version and the official published version of record.

People interested in the research are advised to contact the author for the final version of the publication, or visit the DOI to the publisher's website.

- The final author version and the galley proof are versions of the publication after peer review.

- The final published version features the final layout of the paper including the volume, issue and page numbers.

Link to publication

\footnotetext{
General rights rights.

- You may freely distribute the URL identifying the publication in the public portal. please follow below link for the End User Agreement:

www.umlib.nl/taverne-license

Take down policy

If you believe that this document breaches copyright please contact us at:

repository@maastrichtuniversity.nl

providing details and we will investigate your claim.
}

Copyright and moral rights for the publications made accessible in the public portal are retained by the authors and/or other copyright owners and it is a condition of accessing publications that users recognise and abide by the legal requirements associated with these

- Users may download and print one copy of any publication from the public portal for the purpose of private study or research.

- You may not further distribute the material or use it for any profit-making activity or commercial gain

If the publication is distributed under the terms of Article $25 \mathrm{fa}$ of the Dutch Copyright Act, indicated by the "Taverne" license above, 
Gender Sensitivity in Health Care Practices:

From Awareness to Action

Halime Çelik 
(C) Copyright Halime Çelik, Maastricht 2009

ISBN 9789052788760

Printed by Datawyse|Universitaire Pers Maastricht

Cover by Geertjan van Zonneveld

The cover symbolizes the constitution of our society: diverse and colourful. The health needs of these people are also diverse and require health professionals who are sensitive for these differences. 


\title{
Gender Sensitivity in Health Care Practices:
}

\section{From Awareness to Action}

\author{
PROEFSCHRIFT
}

Ter verkrijging van de graad van doctor aan de Universiteit Maastricht op gezag van de Rector Magnificus, Prof. mr. G.P.M.F. Mols

volgens het besluit van het College van Decanen, in het openbaar te verdedigen

op vrijdag 20 november 2009 om 12.00 uur

door

Halime Celik

Geboren op 12 juni 1978 te Heusden

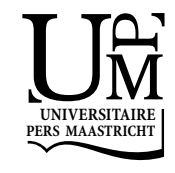




\section{Promotores}

Prof. dr. G.A.M. Widdershoven (UM/VU MC)

Prof. dr. A.L.M. Lagro-Janssen (UMC St Radboud Nijmegen)

\section{Copromotor}

Dr. T.A. Abma (UM/VU MC)

\section{Beoordelingscommissie}

Prof. dr. F.C.B. van Wijmen (voorzitter)

Prof. dr. Y.W.M. Benschop (UMC St Radboud, Nijmegen)

Dr. B.J.A.M. Bottema (UMC St Radboud, Nijmegen)

Prof. dr. A. Brand

Prof. dr. A.J.J.A. Scherpbier

The production of this thesis is sponsored by Temel Zorg.

The studies described in this thesis were funded by grants from the Netherlands Organization for Health Research and Development (ZonMw, grant numbers: 36100015 and 36100 030) and by the School for Public Health and Primary Care (Caphri). 
Preconceived notions are the locks on the door to wisdom. Merry Browne

Aan mijn ouders Aan Yasin Aan Sara \& Selin 



\section{Contents}

CHAPTER 1 General introduction 9

CHAPTER 2 Implementation of diversity in healthcare practices: barriers and 17 opportunities

Celik. H, Abma TA, Widdershoven GAM, van Wijmen FCB, Klinge I

Patient, Education \& Counseling, 2008, 71: 65-71

CHAPTER 3 Bringing gender sensitivity into health care practice: a systematic review

Celik. H, Lagro-Janssen ALM, Klinge I, Widdershoven GAM, Abma TA

Submitted

CHAPTER 4 Gender sensitivity among general practitioners: results of a training programme

Celik H, Klinge I, van der Weijden T, Widdershoven GAM, Lagro-Janssen ALM BMC Medical Education, 2008, 8(36)

CHAPTER 5 Maintaining Gender Sensitivity in the Family Practice:

Facilitators and Barriers

Celik H, Lagro-Janssen ALM, Klinge I, van der Weijden T, Widdershoven GAM Journal of Evaluation in Clinical Practice, 2009. In Press

CHAPTER 6 Process evaluation of a diversity training programme: the value of a mixed method Strategy.

Celik. H, Abma TA, Klinge I, Widdershoven GAM

Submitted

CHAPTER 7 General discussion and conclusion

Summary

Samenvatting

Dankwoord

Curriculum Vitae

List of Publications 



\title{
Chapter 1
}

\author{
General introduction
}




\section{INTRODUCTION}

The WHO's states that the enjoyment of the highest attainable standard of health is one of the fundamental rights of every human being without distinction of race, religion, political belief, economic or social condition. As our concepts of health and healthcare are evolving, new opportunities and challenges are being placed on the quality of healthcare. Good quality of healthcare and a high standard of health is closely intertwined with and influenced by understanding gender differences between patients and their own particular sets of needs, obstacles and expectations. ${ }^{1-3}$ To recognize and appreciate the patient not just as a medical problem, but as a person, health professionals need to be sensitive to understand the individual patient by paying explicit attention to the interplay of characteristics like gender, ethnicity and socio economic class (SES). This is called intersectionality.

\section{THEORETICAL FRAMEWORK}

Gender is a product of the social construction of (biological) differences between males and females. ${ }^{4,5}$ Gender is a dynamic process; it is influenced by changing cultural notions and conceptualizations of masculinity and femininity. ${ }^{6,7}$ When it comes to health, women and men will not only differ in terms of their biological make up (vulnerability for and prevalence of diseases, hormonal make-up, etc.), they will also encounter different responses by healthcare professionals and others. Their experiences of health and illness, their communication and presentation of symptoms will at least partly be influenced by these responses, and their social position, including their ethnicity and social economic position.

Sensitivity for gender issues in health care means that health professionals have the knowledge and are competent to perceive existing gender differences, and to incorporate these into their decision making and actions. ${ }^{8-10}$ A gender sensitive perspective in medicine would imply that life conditions, positions in society, and societal notions about femininity and masculinity should be considered along with biological determinants in all professional interactions. ${ }^{11}$ It is commonly accepted that gender does not exist in a vacuum, but rather in a social and cultural context. ${ }^{1}$ Sensitivity for gender issues ipso facto includes the consideration that various dimensions of difference (age, ethnicity and social-economic status) are connected and work together to shape patients' health needs. ${ }^{12}$ To take account for the interaction of the multiple dimensions is the so-called intersectional approach. Davis defines intersectionality as 'the interaction between gender, race, and other categories of difference in individual lives, social practices, institutional arrangements, and cultural ideologies and the outcomes of these interactions in terms of power'. ${ }^{13}$ The introduction of the concept of intersectionality in health and health care is only emerging and still under discussion. ${ }^{7}$ In this dessertation we have adopted intersectionality as a framework for understanding gender issues and 
health inequities, because it does not categorize patients in homogeneous groups. The concept acknowledges that although categorical differences between women and men can be found, it promotes an individualized and person-centered approach of patients.

To integrate gender related experiences, knowledge and interests at all levels of an institution, the strategy of mainstreaming gender was adopted at the 1995 Fourth World Conference on Women in Beijing (See for a comprehensive description: Celik \& Klinge, 2005). ${ }^{14}$ Mainstreaming gender illuminates the significance of gender as a central element of thinking and acting, and recognizes its role in power relations and institutions. ${ }^{15}$ While this strategy initially appeared as a 'revolutionary concept' ${ }^{\text {'16,17 }}$ discursive debates arose, especially among feminist scholars. ${ }^{18-20}$ They have been critical towards the strategy, since they maintained that important issues were excluded or marginalized in the realm of policy, such as the underrepresentation of women and women issues in policymaking. ${ }^{21}$ Another critical point on mainstreaming gender is that categories of diversity are listed as an add-on to gender. ${ }^{15}$ The intersectional approach to gender in health, as adopted here, emphasizes that various dimensions of difference interact and mutually influence each other.

\section{PROBLEM DEFINITION}

That sex and gender matter in health and health care has been demonstrated in a high number of studies and gender and health have come to the forefront in the scientific arena. It has been shown that there are differences in epidemiology, presentation and course of diseases, as well as in treatment effectiveness and prognosis. ${ }^{22}$ At present, we have increasing knowledge about the influences of different categories on health and how disparities between the sexes in health prevail to exist. However, this growing body of knowledge does not automatically mean that gender sensitivity has been implemented in healthcare practices. We need to identify not only the differences in patients' needs themselves, but also the constraints that healthcare practices and professionals face in trying to meet patients' needs. Thus far, we seem to lack best practices and ways for successful implementation of gender related knowledge in health care.

To promote the uptake and dissemination of gender sensitivity in practice, best practices can be vehicles to apply knowledge, improve it and share the lessons learned with health professionals. According to Grol \& Grimshaw and Green best practices are processes rather than packaged interventions. ${ }^{23,24}$ Continuous learning about how to improve and adapt best practices through feedback, reflection and analysis from theory and practice should be part of this process. 


\section{AIM OF THE PROJECT}

Our project aimed to improve and sustain gender sensitivity in healthcare practices. The aim reached beyond the description of gender issues in healthcare and the theoretical development of the intersectional framework. The main purpose was to apply this framework in practice by developing an intervention (training), implementing the intervention and evaluating its outcomes in order to improve the intervention, and to gain a better understanding of the dynamics in the process of implementation of gender sensitivity in healthcare practice.

The thesis was guided by the following research questions: (1) What is the state of art concerning the provision of gender sensitive healthcare? (2) What are facilitators and barriers regarding the provision of gender sensitive healthcare? (3) How can we bring gender sensitivity into health care practice? (4) How can we promote the implementation of gender sensitivity in health care practices? (5) What are best practices for gender sensitive healthcare?

\section{APPROACH}

To bring gender sensitivity in practice as an attempt to develop best practices we chose to include different healthcare practices: General Practice, Mental health practice, Hospital and Nursing Home practice. This approach allowed us to gain insight into the features of primary and secondary health care practices, and investigate whether these are conducive or not towards the implementation of gender sensitivity. During this implementation project, continuous learning was part of the process. Based on the literature, we started with developing a training program for health professionals. The training aimed to improve the gender sensitivity of the participating general practitioners, general directors, physicians, nurses, nurse managers and gender experts working in health care practices. The evaluation of the training started at the same time as the intervention, which enabled us to monitor the implementation process as well as the results. To provide a nuanced and comprehensive understanding of the implementation of gender sensitivity in different healthcare practices, a combination of quantitative and qualitative research methods were used. The evaluation provided the bases for practical recommendations.

\section{OUTLINE OF THE THESIS}

The thesis is structured as follows: In Chapter 2 we will investigate by means of interviews and focus groups the extent to which healthcare practices are already gender sensitive. In addition we will examine the opportunities and barriers for implementing a 
gender perspective in healthcare practices. In Chapter 3 we will report a systematic literature review related to the implementation of gender sensitivity in the provision of health care in various countries around the world. In Chapter 4 we will describe the quantitative results of the training program for general practitioners, which led to recommendations to enhance gender sensitivity among health professionals. In Chapter 5 we will identify facilitators and barriers perceived by general practitioners to maintain gender sensitivity in practice. In Chapter 6 we will present a process evaluation of a gender sensitive training program provided in a mental health practice, hospital practice and nursing home practice. In this chapter we will show that using mixed methods, and an integration of quantitative and qualitative data resulted in complementary and more comprehensive results. Finally, in Chapter 7 we will provide an overall discussion and conclusion. 


\section{REFERENCES}

1. Lagro-Janssen T (2007). Sex, Gender and Health: Developments in Research. European Journal of Women's Studies 14(1): 9-20.

2. Harmsen JAM, Bernsen RMD, Meeuwesen L, Pinto D, Bruijnzeels MA (2005). Assessment of mutual understanding of physician patient encounters: development and validation of mutual understanding scale (MUS) in a multicultural general practice setting. Patient Education \& Counseling 59: 171-181.

3. Klinge I \& Maguire P (2004). The Policy implications of Gender Mainstreaming for Healthcare Research in the EU. Pharmacoeconomics 22 Suppl. 2: 87-93.

4. Doyal L (2000). Sex, Gender and Health: debates and dilemmas. Social Science \& Medicine 51: 931-939.

5. Doyal L (2001). Sex, Gender, and Health: the need for a new approach. British Medical Journal 323: 1061-1063.

6. Moerman CJ \& Van Mens-Verhulst J (2004) Gender-sensitive epidemiological research: suggestions for a gender-sensitive approach towards problem definition, data collection and analysis in epidemiological research. Psychology, Health \& Medicine 9, 41-52.

7. Bekker MHJ (2003). Investigating gender within health research is more than sex disaggregation of data: a Multi- Facet Gender and Health Model. Psychology, Health \& Medicine 8, 231-244.

8. Celik H, Lagro-Janssen ALM, Klinge I, Widdershoven GAM, Abma T (2009) Bringing Gender Sensitivity into Health Care Practice. (Submitted)

9. WHO (1998). Gender and health: technical report. Geneva: World Health Organization.

10. Verdonk P, Benschop YWM, Haes JCM de, Lagro-Janssen TLM (2008). Medical Students' Gender Awareness. Construction of the Nijmegen Gender Awareness in Medicine Scale (N-GAMS). Sex roles 58:222-234.

11. Risberg G, Johansson EE, Westman G, Hamberg K (2008). Attitudes toward and experiences of gender issues among physician teachers: A survey study conducted at a university teaching hospital in Sweden. BMC Medical Education, 8:10.

12. Bekker MHJ, Vliet KP van, Kolk AM (1999). Realising gender-sensitive health care; the role of research. In: Kolk AM, Bekker MHJ, Van Vliet KP (Eds.). Advanced studies in Women and Health Research: toward gender-sensitive strategies. Tilburg: Tilburg University Press.

13. Davis K (2008). Intersectionality as buzzword: A sociology of science perspective on what makes a feminist theory successful. Feminist Theory 9: 67- 85.

14. Celik H, Klinge I (2005). Mainstreaming gender en diversiteit in de gezondheidszorg. Zijn we op weg naar een diversiteitsbewuste gezondheidszorg? Tijdschrift voor genderstudies 2: 12-22.

15. Hankivsky O (2005). Gender vs. Diversity Mainstreaming: A Preliminary Examination of the Role and Transformative Potential of Feminist Theory. Canadian Journal of Political Science 38(4): 977-1001.

16. Pollack MA \& Hafner-Burton E (2000). Mainstreaming Gender in the European Union. Journal of European Public Policy 7(3):432-456.

17. Rees T (2001). Mainstreaming gender equality in science in the European Union' Gender and Education 13(3), 243-260.

18. True J \& Mintron M (2001). Transnational Networks and Policy Diffusion: The Case of Gender Mainstrreaming. International Studies Quarterly 45: 27-57.

19. Woodward AE (2001). Gender Mainstreaming in European Policy: Innovation or Deception? Discussion paper FSS 01-103. Berlin: Wissenschaftszentrum Berin für Sozialforschung.

20. Woodward AE (2003). European Gender Mainstreaming: Promises and Pitfalls of Transformative Policy. Review of Policy Research 20(1): 65-88.

21. Verloo M (2001). Another Velvet Revolution? Gender Mainstreaming and the Politics of Implementation. IWM Working Paper no 5. Vienna.

22. Wizemann TM \& Pardue ML (2001). Exploring the biological contribution to human health: Does sex matter? Washington DC: National Academy Press. 
23. Grol R \& Grimshaw J (2003). From best evidence to best practice: effective implementation of change in patients' care. The Lancet 632: 1225-1230.

24. Green LW (2001). From Research to "Best Practices" in Other Settings and Populations. American Journal of Health Behaviour 25(3):165-178. 



\title{
Chapter 2
}

\section{Implementation of diversity in healthcare practices: barriers and opportunities}

\author{
H. Celik \\ T.A. Abma \\ G.A.M. Widdershoven \\ F.C.B. van Wijmen \\ I. Klinge
}




\section{A B S TRACT}

The aim of this study is to investigate to which extent diversity is part of current healthcare practices and to explore opportunities and barriers in the implementation of diversity dimensions in healthcare practices. Nine in-depth, semi-structured interviews and three focus groups were conducted in three healthcare settings (mental health, hospital, nursing home care). Our results demonstrate that (the potential of) diversity is an ambiguous issue; diversity is said to be important, but this has not led to adjustments of the neutral, disease-oriented approach of patients. If recognized at all, diversity is reduced to one dimension (sex). Barriers in the implementation of diversity relate to: (a) lacking awareness and knowledge of diversity, (b) poor information and communication, and (c) organizational constraints. Opportunities to implement diversity in healthcare include: (d) an emerging sense of urgency to attend to diversity, (e) the development of good practices, and (f) the political climate. We conclude that various barriers and some opportunities for the implementation of diversity in healthcare practices have been identified. There is an ambiguity in how professionals deal with diversity. As a result, the neutral approach remains dominant in practice and policy. In order to raise the awareness and enhance the competence of professionals, educational programmes and learning networks are required. 


\section{INTRODUCTION}

Since more than a decade, diversity has been addressed by experts as important for health and healthcare. ${ }^{1-4}$ Diversity refers to the combination of certain dimensions of difference (patient's biology, gender, age, culture, and education) that interact and can result in dissimilar needs and preferences. ${ }^{5,6}$ These differences in health demand require careful evaluation because of disparities and disadvantages in access, diagnosis, and treatment between patient populations. The unequal allocation of healthcare services can adversely affect patients' health. ${ }^{7}$ The question is whether or not this body of knowledge has been implemented and what the barriers and opportunities are to integrate diversity in healthcare practices.

Diversity has long been ignored as a relevant issue on policy agenda's in healthcare research and practices. ${ }^{8-11}$ The current approach in healthcare is more or less neutral and widely used as a golden standard. ${ }^{12,13}$ Neutral means an a priori assumption that equality stands for non-discrimination by not making differences in healthcare. However, this approach is not accommodated to a diverse patient population and promotes preservation of inequalities. A concept that makes the multiple combinations of diversity dimensions in patients visible is needed. ${ }^{14}$ The basis and sensitivity for dimensions of diversity seems to be poorly developed in healthcare delivery.

Current healthcare practices are structured in ways that support the neutral approach and keep dimensions of diversity invisible and hidden. It is not widely acknowledged that differences matter and can have clinical implications. ${ }^{15} \mathrm{~A}$ well-known case at this point is the presentation, diagnosis and treatment of angina pectoris (chest pain) by men and women. Men do mostly present their symptoms in a classical or typical manner, whereas women present it mainly atypically. ${ }^{16}$ Because of physicians' bias (focus on typical symptoms and presentation style) men are easily diagnosed as suffering from severe angina pectoris, while women with the same problems (but different presentation style) are left unnoticed. Men were more often than women referred to a specialist. ${ }^{17}$ Undertreatment of women with angina pectoris is also related to socioeconomic status (SES); the lower the status, the higher the rate of morbidity. ${ }^{18-21}$ This example, illustrating the relevance of both sex and SES, shows the need to move beyond a neutral approach. Clinical practice guidelines and policy instruments can play an important role in this movement given their impact on decision making in care giving.

To serve a heterogeneous patient population and to achieve the highest standard on outcomes, a novel strategy for tackling this neutral approach is warranted. ${ }^{22,23}$ The first step for an effective strategy is to explore opportunities and barriers for taking diversity seriously into account in healthcare practices. The aim of this exploratory study is to gain an in-depth insight in the opportunities and barriers for implementing a diversity perspective in healthcare practices. To illuminate the 'blind spot' concerning diversity dimensions in healthcare practices, nine interviews and three focus groups in 
Dutch healthcare settings (mental health, hospital, and nursing home care) were conducted among healthcare professionals and managers.

\section{METHODS}

This exploratory study was based on a qualitative approach since this allowed us to complete an in-depth analysis of the nature of the existing problems regarding the implementation of diversity as experienced by various stakeholders. ${ }^{24}$ Identified stakeholders in this study include: five managers (two general directors and three nursing managers) and four healthcare professionals (one physicians, and three nurses). We performed semi-structured interviews, as this is a suitable approach to examine the experiences and views of various stakeholders. Pilot interviews were conducted with academic experts to optimize the interview guide. Our topics (sex, culture, age, disability and social economic status) served as an initial framework for the interviews. Subthemes at policy level (protocols and guidelines, recruitment, educational and financial policy) and for the care process (information material for patients, intake, diagnosis and treatment) were also topics in the interviews.

In total nine in-depth interviews were conducted in three Dutch healthcare practices: mental health, hospital, and nursing home care. The interviews, which lasted between 40 and $60 \mathrm{~min}$, were tape-recorded and transcribed verbatim. Field notes were taken of contextual information, impressions during interviews and informal talk after each interview. Data analyses were initially done by the principal investigator, the first author of this article; the co-authors gave feedback on the analyses. After reading the field notes, to get a first (general) impression of the data, the interview contents were characterised and classified. The preordained themes and subthemes served as a framework for the directed content analysis. ${ }^{25-27}$

To validate and deepen the insights in the issues gathered from the interviews, three focus groups were conducted, composed of 8-12 healthcare professionals and managers in each of the three Dutch healthcare settings. Each focus group lasted about $40 \mathrm{~min}$. Themes for the discussion in the focus groups included: pros and cons of attention to diversity; barriers and opportunities in the institute, and learning experiences of past projects on diversity dimensions. Each focus group had a moderator (Halime Celik or Nico van Oosten) to guide the discussion using a focus group script. The script included an introduction by participants, a presentation of the aim and themes collected in the interviews by the moderator and a conversation about the (diversity) themes. Field notes were made during focus group meetings and the moderator wrote summaries of each meeting. The field notes and summaries were analyzed by the first author.

For our study we formulated clear questions and used a well-known research design. For the trustworthiness of our data, 'member checks' were held to validate both 
the interviews and the focus group meetings. ${ }^{28}$ As part of the member check respondents and participants received an analysis of their interview or focus group with the question and recordings whether they recognized it. All respondents and participants had consent the final recordings. The combination of methods and sources were used to triangulate the findings.

\section{RESULTS}

On the basis of the interviews and focus groups several barriers and opportunities concerning the implementation of diversity in healthcare were identified (see Table 1). The barriers can be divided into three main categories: lacking awareness and knowledge of diversity, poor information and communication, and organizational constraints.

TABLE 1. Barriers and opportunities for implementing dimensions of diversity in healthcare

\begin{tabular}{ll}
\hline Barriers & Opportunities \\
\hline Lacking awareness and knowledge & Emerging sense of urgency \\
Poor information and communication & Development of good practices \\
Organizational Constraints & Political climate \\
\hline
\end{tabular}

\subsection{BARRIERS}

\subsubsection{LACKING AWARENESS AND KNOWLEDGE}

In order to find ways to better understand patients' health demand and to make better decisions in healthcare delivery, professionals play an active role. In healthcare practices, basic knowledge of diversity dimensions is present among some health professionals. For others, diversity is not considered as relevant for care giving. These caregivers are focused on the disorder. Moreover they are unfamiliar with the impact of dimensions of diversity on patients' health and health demand and unconscious of the notion of diversity.

All patients are the same. They have an illness, and that should be treated. (Interview, Nurse manager 3)

The psychiatric disorder is prominent here. I do not have the idea that we should manage diversity. (...) For me, there is not a real difference between treating a man or a woman. (...) We do not take different cultural backgrounds into account, since in general we are not familiar with its 'ins' and 'outs'. (...). Patients' age also does not matter as long as patients are treated warmly and with respect. (Interview, Nurse 1) 
The neutral approach becomes evident in the above quotes; every patient is similar and should be treated alike with respect and warmth. Making differences according to sex, age and cultural background is not seen as relevant. Hence, significant gaps in awareness and knowledge regarding dimensions of diversity are present in healthcare, and this can be a barrier to attend to diversity in practice.

\subsubsection{POOR INFORMATION AND COMMUNICATION}

Information materials for patients are used in healthcare to inform patients (and their families) about the organisation, care supply and how to use facilities and medication. People's competency to understand patient information differs as a result of, for example, native language, and education background. Healthcare practices do not use technically complicated words in correspondence with patients to inform them via leaflets. However, this kind of user friendly information is only available in local language of the healthcare institute, as the following quote shows:

Leaflets are only available in Dutch. Nevertheless, we pay attention to the language and the size of the letters. The written language should be simple and the letters should be in the right size. (...) We provide clear and specific information about the illness. There is no space for patients' specific identity in information material. (Interview, Nurse Manager 2)

Difficulties in gaining access to healthcare can be raised when information for potential patients is not easy to read. The readability of information is generally based on the language, the number/length of sentences, and the formal use of words. Although patient information by itself does not limit the access to healthcare or the use of healthcare facilities, it makes patients dependent on others, who have to translate this information. Furthermore it can have an effect on patients' compliance, when, for example, it is unclear to them why they should use the particular medication or should undergo the particular treatment.

Misunderstanding and miscommunication can also occur because of differences in communication style, and as a result of language barriers. Professionals confronted with non-Dutch speaking patients encounter difficulties in labeling patients' clinical 'story'. This is acknowledged in the next quote:

If we have a patient who cannot speak. Dutch then we immediately have a problem. (...) We are dependent on the translation of children.(...) when necessary we can make use of over-the-phone interpretation. (Interview, Nurse Manager 1).

The quality of healthcare is considered to be affected by mutual understanding between patient and physician..$^{29}$ Dimensions of diversity can affect the communication during diagnosis and treatment in healthcare. For example, different cultural norms and values as well as gender differences are related to the communication between patients and doctors. ${ }^{30}$ According to Meeuwesen et al it is necessary to use a gender-sensitive approach in communication. In many instances however, problems of patients stay re- 
lated to the illness only, and the neutral way of approaching patients remains dominant. ${ }^{31}$

The point of departure is that everyone is the same. (Interview, Nurse 2)

\subsubsection{ORGANIZATIONAL CONSTRAINTS}

Conditions as lack of time can be a limit to enable professionals to take diversity dimensions into account. Healthcare professionals are faced with significant problems in controlling and managing time. In the anticipation to diversity dimensions, the scarcity of time has a negative effect. Particularly for emergency care (first aid) professionals report the shortage of time.

When immediate action is required, then there is no time for diversity. (...) (Interview, Nurse 3)

In an emergency case we do everything we can, regardless the diversity of the patient. (Focus group Hospital, Nurse B)

The current unbalanced male/female composition in healthcare staff is an organizational constraint to meet preferences of patients with regard to the sex of their caregivers. There exist healthcare practices in which it is a standard procedure to ask entering patients whether they prefer a female or a male nurse. In practice, however, it is often not possible to accommodate preferences.

We always ask entering patients what they prefer: a female or a male caregiver. (Interview, Nurse 2)

(...) However, it is a practical problem that we hardly have any male caregivers. (Interview, General Director 2)

In the Netherlands, professionals in the field of mental health tend to reduce diversity to sex and ignore other diversity dimensions. Since attention to sex and gender was stimulated by Dutch governmental programmes in the 1990s, some mental healthcare professionals live with the myth that goals have already been achieved. Diversity is already taken into account it is said, while actually only the sex dimension gets partly attention.

For diversity I remark that there is a kind of dialectics of progress: it is already done! (...) I notice a kind of myth of achieved goals as a result of the dominant attention for gender specific programmes in the last years. (Focus group Mental Health, Nurse Manager A)

\subsection{OPPORTUNITIES}

Despite the presented barriers there are also opportunities to implement diversity in healthcare. The opportunities can be divided into three categories: an emerging sense of 
urgency, the development of good practices, and the political climate that stimulated the attention to gender specific care.

\subsubsection{EMERGING SENSE OF URGENCY}

Professionals for instance in hospital settings are conscious of unaddressed differences among patients, and pronounce that not formalizing this in policy can result in incidental attention. Although these professionals endorse the attention to diversity, the diagnosis itself holds a prominent place and diversity is still reduced to sensitivity for the clearly present biological aspects (sex).

Differences are not highlighted, except for radiation treatments protocols. Because of the radiation risk for pregnancy, especially women are informed. (...) There is also a difference in sex in catheterizing a patient. (...). (Interview, Nurse 3)

(...) Personally speaking, there are aspects that can disappear easily and may not come back. Then there is the danger of overlooking. (Interview, General Director 1)

In the nursing home, professionals do not have much cultural diversity among patients, since until now they have merely Dutch patients. However, they also recognize this is going to change in the near future, with a new generation of (aging) immigrants. They notice that an anticipatory movement in advance is therefore required.

Cultural background is not relevant, since we seldom have patients from different ethnic groups. (...) The immigrant population is reaching an old age. It can be of future interest on which we can anticipate. (Interview, Nurse 2)

Some professionals mention that diversity among employees is desirable.

Diversity among buman resources could be much better (...). However, only few males and immigrants do apply for these jobs. (Interview, General Director 1)

Previous quotes show an emerging sense of urgency regarding the attention to diversity among professionals in healthcare practices. A 'sense of urgency' gets people out of couch, out of the bunker and they are ready to move forward. ${ }^{32}$

\subsubsection{GOOD PRACTICES}

Some professionals adjust their communication style to the level of patients' educational background. An illustrative citation:

In the care process communication is particularly important. (...) Patients' education can have a substantial effect on treatment and on the way of providing information. (...) Talking speed and the kind of words we use changes immediately. (Interview, Nurse 2)

For good care delivery, physicians need to understand their patients, and patients need to be understood. Developing good communication in practice, finding a way to tailor 
healthcare delivery to patients, is an example of good practice. Genderspecific care supply is present in policy and treatment programmes in the mental health setting under study. Positive skills and knowledge to take into account gender dimensions can be an example of good practice to be disseminated and implemented further in practice and policy.

We know that women report their feelings much better than men and that an older patient is more likely to face loss of a family member. This information is included in specific treatments. (...) I see similarities between intercultural management and gender specific care supply. In my view it is all the same. (...) It is all about finding a connection to patients' perception. (Interview, Nursing Manager 2)

This quote shows that professionals in mental healthcare use and convey gained knowledge of gender to other dimensions of diversity. It seems that skills for one dimension are viewed to be applicable to other dimensions of difference.

\subsubsection{Political Climate}

Attention to relevant dimensions of diversity in healthcare is influenced by the spirit of the times, and as a result of political trends. For instance, since the beginning of the eighties the Dutch government promoted and supported the integration of 'genderspecific care' in regular care in order to improve the quality of the care provided (See the report of the national steering group for gender-specific care). ${ }^{33}$ This governmental initiative was taken on board mainly in mental healthcare. In the mental health institute under study, the rewards of the government stimulation obviously did not fade away, since there are still specific programs in which gender issues are embedded.

$W$ e set the practice in motion regarding gender specific care giving. There are specific treatment groups and employees with particular interest for gender. (Interview, General Director 1)

Influences outside the organization can constitute a positive spirit for healthcare managers to take actions and create conditions to raise awareness of diversity among healthcare professionals. Political trends, although they come in successive waves, can result in additional financial resources to implement new guidelines. It is therefore important to timely act to emerging 'senses of urgency'.

\section{DISCUSSION AND CONCLUSION}

\subsection{Discussion}

In this study we found that implementation of attention to diversity dimensions in healthcare practices are impeded by various barriers. These barriers can be divided in 
three main categories: lacking awareness and knowledge, shortcomings in information and communication, and organisational constraints. Despite these barriers, there are also opportunities for implementing diversity in healthcare. One category is the 'sense of urgency' for diversity. Furthermore, there are good practices and external factors which can have an impetus on healthcare practices to take additional actions.

Ambiguity is a contradictory interpretation about what needs to, can and should be done. ${ }^{34,35}$ Diversity is an ambiguous issue in healthcare. On the one hand, professionals recognize dimensions of diversity as relevant and endorse the attention to these dimensions in healthcare. On the other hand, in the practices under study they underestimate the consequences of not taking dimensions of diversity into account and tend to treat patients 'reasonably standard', as had been described by Beagan and Celik \& Klinge. 12,36 As a consequence, the diagnosis of the disease holds a prominent place. If recognized at all, diversity is reduced to one dimension (sex). Special needs related to different ethnic backgrounds and other dimensions of diversity (age, social economic status) are hardly noticed in the standard approach. Mackenbach shows in his study about large cities in the Netherlands, the importance of socioeconomic inequalities in health. ${ }^{37}$ Dimensions of diversity and the interrelation between them, such as the relation between gender and socioeconomic status, have an important influence on patients' health and illness. ${ }^{38,39}$

However in healthcare practice neutrality remains dominant. Within a context of an emerging awareness and knowledge of diversity it is a challenge to increase sensitivity for diversity and as a result to adopt the view of the 'patient-as-a-person'. ${ }^{40} \mathrm{~A}$ 'sense of urgency' in healthcare settings, could strengthen the effects of an educational programme for healthcare professionals. ${ }^{32}$ Although awareness and knowledge by themselves are not necessarily sufficient to promote behavioural change, it can be seen a major step of a successful implementation strategy. ${ }^{41}$

Adequate (clinical) information and communication can promote health and healthcare in ways that respond to patients' concerns, help patients to better understand clinical pathways and make informed decision on treatment strategies. Good communication between doctors and patients does matter for the quality of healthcare. ${ }^{42,43}$ Difficulties in clinical settings can be experienced due to language barriers and cultural differences. This can result in unmet needs, beliefs and a mismatch between provided treatments and the needs of patients. ${ }^{44,45}$ Improvements can be (partly) achieved by providing information material in at least the native languages for the main minority groups. Furthermore the composition of health professionals should ideally be a reflection of the composition of the population it serves. ${ }^{22}$ Lessons from earlier experiences can be used as good practices for future initiatives. However, in emergency medicine the situation can be different, since time can be a limiting factor. In this case, it is not (entirely) possible to be open for patients' specific agenda. Besides emergency medicine, medical institutions can as a result of economic pressures also avoid egalitarian consultation in order to fit many patients into a limited schedule. ${ }^{46}$ This will make it difficult 
to match patients with providers characteristics and to give patients the amount of time and attention required to diversity embracing care.

In the eighties the Dutch government promoted and supported the integration of 'gender-specific care' and this initiative was taken on board specifically in mental health institutions. In the mental health institute under study the effects of these investments were still noticeable. In the hospital and nursing home studies no such effects could be identified. Despite the beneficial effects in mental healthcare, professionals also reported a drawback. It seems difficult for health professionals in these settings to incorporate other dimensions of diversity, since there is a kind of 'myth' of achieved goals. Institutions without any past projects on diversity dimensions will not encounter this 'limitation' and may probably have a more fresh outlook. Furthermore professionals in mental health do transfer knowledge and skills for one dimension (sex) to an other dimension (culture) as if the dimensions are exchangeable.

According to Verloo the 'one size fits all' assumption, meaning that dimensions of diversity are similar, is based on an incorrect assumption of sameness of the dimensions. ${ }^{47}$ According to social science literature, access and efforts to diversity care may also be influenced by other factors than we found in our study. Disparities can be affected by physician-patient relationship/communication in which patients' and physicians' characteristics play an important role. It is inappropriate to assume that all patients have the same needs, and thus, they will all be satisfied with the same approach. ${ }^{48}$ For example, women see physicians more than men $^{49}$ and migrants may have a different interpretation of their symptoms than the health professional..$^{50}$ Furthermore, older physicians are less egalitarian, less patient, less attentive and less respectful with older patients, and rarely attend to their psychosocial issues. ${ }^{51,52}$

This study is based on three case studies. Yet, the value of the results can go beyond these three healthcare settings. This study provides insights into the opportunities and barriers for the implementation of diversity in various healthcare practices, since diversity is still a challenge in general for healthcare settings. In addition, our results can have a potential learning effect.

\subsection{CONCLUSION}

In this study we found overt and covert barriers and opportunities for diversity in healthcare. Regarding diversity there is ambiguity in how professionals deal with diversity. If recognized at all, diversity is reduced to one dimension (sex). Special needs and preferences related to different cultural backgrounds, age, and social economic status are hardly noticed. The 'neutral' approach still seems to dominate practice and policy in the settings under study. In order to adequately address diversity, it seems possible to overcome barriers, and exploit the opportunities, when appropriate tools are used. An educational programme can be a tool, since this will have the potential to stimulate the 
'sense of urgency', and to overcome the barrier of lacking awareness and knowledge of diversity.

\subsection{PRACTICE IMPLICATIONS}

The barriers and opportunities can be used to develop educational diversity programs, which can be used for training professionals in healthcare practice. The current perception of care practices may be heavily hinged on what professionals have learned and how they were generally professionalized. To the extent that gender differences remain unknown and unaddressed in the provision of healthcare, may also be a result of the context where the training is conducted. ${ }^{53}$ To enhance the attention for diversity, training programs should focus on professionals in the context of the particular healthcare setting. This supports the urge to intensively educate and train professionals in how to handle care from a diversity perspective in the particular context. Apart from training programs, accumulation and dissemination of knowledge seems to be essential in healthcare. This could be achieved by raising knowledge (building) networks. In these networks professionals can learn with and from each other, how to consider diversity and how to apply existing best practices. Educational programmes and knowledge networks can be an appropriate tool to take patients' needs and preferences into account in order to improve the quality of care. 


\section{REFERENCES}

1. WHO (2001). Mainstreaming gender in health: the need to move forward. Seminar on gender mainstreaming health policies in Europe. Madrid: World Health Organisation.

2. UN (1995). Report of the fourth world conference on women. Beijing: United Nation.

3. Van Mens-Verhulst J (2001). Diversiteit in theorie en praktijk: een bericht uit de feministische hulpverlening. [Diversity in theory and practice: a message from the feminist care]. Tijdschrift voor Humanistiek 6:7-17.

4. Bekker MHJ, van Vliet KP, Kolk AM (1999). Realising gender-sensitive health care; the role of research. In: Kolk AM, Bekker MHJ, Van Vliet KP, editors. Advanced studies in women and health research: toward gender sensitive strategies. Tilburg: Tilburg University Press.

5. Street RL (2002). Gender differences in health care provider-patient communication: are they due to style, stereotypes, or accommodation? Patient Education \& Counseling 48:201-206.

6. Crenshaw KW. Mapping the margins: intersectionality, identity politics, and violence against women of color. In: Albertson Fineman M, Mykitiuk R (Eds). In the public nature of private violence. New York: Routledge; 1994. p. 93-118.

7. Cohen M (1998). Toward a framework for women's health. Patient Education \& Counseling 33:187-196.

8. Bekker MHJ (2003). Investigating gender within health research is more than sex disaggregation of data: a multi-facet gender \& health model. Psychology Health \& Medicine 8:231-243.

9. Klinge I, Maguire P (2004). The policy implications of gender mainstreaming for healthcare research in the EU. PharmacoEconomics 22:87-93.

10. Moerman C, Van Mens-Verhulst J (2004). Gender-sensitive epidemiological research: suggestions for a gender-sensitive approach towards problem definition, data collection and analysis in epidemiological research. Psychology Health \& Medicine 9:41-52.

11. Wieringa N, Reijneveld M, Stonks K (2005). Diversity from an epidemiological perspective: looking for underlying causes and changing merits. In: Diversity among patients in medical practice: challenges and implications for clinical research. Amsterdam: University of Amsterdam.

12. Beagan L (2000). Neutralizing differences: producing neutral doctors for almost neutral patients. Social Science \& Medicine 8:1253-1265.

13. Risberg G (2004). I am solely a professional, neutral and genderless. PhD thesis Umea University.

14. Yuval-Davis N (2006). Intersectionality and feminist politics. European Journal of Women's Studies 13:193-209.

15. McGoldrick M (1998). Re-visioning family therapy: race, culture and gender in clinical practice. New York, London: Guilford Press.

16. Wenger NK, Speroff L, Packard B (1993). Cardiovascular health and disease in women. The New England Journal of Medicine 329:247-256.

17. Bickell NA, Pieper KS, Lee KL, Mark DB, Glower DD, Pryor DB, Califf RM (1992). Referral patterns for coronary artery disease treatment: gender bias or good clinical judgment? Annals of Internal Medicine 116:791-797.

18. Vogels EA, Lagro-Janssen ALM, Van Weel C (1999). Sex differences in cardiovascular disease: are women with low socioeconomic status at high risk. British Journal of General Practice 49:963-966.

19. Birdwell BG, Herbers JE, Kroenke K (1993). Evaluating chest pain: the patient's presentation style alters the physician's diagnostic approach. Archives of Internal Medicine 153:1991-1993.

20. McSweeney JC, Cody M, O’Sullivan P, Elberson K, Moser DK, Garvin BJ (2003). Women's early warning symptoms of acute myocardial infarction. Circulation 108: 2619-2623.

21. Vaccarino V, Parsons L, Nathan RE, Barron HV (2005). Sex-based differences in early mortality after myocardial infarction. The New England Journal of Medicine 341: 217-225.

22. Bowes A (2006). Mainstreaming equality: implications of the provision of support at home for majority and minority ethnic older people. Social Policy \& Administration 40:739-757. 
23. Council of Europe (1998). Gender mainstreaming. Conceptual framework, methodology and presentation of good practices. Strasbourgh: Council of Europe.

24. Pope C, Mays N (1995). Reaching the parts other methods cannot reach: an introduction to qualitative methods in health and health services research. BMJ 311: 42-45.

25. Miles MB, Huberman AM (1994). Qualitative data analysis: an expanded sourcebook. Thousands Oaks: Sage.

26. Morse JM, Field PA (1995). Qualitative research methods for health professionals. Thousands Oaks: Sage.

27. Hsieh HF, Shannon SE (2005). Three approaches to qualitative content analysis. Qualitative Health Research 15:1277-1288.

28. Meadows LM, Morse JM (2001). Constructing evidence within a qualitative project. In: Morse JM, Swanson JM, Kuzel AJ, editors. The nature of qualitative evidence. Thousand Oaks, CA: Sage.

29. Harmsen JAM, Bernsen RMD, Meeuwesen L, Pinto D, Bruijnzeels MA (2005). Assessment of mutual understanding of physician patient encounters: development and validation of a mutual understanding scale (MUS) in a multicultural general practice setting. Patient Education \& Counseling 59:171-181.

30. Van den Brink-Muinen A, van Dulmen AM, Messerli-Rohrbach V, Bensing JM (2002). Do gender-dyads have different communication patterns? A comparative study in Western-European general practices. Patient Education \& Counseling 48:253-264.

31. Meeuwesen L, Bensing JM, van den Brink-Muinen A (2002). Communicating fatigue in general practice and the role of gender. Patient Education \& Counseling 48:233-242.

32. Kotter JP, Cohen DS (2002). The heart of change. Real life stories of how people change their organizations. Harvard: Harvard Business School Press.

33. Stuurgroep Vrouwenhulpverlening Ministerie van VWS. Naar een seksespecifieke en multiculturele gezondheidszorg in de 21ste eeuw. Eindrapportage en beleidsaanbevelingen. [The final report of the national steering group for gender specific care]. Den Haag: Ministerie van Volkgezondheid, Welzijn en Sport; 1999.

34. Abma TA (2005). Responsive evaluation in health promotion: its value for ambiguous contexts. Health Promotion International 20(4):391-397.

35. Abma TA, Noordegraaf M (2003). Public managers amidst ambiguity, towards a typology of public management settings. Evaluation 9:285-306.

36. Celik H, Klinge I (2005). Mainstreaming gender en diversiteit in de gezondheidszorg. Zijn we op weg naar een diversiteitsbewuste gezondheidszorg. [Mainstreaming gender and diversity. Are we moving toward a diversity competent health care]. Tijdschrift voor Genderstudies 2:12-22.

37. Mackenbach JP (1993). Inequalities in health in the Netherlands according to age, gender, marital status, level of education, degree of urbanization and region. European Journal of Public Health 3:112-118.

38. Kunst AE, Mackenbach JP (1994). Measuring socio-economic inequalities in health. Copenhagen: World Health Organization.

39. Mackenbach JP (1994). Socioeconomic inequalities in health in the Netherlands: impact of a five year research programme. BMJ 309:1487-1491.

40. Mead N, Bower P (2000). Patient centeredness: a conceptual framework and review of the empirical literature. Social Science \& Medicine 51:1087-1110.

41. Grol R, Wensing M, Eccles M (2005). Improving patients' care: the implementation of change in clinical practice. Edinburgh: Elsevier Butterworth Heinemann.

42. Van den Brink-Muinen A (2002). The role of gender in healthcare communication. Patient Education \& Counseling 48:199-200.

43. Meeuwesen L, Bensing JM, van den Brink-Muinen A (2002). Communicating fatigue in general practice and the role of gender. Patient Education \& Counseling 48:223-242.

44. Yebei VN (2000). Unmet needs, beliefs and treatment-seeking for infertility among migrant Ghanaian women in the Netherlands. Report Health Matters 8:134-141. 
45. Harmsen JAM (2003). When cultures meet in medical practice. Improvement in intercultural communication evaluated. $\mathrm{PhD}$ thesis.

46. Haug M, Lavin B (1983). Consumerism in medicine: challenging physician authority. Beverly Hills: Sage.

47. Verloo M (2006). Multiple inequalities, intersectionality and the European Union. European Journal of Women's Studies 13:211-228.

48. Greene MG, Adelman RD, Friedmann E, Charon R (1994). Older patients satisfaction with communication during an initial medical encounter. Social Science \& Medicine 38:1279-1288.

49. Verbrugge LM (1989). The twain meet: empirical explanations of sex differences in health and mortality. Journal of Health and Social Behavior 30:282-304.

50. Annandale E, Hunt K (2000). Gender inequalities in health. Buckingham: Open University Press.

51. Adelman RD, Greene MG, Charon R, Friedmann E (1990). Issues in the physician-geriatric patient relationship. In: Giles H, et al., editors. Communication, Health and the Elderly. Manchester: Manchester University Press, p. 126-134.

52. Adelman RD, Greene MG, Charon R (1991). Issues in physician elderly patient interaction. Ageing \& Society 11:127-148.

53. Rutenberg N, Watkins SC (1997). The buzz outside the clinics: conversations and contraception in Nyanza Province, Kenya. Studies in Family Planning 28:290-307. 



\title{
Chapter 3
}

\section{Bringing gender sensitivity into health care practice: a systematic review}

\author{
H. Celik \\ A.L.M. Lagro-Janssen \\ I. Klinge \\ G.A.M. Widdershoven \\ T.A. Abma
}




\section{A B S T R ACT}

Men and women are not the same when it concerns their health; risks, symptoms, complaints and experience of a disease may vary. Despite the body of literature on gender dimensions and disparities between the sexes in health, practical improvements will not be realized effectively as long as we lack an overview of the ways how to implement these ideas. This systematic review provides a content analysis of literature on the implementation of gender sensitivity in healthcare. For this review, literature was identified from CINAHL, PsycINFO, Medline, EBSCO and Cochrane (1998-2008) and the reference lists of relevant articles. The quality and relevance of 752 articles were assessed. Based on a three-step inclusion process: (1) selection based on title/abstracts; (2) selection based on full text; and (3) citation tracking, 11 empirical studies were included. Our results demonstrate that the implementation of gender sensitivity includes factors related to the professional, organizational and the policy level. Yet, the majority of studies focus solely on behavioural change of professionals by education or on the organizational culture or infrastructure. The development of comprehensive interventions to implement gender and their evaluation are needed to improve gender sensitivity in healthcare. These interventions should take into account the forming of a core group with committed key players in an institution, developing an appealing vision for the future, training and educating professionals, sharing successes by good and best practices and providing feasible solutions to the main obstacles experienced by the key actors in the process of change. 


\section{INTRODUCTION}

Men and women are not the same when it concerns their health; risks, symptoms, (presentation of) complaints and experience of a disease may vary. If sex and gender differences are not systematically taken into account by health professionals, inequities may arise. That sex and gender matter in health(care) has been demonstrated in a vast amount of studies. ${ }^{1-7}$ Some recommendations have been given to enhance gender sensitivity in healthcare. ${ }^{8}$ Gender sensitivity means that health professionals are competent to perceive existing gender differences and to incorporate these into their decisions and actions. It is commonly accepted that gender does not exist in a vacuum; gender is part of a socio-political and cultural context. Intersectionality goes beyond gender sensitivity and includes the consideration of other dimensions of difference, like social class and ethnicity. The interaction between these dimensions shapes patients' health needs. ${ }^{9-11}$ Whereas concerns about gender and health(care) have come to the fore in the scientific arena, gender sensitivity will not automatically be adopted in healthcare. ${ }^{12}$ Implementation literature suggests that innovations within healthcare generally require comprehensive approaches at different levels. ${ }^{13}$ Ideally implementation on an individual and professional level parallels implementation at organizational level. ${ }^{14}$ For example, a gender training program can raise the awareness and knowledge of professionals, but organizational learning is required to change working routines. ${ }^{15}$

Despite the body of literature on gender dimensions and disparities between the sexes in health, practical improvements will not be realized effectively as long as we lack an overview of the ways how to implement these ideas. ${ }^{16}$ Insight in the obstacles and facilitating factors to enhance gender sensitivity in practice is needed. ${ }^{17}$ This article aims to fill that gap providing a systematic analysis of the opportunities and barriers for the implementation of gender sensitivity in healthcare.

\section{METHODS}

Articles were identified through searches conducted in five electronic databases: CINAHL, PsychINFO, Medline and EBSCO. A search in the Cochrane library was performed to find comparable review studies. Table 1 outlines the keywords/search terms and resulting output. All searches covered 10 years (January 1998 - June 2008); it was expected that before 1998 not much would have been published in this domain. The searches were restricted to English articles for practical reasons, and conducted by two researchers (HC and SM). In total 752 articles were found. 
TABLE 1. Search Strategy and Results

\begin{tabular}{|c|c|c|c|c|}
\hline No & Search Strategy & Database & Output & Relevant articles \\
\hline \multirow[t]{6}{*}{1} & Gender specific care OR & Cinahl & 246 & 21 \\
\hline & Gender specific patient care OR & Psychinfo & 15 & 0 \\
\hline & Gender specific health care AND & Medline & 29 & 6 \\
\hline & Gender appropriate care OR & Ebsco & 0 & 0 \\
\hline & Gender appropriate patient care OR & Cochrane & $\mathrm{n} / \mathrm{a}$ & 0 \\
\hline & Gender appropriate health care & & & \\
\hline \multirow[t]{5}{*}{2} & Search 1 AND & Cinahl & 15 & 7 \\
\hline & Mainstream OR & Psychinfo & 1 & 0 \\
\hline & Sensitivity & Medline & 3 & 0 \\
\hline & & Ebsco & $\mathrm{n} / \mathrm{a}$ & $\mathrm{n} / \mathrm{a}$ \\
\hline & & Cochrane & $\mathrm{n} / \mathrm{a}$ & $\mathrm{n} / \mathrm{a}$ \\
\hline \multirow[t]{5}{*}{3} & Woman centered care OR & Cinahl & 17 & 2 \\
\hline & Woman focused care & Psychinfo & 5 & 1 \\
\hline & & Medline & 21 & 3 \\
\hline & & Ebsco & 0 & 0 \\
\hline & & Cochrane & $\mathrm{n} / \mathrm{a}$ & $\mathrm{n} / \mathrm{a}$ \\
\hline \multirow[t]{6}{*}{4} & Health OR & Ebsco & 28447 & $\mathrm{n} / \mathrm{a}$ \\
\hline & Healthcare OR & & & \\
\hline & Health care OR & & & \\
\hline & Health delivery OR & & & \\
\hline & Healthcare delivery OR & & & \\
\hline & Health care delivery & & & \\
\hline \multirow[t]{5}{*}{5} & Gender mainstreaming & Cinahl & 38 & 5 \\
\hline & & Psychinfo & 34 & 4 \\
\hline & & Medline & 31 & 3 \\
\hline & & Ebsco & 26 & 3 \\
\hline & & Cochrane & 2 & 0 \\
\hline \multirow[t]{5}{*}{6} & Equity OR & Cinahl & 71 & 1 \\
\hline & inequity AND & Psychinfo & 21 & 0 \\
\hline & Gender AND & Medline & 18 & 1 \\
\hline & Implementation & Ebsco & 8 & 0 \\
\hline & & Cochrane & $\mathrm{n} / \mathrm{a}$ & 0 \\
\hline \multirow[t]{10}{*}{7} & Equality OR Inequality AND & Cinahl & 82 & 0 \\
\hline & Gender AND & Psychinfo & 31 & 0 \\
\hline & Implementation & Medline & 23 & 1 \\
\hline & & Ebsco & 14 & 3 \\
\hline & & Cochrane & 1 & 0 \\
\hline & Total: 51 articles & Cinahl & & 33 \\
\hline & (without duplicates) & Psychinfo & & 5 \\
\hline & & Medline & & 8 \\
\hline & & Ebsco & & 5 \\
\hline & & Cochrane & & 0 \\
\hline
\end{tabular}


The selection of articles took place in several steps (Table 2): 1) Screening of titles and abstracts (HC and SM); 2) Screening of the full text (HC) and agreement between the authors (HC, TA and TLJ); and 3) Snowballing (HC). During the first step articles without an abstract, method section and duplicates were eliminated. Articles without original empirical research (reviews, editorials, commentaries, theoretical analyses) were also excluded. Based on this selection process, 51 articles remained. CINAHL produced the highest number of relevant articles (33), followed by Medline (8), PsychINFO (5) and EBSCO (5). No comparable review article was found in Cochrane. With help of an experienced librarian a protocol was developed for the second elimination step aiming to identify articles not relevant for our research question and of insufficient quality. The protocol was used to analyse the detailed full text and included a format to report the relevant features of the articles. The detailed full text review of 51 articles was conducted by three reviewers (HC, TLJ and TA) in order to decide about inclusion. When the reviewers did not agree on inclusion or exclusion of the articles, agreement was reached on the basis of discussion between the researchers. From the initial list of 51 articles, a total of 8 articles were selected and included in this review. Finally the snowball method was used to find articles by tracking the reference lists of the remaining 8 articles. Judgment of the references was based on the following exclusion criteria: not relevant for our research question, duplicates, books or chapters and insufficient study quality. A total of 3 articles were initiated by snowballing. Ultimately, 11 articles were included in this review.

The data extraction from the 11 included articles was performed by $\mathrm{HC}$ and was subsequently checked by TLJ and TA. Additionally, the results were compared and discussed. Because of the small size methods such as quantitative studies pooling and statistical analysis were not performed. The review followed instead a content analysis.

\section{RESULTS}

\subsection{CHARACTERISTICS OF THE STUDIES}

Seven studies used qualitative methods, three were quantitative and one was a mixed methods study (See Table 3). The studies all investigated the implementation of sex or gender related knowledge or theories. With some exception the majority of the studies focused on the healthcare sector. Most studies dealt with European countries. Concerning the implementation of gender sensitivity our results covered factors related to the professional, organizational and political level, as presented below. 
TABLE 2 Flowchart inclusion process

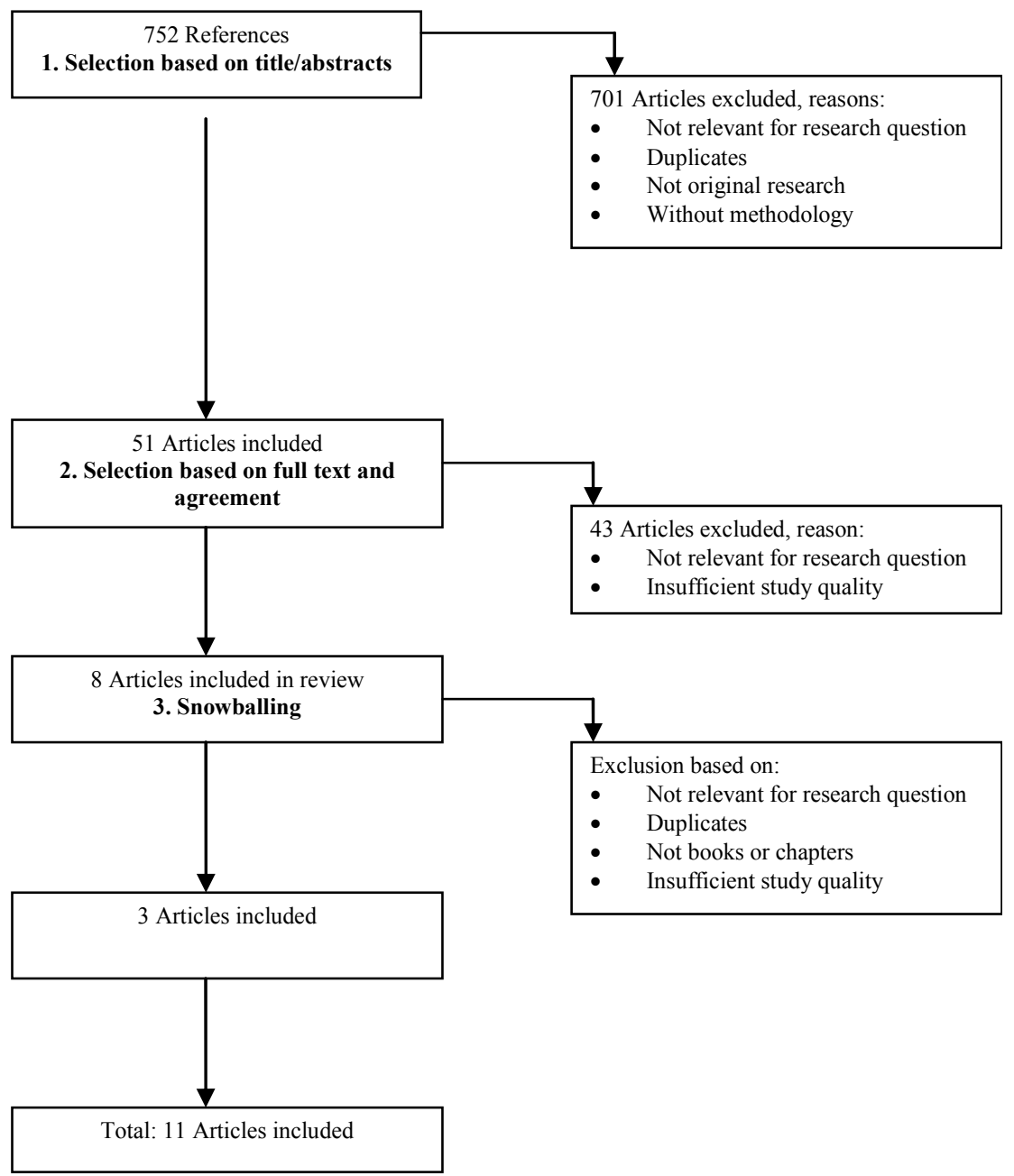

\subsection{FACTORS RELATED TO THE PROFESSIONAL LEVEL}

\section{GENDER SENSITIVE MEDICAL CURRICULA}

In quite a few articles the lacking competence of health professionals to perceive gender issues is considered to be one of the main starting points to improve gender sensitivity in healthcare. The regular medical education is an important target to achieve gender equity in health, as it transfers norms, knowledge and skills. Two studies were performed to evaluate the integration of gender in medical curricula. One study investigated the inclusion of gender in educational materials for students in a Dutch medical 
faculty..$^{18}$ Motivated teachers proved to be as important as the practical relevance of educational materials to promote the adoption of gender among students. The second study, concerning a national project to integrate gender in all Dutch medical faculties, demonstrated that the support and commitment of educational directors and authoritative figures played a decisive role for the integration of gender. ${ }^{19}$ Gender was more easily integrated in interdisciplinary case-based curricula than in traditional lecture based, biomedical curricula. Gender issues conflict with a biomedical health model that promotes a neutral approach to gender, and fit better with a holistic health model. Furthermore, openness and a learning network between medical schools had a positive effect on the integration as actors discussed the results of gender implementation at conferences and meetings.

Risberg et al recently also stress the crucial role of teacher's attitude for the successful implementation of gender in medical curricula. ${ }^{20}$ Male teachers' attitude about the importance of gender issues in their work includes avoidance and simplification. Avoidance means that men and women are treated alike. Simplification refers to an attitude suggesting that gender related problems are easy to address, or already solved. Especially female teachers, did show an interest in gender issues, indicating that this female educators attitude was more gender sensitive than male educators. So, physician teachers' attitude can explain whether gender issues will be accepted or denied in medical education and the socialization of medical students.

\section{ON-THE-JOB GENDER TRAINING}

Training which takes place at the professional work place, the so called, on-the-job training, can contribute to professionals socialization process. Gunn and colleagues provided hospital professionals on an obstetric ward, a gender training. ${ }^{21}$ Evaluation of the training showed that participants gained knowledge and skills to better manage psychosocial issues during pregnancy. Participants valued the opportunity to put theory into practice. Pope et al also emphasize that training on the job is important. ${ }^{22}$ Since there is a considerable amount of variation among educational needs of individual professionals, it is recommended to tailor education programmes on-the-job to these needs. 


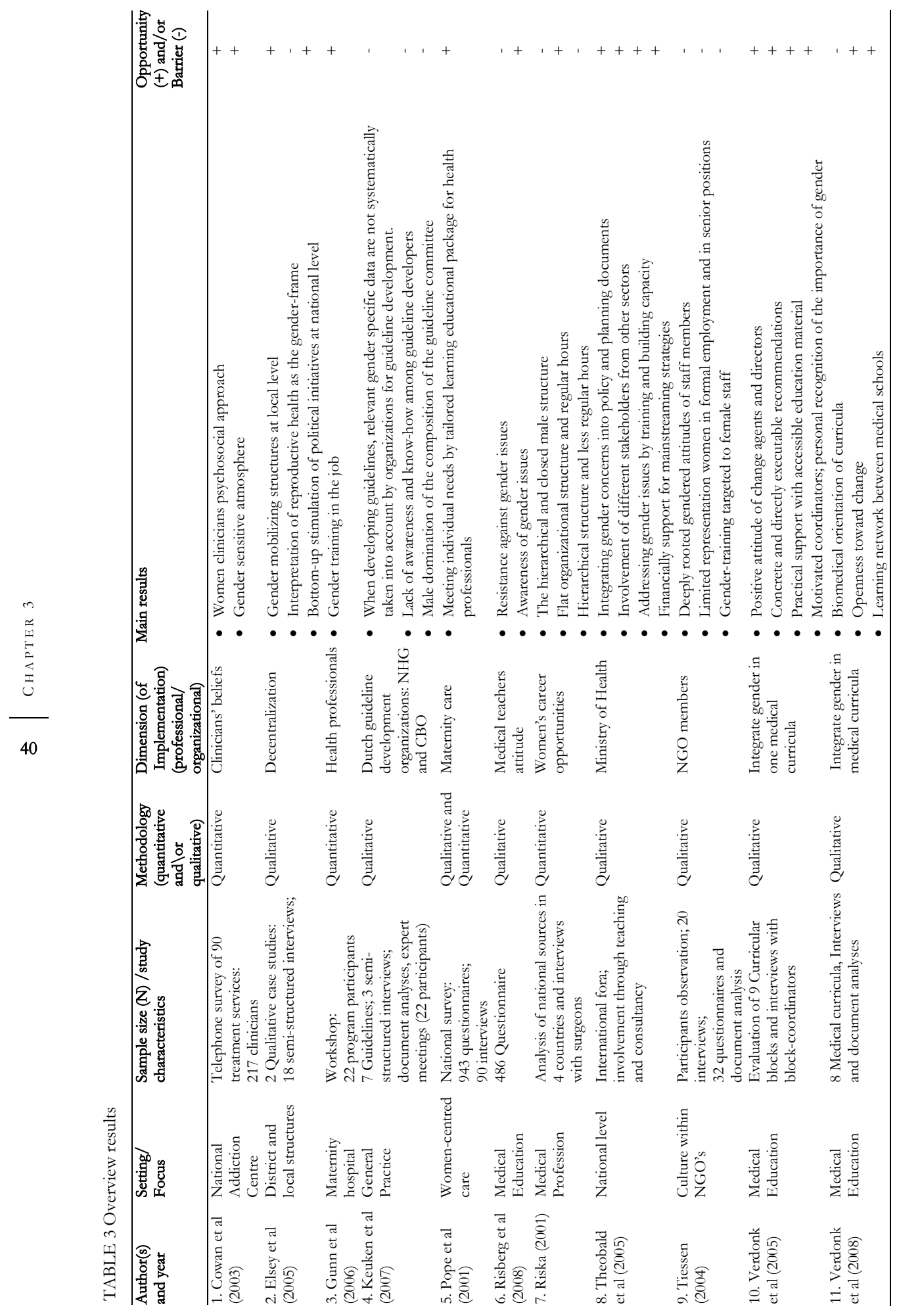




\subsection{FACTORS RELATED TO THE ORGANIZATIONAL LEVEL}

\section{ORGANIZATIONAL CULTURE}

Organizational culture, in which norms and values are deeply incorporated, is one of the areas to be addressed to integrate gender into healthcare. Tiessen points out that the unequal men to women ratios in the staff within healthcare organizations perpetuate inequalities between men and women. ${ }^{23}$ In translating gender policies into practice, professionals are not neutral actors, but they help to constitute and maintain the status quo. As a result, masculine interests (i.e. making a career) remain dominated over feminine interests (i.e. combining work-family life). To foster gender-sensitive practices a balance between male and female staff is desirable. The study showed that dominance of men in staff positions can be a barrier to integrate gender within organizations. The capacity of staff to address gender issues in their work can be fostered by gendertraining if it is not only targeted to female staff.

\section{ORGANIZATIONAL INFRASTRUCTURE}

As mentioned by Risberg and colleagues, women are more inclined to be gender sensitive. ${ }^{20}$ Riska describes that even when formal barriers have been eliminated and women have entered healthcare organizations, they still face a glass ceiling. ${ }^{24}$ Medical work remains in many respects segregated along gender lines. Despite the increase in the proportion of women in medical professions in western societies, women's career advancement in the medical profession has not evenly grown. One barrier for female doctors in healthcare systems is shaped by the organizational structure. A flat organizational structure and regular working hours in healthcare centres provide more professional and family life to women than hierarchical structure with less regular working hours in hospitals.

Cowan et al showed that women clinicians are more attentive of women clients' needs related to alcohol and drug problems and that women clients appreciate a female physician. ${ }^{25}$ Women clinicians are more sensitive towards gender issues, for example addressing parenting issues. Specialized women services do not necessarily provide programmes that respond sufficiently to women clients' needs, nevertheless, they can positively influence the atmosphere in which women clients can maintain their own identity and maximize their full potential.

\section{PROTOCOLS AND GUIDELINES}

Clinical practice guidelines are important tools to provide health professionals the best available evidence and optimal strategies for diagnoses and treatment in specific clinical circumstances. Keuken et al conclude that even when gender specific evidence is available, this is not systematically considered in the process of guideline development by Dutch guideline development organizations. ${ }^{26}$ Guideline developers lack a comprehensive set of directions (awareness and know-how) on gender specific issues, and women 
are underrepresented in guideline committees. The involvement of experts in gender medicine may be a useful asset during the guideline development process.

\subsection{FACTORS RELATED TO THE POLICY LEVEL}

\section{MAINSTREAMING NATIONAL POLICIES}

A widely accepted definition for a gender mainstreaming strategy was formulated by the Council of Europe: 'Mainstreaming gender is the (re)organization, improvement, development and evaluation of policy processes, so that a gender equality perspective is incorporated in all policies, at all levels and at all stages, by the actors normally involved in policy-making. ${ }^{27}$ The strategy of gender mainstreaming has been adopted by a number of national governments to impact national policies, although with varying success. ${ }^{28}$ The influence on health care policies has been influential in for example Germany, Austria and Sweden. ${ }^{29}$

Theobald et al explored the implications of building a gender-sensitive health sector. ${ }^{30}$ For mainstreaming gender in the health sector it is important that gender concerns are addressed within key national policy documents and as a result create legitimacy for efforts to improve gender equity of health programs. Furthermore, gender mainstreaming in one sector requires the involvement of other sectors to develop critical mass. In addition, to identify and address gender issues there is a need for training in order to build capacity for mainstreaming gender. Therefore, a normative 'one size fits all' approach should be left.

DECENTRALIZATION

To address gender issues effectively in practice, strategies cannot be attributed to the national level only. Decentralization is a process of bringing decision-making closer to the people at the district or local level. Elsey and colleagues describe that gender mainstreaming policies need to be decentralized and translated into concrete changes in order to institutionalize gender issues. ${ }^{31}$ This calls for the need to support genderspecific capacity at local level and its financial and technical support. Another key to institutionalize gender issues is 'strategic framing' of gender, which means developing the understanding of gender issues. Finally, the authors' revealed the top-down stimulation of change has to go hand in hand with 'bottom-up' stimulation of initiatives at local level.

\section{CONCLUSION AND DISCUSSION}

Our results show that the implementation of gender sensitivity has a variety of features. Health professionals' and medical teachers' attitude towards gender, the culture and men-women ratios within health organizations and the political environment help or 
prevent the implementation of gender sensitivity in practice. A multiple track approach to implement gender sensitivity is therefore needed.

The implementation process of gender sensitivity can be initiated either top-down (European Union, national governments) or bottom-up (educating of students and professionals). The WHO Report about social determinants of health pleas for a wide spectrum approach in which problems related to gender issues are addressed both outside and within the health sector. ${ }^{32}$ Remarkably, our results show that many studies focus solely on behavioural change of professionals by education. In education, the success of implementing gender related issues depends on the intrinsic motivation of educational directors and the teachers' attitude. The latter, the so called 'role model' for future health professionals, plays a pivotal role in education as students learn not just from what their teachers say but also from their stance towards gender issues and the attitudes they exhibit. ${ }^{33}$ Role modeling and socialization within professions is thought to foster professionals' identity. ${ }^{34,35}$

Although education is an important element of gender sensitivity, we agree with Grol \& Grimshaw that changes in clinical practice are only partly within health professionals' control. ${ }^{36}$ The prevailing organisational context (the organisational culture and infrastructure) and the wider policy environment are keys to open ways for gender sensitivity in healthcare practices. An organizational context, in which masculine interests remain dominant, can perpetuate inequalities. A balance between men and women staff and overcoming the glass ceiling phenomenon for women is needed to influence the content and priorities in future medicine. The studies suggest that a more representative participation of women staff members, with talents and skills which differ from their male counterparts, will lead to more gender sensitivity. Additionally, implementing gender sensitivity into protocols and guidelines is a tool to provide health professionals with the best available evidence and strategy regarding gender issues in specific clinical circumstances. Gender mainstreaming in national policy documents requires a process of decentralization in order to translate gender related issues in specific needs and to mobilize and support professionals.

A comprehensive intervention covering both the professional and the organizational level to implement gender sensitivity in healthcare has not been found. Remarkably, some studies run into organizational constraints, while (behavioural) change is only targeted at the professional level. ${ }^{18-20}$ In stead of searching for proper solutions, these studies describe these constraints as a boundary for improving gender sensitivity. This underlines the need for a comprehensive approach. Comprehensive approaches take into account the forming of a core group with committed key players in an institution, developing an appealing vision for the future, training and educating professionals, sharing successes by good and best practices and providing feasible solutions to the main obstacles experienced by the key actors in the process of change..$^{37,38}$ 


\section{REFERENCES}

1. United Nations (1995). Platform for Action. In: Report of the Main Committee of the Fourth World Conference on Women, Beijing.

2. WHO (2007). Madrid Statement. Mainstreaming gender equity in health: The need to move forward. Spain: Madrid, 14 September 2001. Retrieved December 17, 2007 from WHO website: www.euro.who.int/document/a75328.pdf.

3. Verdonk P, Benschop YWM, de Haes HCJM, Lagro-Janssen TLM (2008). From gender bias to gender awareness in medical education. Advances in Health Sciences Education 14:135-152.

4. Doyal L (2003). Sex and gender: the challenges for epidemiologists. International Journal of Health Services 33:569-579.

5. Klinge I (2007). Bringing Gender Expertise to Biomedical and Health-Related Research. Gender Medicine 4 (Suppl.B):S59-63.

6. Lagro-Janssen T (2007). Sex, Gender and Health. Developments in Research. European Journal of Women's Studies 14:9-20.

7. Celik H, Abma TA, Widdershoven GA, van Wijmen FCB, Klinge I (2008). Implementation of diversity in healthcare practices: Barriers and opportunities. Patient Education \& Counseling 71:65-71.

8. Celik H, Klinge I, van der Weijden T, Widdershoven G, Lagro-Janssen, T (2008). Gender sensitivity among general practitioners: Results of a training programme. BMC Medical Education 8:38.

9. Bekker MHJ (2003). Investigating gender within health research is more than sex disaggregation of data: A multi-facet gender and health model. Psychology, Health \& Medicine 8:232-243.

10. Crenshaw KW (1994). Mapping the Margins: Intersectionality, Identity Politics, and Violence against Women of Color. In The Public Nature of Private Violence. Edited by Albertson Fineman M and Mykitiuk R. New York: Routledge, pp.93-118.

11. Bekker MHJ, Vliet KP van, Kolk AM (1999). Realising gender-sensitive health care; the role of research. In: Kolk AM, Bekker MHJ, Van Vliet KP (Eds.). Advanced studies in Women and Health Research: toward gender-sensitive strategies. Tilburg: Tilburg University Press.

12. Celik H, Lagro-Janssen T, Klinge I, van der Weijden T, Widdershoven G. Maintaining Gender Sensitivity in the Family Practice: Facilitators and Barriers. Journal of Evaluation in Clinical Practice (In press).

13. Grol R, Grimshaw J (2003). From best evidence to best practice: effective implementation of change in patients' care. Lancet 362: 1225-1230.

14. Grol R (1997). Beliefs and evidence in changing clinical practice. British Medical Journal 315:418-421.

15. Celik H, Abma TA, Klinge I, Widdershoven GAM. Process Evaluation of a Diversity Training Program: the Value of a Mixed Method Strategy. (Submitted).

16. Bosch M, van der Weijden T, Wensing M, Grol R (2006). Tailoring quality improvement interventions Tailoring quality improvement interventions to identified barriers: a multiple case analysis. Journal of Evaluation in Clinical Practice 13:161-168.

17. Doyal L (2000). Gender Equity in Health: Debates and Dilemmas. Social Science \& Medicine 51:931939.

18. Verdonk P, Mans LJL, Lagro-Janssen ALM (2005). Integrating gender into a basic curriculum. Medical Education 39:1118-1125.

19. Verdonk P, Benschop YWM, De Haes JCJM, Lagro-Janssen ALM (2008). Making a gender difference: case studies of gender mainstreaming in medical education. Medical Teacher 30:e194-201.

20. Risberg G, Johansson EE, Westman G, Hamberg K (2008). Attitudes toward and experiences of gender issues among physician teachers: A survey study conducted at a university teaching hospital in Sweden. BMC Medical Education 8(10).

21. Gunn J, Hegarty K, Nagle C, Forster D, Brown S, Lumley J (2006). Putting woman-centered Care into Practice: A New (ANEW) Approach to Psychosocial Risk Assessment During Pregnancy. Birth 33(1):46-55. 
22. Pope R, Graham L, Patel S (2001). Woman-centred care. International Journal of Nursing Studies 31:227-238.

23. Tiessen R (2004). Re-inventing the Gendered Organization: Staff Attitudes toward Women and Gender Mainstreaming in NGOs in Malawi. Gender, Work and Organization 11(6):659-708.

24. Riska E (2001). Towards gender balance: but will women physicians have an impact on medicine? Social Science \& Medicine 52:179-187.

25. Cowan L, Deering D, Crowe M, Sellman D, Futterman-Collier A, Adamson S (2003). Alcohol and drug treatment for women: clinicians' beliefs and practice. International Journal of Mental Health Nursing 12:48-55.

26. Keuken DG, Haafkens JA, Moerman CJ, Klazinga NS, Ter Riet G (2007). Attention to Sex-Related Factors in the Development of Clinical Practice Guidelines. Journal of Women's Health 16(1):82-92.

27. Council of Europe (1998). Gender Mainstreaming: Conceptual Framework. Methodology and Presentation of Good Practice, EG-S-MS (98) 2. Strasbourg: Council of Europe.

28. Verloo M (2001). Another Velvet Revolution. Gender Mainstreaming and the Politics of Implementation. IWM working paper 5/2001. Vienna: IWM Publications. www.iiav.nl/epublications/2001/anothervelvetrevolution.pdf

29. Jahn I (2005). Die Berücksichtigung der Geslechterperspektive. BundesgesundheitsblattGesundheitsforschung-Gesundheistsschutz 48(3) 287-285.

30. Theobald S, Tolhurst R, Elsey H, Standing H (2005). Engendering the bureaucracy? Challenges and opportunities for mainstreaming gender in Ministries of Health under sector-wide approaches. Health Policy and Planning 20(3):141-149.

31. Elsey H, Kilonzo N, Tolhurst R, Molyneux C (2005). Bypassing districts? Implications of sector-wide approaches and decentralization for integrating gender equity in Uganda and Kenya. Health Policy and Planning 20(3):150-157.

32. WHO (2007). Unequal, Unfair, Ineffective and Inefficient Gender Inequity in Health: Why it exists and how we can change it Final Report to the WHO Commission on Social Determinants of Health. http://www.who.int/social_determinants/resources/csdh_media/wgekn_final_report_07.pdf

33. Krumm S, Kilian R, Becker T (2006). Attitudes towards patient gender among psychiatric hospital staff: results of a case study with focus groups. Social Science \& Medicine 62:1528-1540.

34. Allan HT, Smith PA, Lorentzon M (2008). Leadership for learning: a literature study of leadership for learning in clinical practice. Journal of Nursing Management 16(5):545-555.

35. Murray C, Main A (2005). Role modelling as a teaching method for student mentors. Nurs Times 101(26):30-33.

36. Grol R, Grimshaw J (2003). From best evidence to best practice: effective implementation of change in patients' care. Lancet 362:1225-1230.

37. Kotter JP, Cohen DS (2002). The heart of change. Real life stories of how people change their organizations. Harvard: Harvard Business School Press.

38. Abma TA (2006). Evaluation and communities as practice. Psychiatry as a case example. Evaluation $13(1): 32-48$. 



\section{Chapter 4}

\section{Gender sensitivity among general practitioners: results of a training programme}

H. Celik

I. Klinge

T. van der Weijden G.A.M. Widdershoven A.L.M. Lagro-Janssen 


\section{A B S TRACT}

Gender differences contribute to patients' health and illness. However in current healthcare practices attention to gender differences is still underdeveloped. Recognizing these differences and taking them into account can improve the quality of care. In this study we aimed to investigate whether GPs' gender sensitivity can be stimulated by a training programme. The focus was on three diseases: angina pectoris, depression and urinary incontinence. This study had a quantitative, explorative and descriptive design. By means of a training programme 18 GPs were trained to focus on gender-sensitive recommendations for the three diseases. With standardised registration forms, data were collected during a 6-month period. During the registration period, the GPs were visited by the study team to discuss the process of data collection. The results show that the GPs filled in registration forms for 100 patients: 39 with angina pectoris (31 women and 8 men), 40 with depression (26 women and 14 men), and 21 with urinary incontinence ( 20 women and 1 man). The results show that gender sensitivity can be stimulated among trained professionals. The combination of the training programme, clear and practical recommendations, daily discussion of relevant cases between the GP couples, feedback and support during registration by the study team probably contributed to the outcome. We conclude that GPs' gender sensitivity was stimulated by the training programme and the supporting visits. Ideally, structural attention could be realised by embedding gender issues in existing organisational structures of general practices. 


\section{INTRODUCTION}

Differences between men and women in health depend on the interaction of biological, psychological, socio-economic, and cultural factors. ${ }^{1-5}$ Gender includes masculinity and femininity and refers to the array of socially constructed roles, behaviours and values that society ascribes to the two sexes on a differential basis. Recognition of gender differences can prevent inequity in caregiving. As a result the health of women and men can be improved. ${ }^{6,7}$ In conventional medicine, a patient's illness is usually reduced to a set of signs and symptoms within a biomedical framework. ${ }^{8}$ In this framework attention to gender issues is underdeveloped as evidenced by the clinical practice guidelines, which are widely used for decision-making in healthcare. To date, most guidelines do not cover gender issues. ${ }^{9}$ Moreover, medical training and General Practitioner (GP) specialist training is gender neutral, as little or no attention is paid to sex and gender differences in medical education. ${ }^{10}$ Therefore, it is not surprising that much about gender differences remains unknown and unaddressed in the provision of healthcare.

For adequate care the approach of health professionals should be more attuned to gender issues. Gender sensitivity of health professionals can be defined as showing sensitivity to gender issues in clinical decision-making. Optimizing this requires an awareness that gender (1) has an impact on health, and (2) affects the presentation of health complaints. This sensitivity allows health professionals to deal effectively with gender which will have positive effects on men as well as women.

We developed and implemented a training programme that focused on gendersensitive recommendations. During the programme GPs were trained to take gender into consideration for three prevalent diseases in which gender is an important factor for the quality of care: angina pectoris, depression and urinary incontinence. The central question in this study is whether the training programme actually contributed to GPs' gender sensitivity.

\section{METHODS}

\subsection{STUDY DESIGN}

A quantitative, explorative and descriptive research design was used as basis for our study. This study was part of a larger research project conducted by Maastricht University in collaboration with partners from the Academic Medical Centre of the University of Amsterdam and Radboud University Nijmegen Medical Centre. The study reported here, investigates the gender sensitivity of trained GPs in relation to suggested gender sensitive recommendations. 


\subsection{STUDY POPULATION}

The study population consisted of 9 experienced GPs (8 men and 1 woman) and 9 GPs in third year of training ( 2 men and 7 women). According to the standard training for general practitioners each GP trainee was coupled with another GP teacher, the academic instructor for the specialist training. They participated as volunteers in this study as a team from the same practice.

\subsection{DISEASE SELECTION}

Three important public health diseases were chosen: angina pectoris, depression, and urinary incontinence. These fulfilled the following selection criteria: availability of clinical practice guidelines, highly prevalent, proven link with gender differences, and the disease should be initially treated by GPs.

\subsection{RECOMMENDATIONS}

A structured literature review using a previously described search strategy on the three diseases was performed by researchers at the University of Amsterdam, in scientific databases including Pubmed, Embase, and Psycinfo. ${ }^{9}$ Articles were selected according to quality assessment (Cochrane), clinical relevance of gender aspects and presence of additional information compared to the existing guidelines of the Dutch College of General Practitioners (DCGP-guidelines). From the selected articles we formulated several recommendations with regard to these three diseases. ${ }^{11}$ In this study we present these gender sensitive recommendations.

\subsection{TRAINING PROGRAMME}

Based on the results of the literature review, an interactive training programme consisting of two modules was developed and executed by the coordinator of the programme (Toine Lagro-Janssen). For the programme description see Lagro-Janssen \& Botden. ${ }^{12}$ The training programme focused on the recommendations (see boxes 1-3) for a gender sensitive approach to the three diseases in the general practice. The modules included a general introduction in to gender-related issues and interactive lectures. Audio visual materials related to gender issues were used for discussion purposes with the participants by the coordinator of the programme. GPs were trained to put the recommendations into practice. The programme ended with instructions on how to use the designed registration forms containing the gender sensitive recommendations and how to discuss the contents for educational and research purposes. 


\section{BOX 1 Gender sensitive recommendations for angina pectoris}

1. With chest pain attention should be paid to diabetes as a risk factor in women also when atypical symptoms for chest pain are present. The reason is that due to diabetes mellitus the risk for cardiovascular disease will increase double for men and triple for women. ${ }^{13}$

2. Information about the socioeconomic status should be obtained, since the proportion of chest pain referring to angina pectoris increases with the decreasing level of socioeconomic status. ${ }^{14}$ Furthermore, low socioeconomic status in women is related to higher morbidity from angina pectoris than for men. ${ }^{15}$

3. Symptoms which do not immediately disappear in women during rest, should not be ignored, since there can be an underlying angina pectoris. ${ }^{16}$ Typical symptoms for angina pectoris will present during physical activity and rapidly disappear with rest.

\section{BOX 2 Gender sensitive recommendations for depression}

1. The GP should ask whether there are sexual problems in depressed patients, since they do not often mention this spontaneously. In depressed patients there is generally a decrease of sexual functioning. Specifically for women

1. GP's should know that depression in women can be masked by anxiety, since women with depression suffer from anxiety. ${ }^{17}$ Furthermore, women report more symptoms consistent with anxiety than men. ${ }^{18}$

2. GP's should ask depressed women about their past sexual experiences, since a history of sexual abuse is strongly associated with depression in women. ${ }^{19}$

Specifically for men

1. The GP should know that depression in men could be masked by alcohol abuse, 20 since depressed men show significantly more alcohol abuse..$^{17,21}$

2. In depressed male patients there is generally a decrease in libido, and erectile dysfunction. Men frequently experience loss of libido, and erectile dysfunction as a serious disability. The GP should ask whether the patient suffers from these symptoms, since men do not often mention this spontaneously. ${ }^{22}$

\section{BOX 3 Gender sensitive recommendations for urinary incontinence}

1. Recommending the use of a diary in men and women can be an instrument for improving the quality of care.

2. GPs should consider sexual issues in the management of patients with incontinence, since incontinence is a risk factor for sexual dysfunction in men and women. ${ }^{23}$

Specifically for women

1. GP's should promptly provide active treatment for women who consult their GP with incontinence which exists for a long period.

Specifically for men

1. The GP need to attend to the emotional well-being, since most men do not report distress spontaneously.24 Men consulting a GP may not minimize the extent of their incontinence compared to women, due to their fear of prostate cancer or impotence. These underlying concerns may cause distress which negatively impacts on their well-being. 


\subsection{REGISTRATIONS}

The GPs were asked to fill out standardised registration forms for patients seen for the first time for one of the three aforementioned diseases, immediately after the consultation. The purpose of the registration forms was to support and increase GPs' gender sensitivity toward patients. These quantitative data were collected during a 6-month period. Informed consent was obtained to use these data for scientific publications. If the GP did not follow a particular recommendation, the GP had to explain the reason for this on the form. At the end of the day all of the completed forms in the practice were discussed with each GP couple. The routine of daily conversations about their experiences and their difficult cases constituted a standard aspect of this gender- sensitivity training. During the 6-month period the study team visited the GP practices twice to discuss the process of data collection.

\subsection{DATA ANALYSIS}

To score gender sensitivity, all registration forms were coded. If GPs followed the recommendations, we assumed that they were more gender sensitive. Each recommendation was assigned a code 1 when the GP's adherence to the recommendation was gender sensitivity and 0 if the adherence was not gender sensitivity. Hence, not gender sensitive means non-adherence to the gender-sensitive recommendation. Take for example, the first recommendation for angina pectoris. In the event of chest pain attention should be paid to diabetes as a risk factor in women also when atypical symptoms are present. If attention was paid to diabetes as a risk factor in women with typical and atypical symptoms, the adherence was expected to be gender sensitive, and we assigned this result a code 1 . If diabetes was not considered as a risk factor, this was not expected to be gender sensitive, and we gave this a code 0 . Data were analysed with descriptive statistics, using SPSS 13.

\section{RESULTS}

In total 100 registration forms for patients were completed (39 patients with angina pectoris, 40 patients with depression, and 21 patients with urinary incontinence).

\subsection{ANGINA PECTORIS}

Of 39 patients with angina pectoris, GPs registered 31 female and 8 male patients. As shown in Table 1, diabetes was considered for almost all female and male patients. In the GP practices references to socioeconomic status (financial problems) and complaints of chest pain during rest periods were relatively more frequent noticed for men 
than for women. Reasons given for not determining the socioeconomic status for male patients were the urgency of the medical situation and difficulty to apply this principle. In addition to the urgency of the medical situation, reasons given for not determining the socioeconomic status of women were: prior knowledge of this $(\mathrm{N}=1)$, forgetting, or considering the symptoms as unproblematic.

TABLE 1 Indicators for angina pectoris

\begin{tabular}{lcc}
\hline Indicators & $\begin{array}{c}\text { Considered } \\
\text { in women }\end{array}$ & $\begin{array}{c}\text { Considered } \\
\text { in men }\end{array}$ \\
\hline Diabetes & 30 & 8 \\
Socioeconomic status & $(97 \%)$ & $(100 \%)$ \\
& 10 & 4 \\
Complaints during rest & $(34 \%)$ & $(50 \%)$ \\
& 18 & 6 \\
\hline
\end{tabular}

Angina Pectoris $\mathrm{N}=39: \mathrm{N}=31$ female and $\mathrm{N}=8$ male

\subsection{DEPRESSION}

Registration forms were filled out for 40 patients with depression (26 women and 14 men). For female patients suffering form depression, the GPs acted according to the recommendation regarding anxiety in the case of 25 patients (96\%) (Table 2). The recommendation regarding sexual abuse was followed for 8 female patients (31\%). Reasons given for not asking depressed women about their sexual history were: the GP did not find an appropriate opportunity to ask about it, it was difficult to ask during the first consultation due to the sensitive nature of the question, the patients related their sexual history spontaneously, or the GP already knew the sexual history. Sexual problems were addressed in the case of $15(58 \%)$ female patients. Alcohol abuse was discussed with all male patients, while sexual problems in men were discussed with 4 (29\%) patients (Table 3).

TABLE 2 Indicators for women with depression

\begin{tabular}{lc}
\hline Indicators & Considered \\
\hline Anxiety & 25 \\
& $(96 \%)$ \\
Sexual abuse & 8 \\
& $(31 \%)$ \\
Sexual problems & 15 \\
& $(58 \%)$ \\
\hline
\end{tabular}

Depression $\mathrm{N}=26$ female 
TABLE 3 Indicators for men with depression

\begin{tabular}{lc}
\hline Indicators & Considered \\
\hline Alcohol abuse & 14 \\
& $(100 \%)$ \\
Sexual problems & 4 \\
\hline
\end{tabular}

Depression $\mathrm{N}=14$ male

\subsection{URINARY INCONTINENCE}

Of 21 patients with urinary incontinence were 20 women and 1 man registered. The results suggest that the presentation of urinary incontinence complaints to the GP was low, particularly among male patients. During the registration period GPs reported that this could be because patients do not schedule a consultation, but just ask the GP assistant by phone to prescribe incontinence pads for them. The recommendation to advise the patient to keep a diary for urinary incontinence was followed by the GPs for 2 $(11 \%)$ of the female patients. The recommendation for active treatment and addressing sexual dysfunction was followed for $15(79 \%)$ and 11 (58\%) of the female patients, respectively, as shown in Table 4 . Since, there was only one male patient; the result was not included.

TABLE 4 Indicators for women with urinary incontinence

\begin{tabular}{lc}
\hline Indicators & Considered \\
\hline Diary keeping & 2 \\
& $(11 \%)$ \\
Active treatment & 15 \\
Sexual dysfunction & $(79 \%)$ \\
\end{tabular}

Incontinence $\mathrm{N}=20$ female

\subsection{GENDER SENSITIVITY}

GPs mean gender sensitivity for all patients was 1.84 (SD:.79). That means that on average, the GPs applied two out of three recommendations to all patients. 


\section{DISCUSSION}

To our knowledge this is the first study that investigates gender sensitivity of GPs which extends beyond the existing guidelines. The results show that gender sensitivity can be stimulated among trained professionals for non-routine patient cases. The combination of the training programme, clear and practical recommendations, daily discussion of relevant cases by the GP couples, as well as feedback and support from the study team probably all contributed to the outcome.

During the registration period, the GPs were visited by the study team to discuss the process of data collection. These visits served as a reminder to fill out the registration forms and were aimed at working out the practical difficulties of applying the recommendations in the GP practice. During the visits we found that GP teams did not fill out a form for all first visits of patients suffering from angina pectoris, depression and urinary incontinence. Interestingly, the GPs did not register the routine cases, but selected patients with expected gender-related problems to register and discuss with each other for educational purposes.

Our data show that more registration forms were completed for female than for male patients for the three conditions. An explanation could be that women have more contact with their GPs than men. ${ }^{25,26}$ For angina pectoris in particular special attention to women was deemed urgently warranted during the training programme. This was in reaction to the tendency to the focus on typical symptoms and a masculine presentation style. ${ }^{27}$ This focus was not to minimize the gender effects on the health of men with angina pectoris, but rather to correct existing imbalances in the general practice. Even though attention should be paid to atypical symptoms in women, attention to typical symptoms is still required for both sexes. Concerning depression and urinary incontinence, the number of registration forms completed for female patients can be explained by higher prevalence of these conditions in women in the general practice. ${ }^{28}$ In line with earlier studies, it is also possible that an increasing awareness of gender issues in medical education and practice has resulted in an increased focus on women. ${ }^{29}$

In general, GPs adherence to the gender sensitive recommendations in this study was relatively high. We did not find differences in gender sensitivity towards women and men. Recommendations regarding the socioeconomic status of patients with angina pectoris, sexual abuse in women with depression, sexual problems in men with depression, and diary keeping in women with urinary incontinence, were followed less frequently. In instances when the GP already knew the socioeconomic status or the patient related the sexual history spontaneously, these recommendations were obviously irrelevant. Nevertheless, in the majority of the cases the reasons for not following these recommendations -e.g. forgetting to ask or reluctance to discuss sexual history during first consultation- leave room for improvement.

This study can be regarded exploratory in character. To determine the effects of the programme a study with before-after measurement and/or a concurrent control 
group is necessary. The effect of the training programme may have been boosted by the practice visits during the study period. The samples per professional were too small to detect a trend in the GPs' sensitivity over the 6-months period. For a large-scale and long-term effect, it should be kept in mind that a training programme for general practitioners is just one of the sources to improve the position of gender issues in medical decision-making. Ideally, progress could be realised by embedding gender issues into existing organisational structures of the general practice. This is in agreement with findings in our earlier study. ${ }^{30}$ Organizational constraints can be a barrier to incorporating and maintaining gender issues into healthcare practices. Therefore it is important to explore ways of effectively addressing gender issues in the organisation of the family practice by developing tailored recommendations. Further qualitative research of GPs' impressions and feedback on this subject is recommended as it will complement gender-related research and practice. 


\section{REFERENCES}

1. Danielsson U, Johansson EE (2005). Beyond weeping and crying: a gender analysis of expression of depression. Scandinavian Journal of Primary Health Care 23:171-177.

2. Pears E, Hannaford PC, Taylor MW (2003). Gender, age and deprivation differences in the primary care management of hypertension in Scotland: a cross-sectional database study. Family Practice 20:22-31.

3. Verloo M (2006). Multiple inequalities, intersectionality and the European Union. European Journal of Women's Studies 13:211-228.

4. Yuval-Davis N (2006). Intersectionality and Feminist Politics. European Journal Women's Studies 13:193-209.

5. Risberg G (2005). I'm just a civil servant - neutral and sexless. About the resistance against the gender perspective and the risk of gender bias in medicine. Lakartdningen, 102(40):2852-2854.

6. Bird E, Rieker PP (1999). Gender matters: integrated model for understanding men's and women's health. Social Science \& Medicine 48(6):745-755.

7. Doyal L (2000). Gender Equity in Health: Debates and Dilemmas. Social Science \& Medicine 51(6): 931939.

8. Mead N, Bower P (2000). Patient centredness: a conceptual framework and review of the empirical literature. Social Science \& Medicine 51:1087-1110.

9. Keuken DG, Haafkens JA, Moerman CJ, Klazinga NS, ter Riet G (2007). Attention to sex-related factors in the development of clinical practice guidelines. Journal of Women's Health 16(1):82-92.

10. Verdonk P, Benschop YWM, de Haes JCJM, Lagro-Janssen ALM (2007). From gender bias to gender awareness in medical education. In Gender matters in medical education: integrating a gender perspective in medical curricula Edited by: Verdonk P. Harderwijk: Drukkerij Wedding, pp.11-25.

11. Lagro-Janssen A, Minne W van der (2006). Gender specific recommendations to three NHG guidelines. Nijmegen University Medical Centre.

12. Lagro-Janssen A, Botden M (2006). Training gender specific medicine in post graduate general practitioners. Nijmegen University Medical Centre.

13. Bebbington PE, Dunn G, Jenkins R, Lewis G, Brugha T, Farrell M, Meltzer H (1998). The influence of age and sex on the prevalence of depressive conditions: report from the National Survey of Psychiatric Morbidity. Psychological Medicine 28:9-19.

14. Richards H, McConnachie A, Morrison C, Murray K, Watt G (2000). Social and gender variation in the prevalence, presentation and general practitioner provisional diagnosis of chest pain. Journal of Epidemiology and Community Health 54(9):714-718.

15. Vogels EA, Lagro-Janssen ALM, Van Weel C (1999). Sex differences in cardiovascular disease: are women with low socioeconomic status at high risk. British Journal of General Practice 49(449):963-966.

16. McSweeney JC, Cody M, O'Sullivan P, Elberson K, Moser DK, Garvin BJ (2003). Women's early warning symptoms of acute myocardial infarction. Circulation 108(21):2619-2623.

17. Have ten M, Schoemaker C, Vollebergh W (2002). Genderverschillen in psychische stoornissen, consequenties en zorggebruik [Gender differences in psychiatric disorders, conseqences and consumption of care]. Results from the Netherlands Mental Health Survey and Incidence Study (NEMESIS). Tijdschrift voor Psychiatrie [Journal for Psychiatry] 44(6): 367-375.

18. Breslau N, Schultz L, Peterson E (1995). Sex differences in depression: a role for preexisting anxiety. Psychiatric Research 58(1):1-12.

19. Hegarty K, Gunn J, Chondros P, Small R (2004). Association between depression and abuse by partners of women attending general practice: descriptive, cross sectional survey. BMJ 328(7440):621-624.

20. Roeloffs CA, Fink A, Unutzer J, Tang L, Wells K (2001). Problematic substance use, depressive symptoms, and gender in primary care. Psychiatric Services 52(9):1251-1253. 
21. Kessler RC, Crum RM, Warner LA, Nelson CB, Schulenberg J, Anthony JC (1997). Lifetime cooccurrence of DSMIII-R alcohol abuse and dependence with other psychiatric disorders in the National Comorbidity Survey. Arch Gen Psychiatry 54(4):313-321.

22. American Psychiatric Association (2000). Practice Guideline for the Treatment of Patients With Major Depressive Disorder.

23. Hansen BL (2004). Lower urinary tract symptoms (LUTS) and sexual function in both sexes. European Urology 46(2):229-234.

24. Teunissen D, Lagro-Janssen $\mathrm{T}$ (2004). Urinary incontinence in community dwelling elderly: are there sex differences in help-seeking behaviour? Scandinavian Journal of Primary Health Care 22(4):209-216.

25. Briscoe ME (1987). Why do people go to the doctor? Sex differences in the correlates of GP consultation. Social Science \& Medicine 25(5):507-513.

26. Waldron I (1983). Sex differences in illness incidence, prognosis and mortality: issues and evidence. Social Science \& Medicine 17(10):1107-1123.

27. Wenger NK (2003). Coronary heart disease: the female heart is vulnerable. Progress in cardiovascular disease 46(3):199-229.

28. Lisdonk EH van de, Bosch WJHM, Huygen FJA van den, Lagro-Janssen ALM (2003). Ziekten in de huisartspraktijk. Utrecht: Bunge.

29. Zelek B, Phillips SP, Lefebre Y (1997). Gender sensitivity in medical curricula. Canadian Medical Association Journal 156(9):1297-1300.

30. Celik H, Abma TA, Widdershoven GA, van Wijmen FCB, Klinge I (2008). Implementation of diversity in healthcare practices: Barriers and opportunities. Patient Education \& Counseling 71(1):65-71. 


\section{Chapter 5}

\section{Maintaining gender sensitivity in the family practice: facilitators and barriers}

H. Celik A.L.M. Lagro-Janssen I. Klinge T. van der Weijden G.A.M. Widdershoven 


\section{A B S T R ACT}

This study aims to identify the facilitators and barriers perceived by General Practitioners (GPs) to maintain a gender perspective in family practice. Nine semi-structured interviews were conducted among 9 pairs of GPs. The data were analysed by means of deductive content analysis using theory-based methods to generate facilitators and barriers to gender sensitivity. Our results show that gender sensitivity in family practice can be influenced by several factors which ultimately determine the extent to which a gender sensitive approach is satisfactorily practiced by GPs in the doctor-patient relationship. Gender awareness, repetition and reminders, motivation triggers, and professional guidelines were found to facilitate gender sensitivity. On the other hand lacking skills and routines, scepticism, heavy workload, and the timing of implementation were found to be barriers to gender sensitivity. We conclude, that while the potential effect of each factor affecting gender sensitivity in family practice has been elucidated, the effects of the interplay between these factors still need to be determined. 


\section{INTRODUCTION}

The impact of gender on health and illness in the family practice is widely accepted nowadays. ${ }^{1}$ Differences in gender go beyond biological variation between the sexes and refer to the social and cultural influence of being masculine or feminine. ${ }^{2-4}$ Gender is a dynamic process and is in continuous interaction with health processes. ${ }^{5,6}$ In this respect, the significance of gender is evidenced by the fact that ignoring differences may lead to inappropriate care, or even to unnecessary or harmful care. ${ }^{7}$ Despite this knowledge, there is still generally a gap between what is known and what is routinely performed in practice. ${ }^{8,9}$ Relevant evidence on gender differences is still omitted in the current clinical approach of GPs and this is likely to have adverse consequences on the quality of care provided in the family practice. ${ }^{10}$ To facilitate change we need an indepth understanding of the barriers and incentives to gender sensitivity in clinical practice.

To bridge the gap between gender specific evidence and gender sensitivity among GPs, a training programme was developed and provided to GPs. ${ }^{11}$ GPs were trained to take gender into consideration for three prevalent diseases in which gender is an important factor for quality of care: angina pectoris, depression and urinary incontinence. We found that gender sensitivity can be fostered among trained professionals, but to maintain gender sensitivity, a one-time gender training is not considered to be enough for a lasting approach to gender differences in a clinical setting. To achieve a permanent effect, the barriers and facilitators for maintaining gender sensitivity should be revealed. In this study, we have investigated the facilitators and barriers to gender sensitivity and to the implementation and maintenance of a gender sensitive approach in family practice as perceived by GPs.

\section{METHODS}

\subsection{STUDY DESIGN}

All general practitioners, who had undergone training in gender sensitivity in an earlier phase, were invited for our study. This investigation is part of a larger study conducted by Radboud University Nijmegen Medical Centre in collaboration with Maastricht University Medical Centre. A qualitative approach with semi-structured interviews was used.

In the previous phase of this study we implemented an educational programme consisting of two modules to address the concept of gender sensitivity and to raise awareness of its significance in the clinical setting. The program focused on gender sensitive recommendations for angina pectoris, depression and urinary incontinence in the general practices and included peer discussion groups and plenary discussions. ${ }^{11}$ 
The programme ended with instructions on how to use the consultation related registration forms. After completion of the preliminary training in the previous phase the GPs were visited by the research team ( $\mathrm{HC}$ and $\mathrm{WvdM}$ ) at their practices to discuss completed registration forms and the notes they made.

\subsection{STUDY POPULATION}

To initiate change, innovators are needed. According to Rogers, these innovators are usually a small number of people who have a particular interest in new ideas. ${ }^{12,13}$ In our case, all of the 18 motivated GPs (11 men, 7 women), who volunteered for the previous study, also volunteered for this study. They worked in pairs in a family practice as experienced GP (an academic instructor for the specialist training), and GP registrar in the last year of training. This composition enabled us to allow for potential differences with regard to barriers and facilitators between experienced GPs and GPs in-training.

\subsection{DATA COLLECTION}

We collected data by means of semi-structured interviews. In each practice the two general practitioners were interviewed by two interviewers (two-on-two interview). One interviewer was a trained GP and the other was the first author.

The interview guide was developed based on existing literature and previous findings ${ }^{11}$ and covered the structure and processes of the practice as well as the GPs perspective. The following information was sought regarding: the attitude and perspective of GPs toward gender sensitivity in their family practice, the existing attention for gender in the organisational structure/processes, and suitable pathways and policy documents for embedding/maintaining gender in the practice organisation. During each interview the respondents were asked for illustrative examples: Is attention to gender issues encouraged in this practice? How can maintenance of gender sensitivity be realised in this practice. The GPs were questioned about the connection with the existing structures and processes because this is required for successful implementation. ${ }^{14}$

Each interview took place at the practice of the GPs. The interviews lasted between 30 and 40 minutes and were tape-recorded and transcribed. Field notes were taken of contextual information, impressions during the interview and of informal talks after each interview. The interviewers exchanged experiences in order to align the interviews and the notes.

\subsection{DATA ANALYSIS}

The data were analysed by means of deductive content analysis ${ }^{15}$ using theory-based methods to generate facilitators and barriers at different levels as described by Grol and colleagues..$^{14,16,17}$ First, the field notes were read by two researchers (HC and TLJ) to get 
a general impression of the data. Next, the transcripts of the interviews were read and all text regarding gender sensitivity was highlighted. All highlighted passages were then coded using the theory-based methods as a framework. By means of these methods, factors for change can be identified by models with multiple levels: the individual professionals' level, the interpersonal social level and the organisational context level. The model related to the individual professional focused on e.g. cognitive, educational, attitudinal and motivational factors. The interpersonal social level focused on the professional interaction. This model included factors such as social learning, social influence, professional network, and patient influence. Factors related to the organisational context level are organisational structures and processes (including clinical protocols). Depending on a given situation the presence or absence of these factors is either a facilitator or a barrier to (maintain) change.

\section{RESULTS}

\subsection{FACILITATORS}

We have found that several factors at the level of the individual professional promote gender sensitivity: gender awareness, repetition and reminders. At the interpersonal social level: motivation triggers were found that stimulate gender sensitivity, and at the organisational context level: professional standards can facilitate the maintenance of this in family practice

TABLE 1 Facilitators and barriers regarding maintaining gender sensitivity

\begin{tabular}{ll}
\hline Facilitators & Barriers \\
\hline Individual professional level & Individual professional level \\
Gender awareness & Lacking skills and routines \\
Repetition and reminders & Scepticism \\
Interpersonal social level & Interpersonal social level \\
Motivation triggers & Heavy workload \\
Organisational context level & Organisational context level \\
Professional guidelines & Timing of implementation \\
\hline
\end{tabular}

\section{GENDER AWARENESS}

Gender awareness is the recognition and understanding of gender issues by professionals. Most GPs said that the gender training increased their awareness of these issues and provided them with the knowledge to recognize them. The GPs reported that especially 
the process of group learning and exchange with other GPs was very useful for raising awareness in itself which then triggered the individual GP to think about gender.

Introducing the concept of gender into medicine and medical treatment is very good. I have benefited significantly from the knowledge presented. (Ze5,50)

Other GPs reported that they no longer regarded the patient in a neutral way. They experienced the training as an eye-opener. Gender awareness has made them more attuned to how they apply their knowledge in daily patient care. They were able to recognize symptoms related to gender more easily and some GPs reported that they were better at recognizing differences in the presentation style between men and women. They also include gender issues in their treatment.

As a result of the educational program (...), you can recognize and appreciate the intricacies of the gender issue. That is very good. $(A 2,20)$.

Increased gender awareness broadens the GPs perspective with regard to the patient. Clearly, more appropriate care can be provided to the patient if gender issues are addressed rather than ignored. The benefits to both the patient and practitioner are obvious. Some GPs indicated that self-reflection is the key behaviour to maintaining gender sensitivity.

It is very relevant given the fact that you could otherwise actually miss diagnosing a cardiac infarction $($ Ze5,99)

Some GPs reported that becoming gender sensitive is a goal that can be most likely accomplished in the long term. In order to give more appropriate care GPs need time to search for ways to tackle health issues from a gender perspective.

Before I took part in this training, I used to implicitly think that 'men do it all this way and women do it all that way'. This was a caricature of sorts . . (A2-221)

\section{REPETITION AND REMINDERS}

The GPs felt that the visits (by the research group) worked as an on-going incentive and external support for maintaining gender sensitivity in consultation with patients. This can be called frappéz toujours, since GPs stated that the visits helped them to remain conscious of gender issues. Other GPs valued these visits because they fostered enthusiasm for gender sensitivity. The follow-up visits also prevented gender issues from being neglected. Furthermore, talking about gender issues has led to an 'ahaerlebnis'. Our research suggests that the 'aha-erlebnis' is not an isolated phenomenon in this context, but is accompanied by extra motivation and confidence building through the acquisition of new knowledge which can be applied. Not only was it good for the practitioner to realize the significance of gender and its impact on the patient (aha), but the GPs were motivated to address it in their practice. 
Yes, these gatherings were definitely good. You become enthusiastic. The visits prompted the aha response. $(Z e 5,21)$

Some GPs reported that the registration forms, which were used as consultation checklists, also worked as an immediate on-the-spot reminder. It was a kind of manual that supported GP's gender learning. These forms, on which the GPs made notes, guided them to consider and maintain gender issues throughout the consultations.

You bave a reminder (...). By using this form the items become gradually more internalized in your head. In addition, you write them down. (R1, 28)

\section{MOTIVATION TRIGGERS}

Some GPs said that discussing gender issues with colleagues was a trigger for themselves and for their colleagues to remain alert to them. Others said that these discussions, elicited reflection and re-think of the potential impact of gender issues on the presentation of health problems in their patients.

(...) to keep each other alert to see if the presentation of medical problems are or a general nature or whether apparent differences can be attributed to gender. $(Z e 5,463)$

Additionally, one GP reported that he was triggered to be alert for gender related publications.

I notice that now I am attuned to gender issues I am eager to read more on the subject. This has made me enthusiastic. (Bo4, 119)

Rewarding experiences also triggered the GPs to pay attention to gender issues. Moreover, with these positive experiences, in practice, they were able to see the added value for patients. Gender sensitivity contributes to a more comprehensive approach to patient care since it acknowledges gender differences and their clinical implications. This is also rewarding to the practitioner. For example, some GPs reported their success with detecting differences in presentation, and diagnosis of angina pectoris (chest pain) in men and women. Other GPs mentioned that their own experiences motivate them to move beyond a neutral approach.

We have been shaken awake a couple of times. (...) To be aware of whether the patient is a man or woman and to take this fully into account. Let us not fall asleep on this again. (A2,95)

Some reported that they feel empowered by their gender sensitive approach. By being able to make a link between gender related issues and patients' diseases they felt able to see the 'big picture' with regard to the disease. When this 'picture' was reflected to the patient, it was gratifying for the GP.

This has really helped me. You can see things and reflect them back to the patient. This acts as a catalyst for more insight and information from the patient. Yes this is going on. (A2-196) 
Some GP's were motivated to share their gender related experiences with other GPs. They exchanged in valuable way experiences about the way they dealt with gender related issues.

At a certain point you are going to share what you do and what you experience (...). Look, what case do we have here? What are the intricacies involved? $(Z e 5,243)$

Not surprisingly, a shared positive attitude toward gender sensitivity among the colleagues within the same practice was conducive to incorporating gender issues in the practice. This was reinforced with discussions over these issues in regular clinical meetings.

We have regular clinical meetings (...) which do encompass more than just patients. This year we put gender issues on our agenda for these meetings. Here in this practice we can speak to each other about this. That is a big advantage. (Ze5,292)

In addition to the practice, there is a larger network of professionals which also has its benefits. In a network it is possible to share experiences, exchange viewpoints, and it is a source from which to further develop ideas. When an underlying gender-related problem is recognized the patient can also be referred to gender-specialists in the network. Some GPs reported that a referral can be a learning process for GPs, when there is feedback from the specialist with gender-sensitive competencies to the GP.

We had good feedback (...) from a psychiatrist. She called back often to bring our attention to certain issues. She was well acquainted with the intricacies involved. (HE8, 348)

Recognition of gender issues by other co-workers, such as a nurse practitioner and assistants, can also be a motivation trigger. They screen patients and then refer them to the GP. Some GPs mentioned that when these co-workers recognize gender related problems they can make a pre-selection of patient cases based on gender to prevent a referral bias.

For example, the medical support staff could inform patients with diabetes, who had already had a cardiac infarction that they need not wait until you have chest pain to come in. They can encourage them to come in sooner if they experience more minor symptoms such as tightness in the chest. (NIJ6,352)

\section{ProfessionAL GUIDELINES}

Incorporation of gender issues in practice guidelines at the Dutch College of General Practitioners, may promote the maintenance of gender issues in general practice, according to some of the GPs. Next to the main text of the guideline some critical notes can also be helpful to raise awareness for gender issues and to remain gender sensitive.

The standards will need to be adjusted ( ) to reflect the research results showing that women can present atypical symptoms. (UD7, 551) 


\subsection{BARRIERS}

In addition to facilitators, we have also identified factors that impede the maintenance of gender sensitivity of the GPs. At the individual professional level these barriers are lacking skills and routines, and scepticism. Others are heary workload at the interpersonal social level and timing of implementation at the organisational context level.

\section{LACKING SKILLS AND ROUTINES}

Several GPs state that gender sensitivity is not included in their medical training. They are lacking specific communication skills to deal with gender issues in practice. In this regard, most perceived their shortcomings to be in discussing taboos or difficult matters such as sexual and/or domestic violence with patients. These items were on the registration form for depression which suggested attention be paid to them. Furthermore, there was agreement that education is fundamental for successfully mastering it in their daily practice.

I always find it difficult to bring up the subject of sexual abuse. I need to have a kind of introduction and then I can ask questions. Not out of the blue (...). I can't do that. (...). It is also difficult to introduce domestic violence into the conversation. Perhaps this is something to give attention to in education. $(U d 7,216)$

Experienced GPs indicated that it was difficult to change their ingrained habits and routines. These behavioral patterns were a reason to oppose a change.

I think that, surely for young doctors, this project deserves attention in the training for family medicine. However, I wonder if this holds true for general practitioners, like myself, that already have so many years of experience. (Wi3,118)

Some GPs reported that paying attention to gender issues is a complicated matter. They were overwhelmed by the complexities of gender.

\section{( ) bringing gender to the forefront is franght with difficulties. $(Z e 5,151)$}

\section{SCEPTICISM}

Some professionals perceive giving attention to gender issues as an addition to their already full workload that cannot be easily integrated into their care giving. They consider it a secondary consideration, rather than that it is part of the core-business of a general practitioner and, therefore, give it low priority.

You notice that in family practice doctors do what needs to be done and the other things get moved to the bottom of the pile. I think it is very normal that a family doctor always has to prioritize what to get done first. (NIJ6,272)

Changing the status quo and transforming gender into a matter-of-course is a time consuming process which also requires a commitment. Some GPs wonder if they will be able to implement gender sensitivity in their practice. GPs anticipate that their in- 
vestments will not pay-off in the short term. They posed questions regarding the evidence for the effectiveness of addressing gender issues in practice. They were not convinced that there are significant benefits to be gained from an investment in gender issues.

I do not know if there is as much to be gained as you expect. That is up to you, but I would like to see some proof. (NIJ6,169)

Others regard gender issues more simplistically and do not see the complexities involved. They said that being rational and using 'common sense' is enough to address gender related issues properly or they claimed that they already worked as genderoriented practitioners.

Just by using common sense you know that there are a number of sex-specific differences. (Wi3,384).

\section{HEAVY WORKLOAD}

Some GPs consider the amount of work they have to do as a heavy workload. They reported that in a busy environment, with daily obligations, it is difficult to pay attention to gender. Others say that the focus on gender requires an investment of time which they cannot afford given the demand made on them.

Let me put it this way - the biggest problem that I have had is that if you are really going to focus (...) it remains very difficult to do in a busy work environment. $(Z e 5,80)$

Due to the hectic pace at their practice, GPs experience gender sensitivity as an exaggerated expectation given the pressure in their work environment.

Actually there is more and more expected from us. On the one hand, that is justified. On the other hand, the reality of daily practice is that it is very busy and not without stress. (HE8,161)

As a result of the typically heavy workload, some GPs say that they do restrict themselves seriously to the scheduled consultation time, to be able to accommodate the case load. Therefore GPs declared that just observing a gender related problem is not enough. Devoting time to it is needed to make an in-depth assessment and follow-up possible for difficult gender related themes, such as sexual abuse.

I was afraid of getting into a subject and stirring things up, knowing that I only had 10 minutes, which is not enough time to deal with it. (...) Then you know that there should be an additional 15 minutes or more, or you should not even begin on it. (UD7, 276)

\section{TIMING OF IMPLEMENTATION}

Not finding the right timing for implementation could be a barrier to the introduction of a gender sensitive approach to patient care. Some GPs felt that it was not the right time for the introduction of gender issues, because other issues in their practice deserved priority. 
The problem which we are now confronting in the case of the renovation of our building is that we are pre-occupied with practical and financial matters and the medical issues get pushed aside. (R1263)

Other GPs reported that they just moved to their practice. Understandably, gender issues were not a priority at that moment.

We are just starting our practice. Therefore, this year is, therefore, not the best time to participate in this project. (...). Our practice is important and takes priority. Gender at this moment does not. $(\mathrm{R} 1,57)$

Also a dynamic practice environment can have an impact on the normal habits. To achieve change, the status quo should be stable. Some GPs mentioned that a renovation of the practice affected the content of their policy agenda.

Yes, it would be worthwhile to discuss sex-specific issues in our practice. (...) In our discussions this past month we have only discussed building materials. (...) About faucets electrical outlets, cranes and computer lines... That is time-consuming. (HE8,83)

\section{DISCUSSION}

In this study, we have investigated which factors influence the maintenance of gender sensitivity in family practices from the viewpoint of the provider. We identified several barriers $(-)$ and facilitators $(+)$ at the individual professional level: gender awareness $(+)$, repetition and reminders $(+)$, lacking skills and routines $(-)$, scepticism (-); at the interpersonal social level: motivation triggers $(+)$ and heavy workload $(-)$ and at the organisational context level: integrating gender issues in professional guidelines $(+)$ and timing of implementation (-).

In line with our expectation, gender awareness and knowledge appear to be important in maintaining gender sensitivity. Training is the first step, a catalyst. However for a permanent effect more is needed. Professionals need to be educated and motivated with regard to gender sensitivity. As gender-bias is a consequence of the biomedical focus in (post-) medical training, gender sensitive issues should become a structural part of professional education. ${ }^{10,11}$ Structural change in the basic curricula of medical schools and post-medical training will help eliminate the existing gender stereotypes among health providers. Gender stereotypes are preconceptions used by society about what is considered to be typically feminine and typically masculine characteristics, behaviour and illness. Courtenay confirmed the importance of reconstructing the dominant constructions of women as well as of men. ${ }^{18}$ In addition to educational initiatives, professionals with developed gender sensitivity can facilitate the maintenance of gender sensitivity in physicians' practices. Professionals can get more motivated by discussing relevant gender-related cases, for instance, in small group educational meetings. This 
can in turn trigger the motivation of colleagues. Rewarding experiences in the team can help eliminate or reduce existing resistance-to-change and possible scepticism. However overcoming a neutral or biased approach, the tension between gender sensitivity and the involvement of GPs, is by a time-consuming and supportive and awareness raising strategy. ${ }^{19}$ Repetition (which we name 'frappéz toujours') of gender related issues reinforces these concepts which can result in a more favourable attitude toward gender issues. Sutton has pointed out that behavior must be repeated in order to be effective. ${ }^{20}$ Through repetition, motivation becomes stable and by that a habit for professionals. ${ }^{21}$ This is in line with Grol's idea that in order for change to occur, intensive interventions, in which the 'message' is repeated, are necessary. ${ }^{17}$ These interventions should take existing barriers into account.

A common problem in the GP practice is the heavy workload. Certain patientrelated activities are very time-consuming. According to Groenewegen and Hutten, a high workload might lead to stress and time pressure on GPs. ${ }^{22}$ This, in turn, can lead to a lower quality of GP-patient communication, which could mean detecting fewer patient problems and a lower quality of care. Nevertheless, going beyond a neutral approach and recognizing gender related problems in family practice will lead to the improvement of the communication and an adequate care provision. ${ }^{23,24}$ To minimize time constraints during the implementation process, choosing an optimal implementation time can lead to better results.

One of the general reasons to explain the lack of gender sensitivity is the lack of integration of gender issues into professional guidelines. To facilitate and sustain gender sensitivity in family practice, relevant gender sensitive issues should ideally be incorporated into clinical practice guidelines, which are often used as tools for quality improvement in clinical practice. ${ }^{1}$ However, numerous studies show that just disseminating such guidelines is not sufficient to bring about change in medical practice, as adherence to guideline recommendations does not necessarily follow. ${ }^{25,26}$ For implementation strategies for gender issues in practice it appears that very little has ensued from recommendations which focused on a single level. ${ }^{4}$ A strategy for mainstreaming gender requires the systematic integration of a gender perspective at all relevant levels (individual, practical, national and international). ${ }^{27}$

According to Grol \& Grimshaw the most successful strategies for effective implementation in general take all relevant factors into account. ${ }^{8}$ Thus, barriers as well as facilitators need to be identified and examined, independently and in relation to each other, for a more comprehensive understanding of gender issues and their impact on them. Although we are now aware of the importance of understanding factors that facilitate or impede the maintenance of gender sensitivity in family practice, the dynamics (mutual effect) of these factors and their implications still needs clarification.

The value of this qualitative study lies in demonstrating that motivated GPs who had recently participated in a gender sensitive interventional program, reflected on data collected from real clinical settings and doctor-patient consultation. The findings were 
generated by these 'early adopters' of gender issues and will be representative to larger groups of professionals in the sentence that the barriers that are viewed by the early adopters will probably count for the larger group of laggards. Limitation of this study is that the interviewers themselves were not neutral, as regards gender sensitivity. This could have influenced the responses of the respondents towards socially desirable answering.

\section{CONCLUSION}

In the present study, we have identified gender awareness, repetitions and reminders, motivation triggers, and professional guidelines as facilitators perceived by GPs for establishing and maintaining gender sensitivity in family practice. In addition, lacking skills and routines, scepticism, heavy workload, and the timing of implementation were perceived to be barriers. Although we are now aware of the importance of these factors that facilitate or impede the maintenance of gender sensitivity in family practice, the dynamics (mutual effect) of these factors and their implications still needs clarification. 


\section{REFERENCES}

1. Keuken DG, Haafkens JA, Moerman CJ, Klazinga NS, Riet GT (2007). Attention to sex-related factors in the development of clinical practice guidelines. Journal of Women's Health 16(1):82-92.

2. Doyal L (2000). Sex, Gender and Health: debates and dilemmas. Social Science \& Medicine 51:931-939.

3. Doyal L (2001). Sex, gender, and health: the need for a new approach. British Medical Journal 323: 10611063.

4. Lagro-Janssen T (2007). Sex, Gender and Health. European Journal of Women's Studies 14(1):9-20.

5. Moerman CJ, Van Mens-Verhulst J (2004). Gender-sensitive epidemiological research: suggestions for a gender-sensitive approach towards problem definition, data collection and analysis in epidemiological research. Psychology, Health \& Medicine 9:41-52.

6. Bekker MHJ (2003). Investigating gender within health research is more than sex disaggregation of data: a Multi- Facet Gender and Health Model. Psychology, Health and Medicine 8:231-244.

7. Van Wijk CMT, van Vliet KP, Kolk AM (1996). Gender perspectives and quality of care: Towards appropriate and adequate health care for women. Social Science \& Medicine 43(5):707-720.

8. Grol R \& Grimshaw J (2003). From best evidence to best practice: effective implementation of change in patients' care. The Lancet 632:1225-1230.

9. Burgers JS, Grol R, Klazinga NS, Makela M, Zaat J (2003). Towards evidence-based clinical practice: An international survey of 18 clinical guideline programs. International Journal for Quality in Health Care 15(1):31-45.

10. Verdonk P, Benschop YWM, de Haes JCJM, Lagro-Janssen ALM (2008). From gender bias to gender awareness in medical education. Advances in Health Sciences Education 14:135-152.

11. Celik H, Klinge I, van der Weijden T, Widdershoven GAM, Lagro-Janssen ALM (2008). Gender sensitivity among general practitioners: Results of a training programme. BMC Medical Education 8(36).

12. Rogers EM (1995). Diffusion of Innovations. New York: Free Press.

13. Berwick M (2003). Dissemination innovations in Health Care. JAMA, 289(15):1969-1975.

14. Grol R, Wensing M (2006). Effectieve implementatie: een model. [Effective implementation: a model]. In: Implemenatie. Effectieve verbetering van de patiëntenzorg. [Implementation. Effective improvement of patient care]. (Eds R. Grol, M. Wensing) pp.65-92. . Maarssen: Elsevier Gezondheidszorg.

15. Hsieh HF, Shannon SE (2005). Three approaches to qualitative content analysis. Qualitative Health Research 15(9):1277-1288.

16. Grol R, Wensing M (2004). What drives change? Barriers to and incentives for achieving evidence-based practice. The Medical Journal of Australia supplement 180: S57-S60.

17. Grol R (1992). Implementing guidelines in general practice care. Quality in Health Care 1:184-191.

18. Courtenay WH (2000). Constructions of masculinity and their influence on men's well-being: a theory of gender and health. Social Science and Medicine 50(10):1385-1401.

19. Verdonk P, Benschop YWM, de Haes JCJM, Lagro-Janssen ALM (2008). Making a gender difference. Case studies of gender mainstreaming in medical education. Medical Teacher 30(7):e194-e201.

20. Sutton S (1993). The past predicts the future: Interpreting behaviour-behaviour relationships in socialpsychological models of health behaviours. In D. R. Rutter \& L. Quine (Eds), Social psychology and health: European perspectives (pp. 71-88). Aldershot: Avesbury.

21. Sheeran P, Orbell S (1999). Implementation intentions and repeated behaviour: augmenting the predictive validity of the theory of planned behaviour. European Journal of Social Psychology 29:349-369.

22. Groenewegen PP, Hutten JBF (1991). Workload and job satisfaction among general practitioners: A review of the literature. Social Science \& Medicine 32:1111-1119.

23. Lagro-Janssen T (2007). Sex, Gender and Health Developments in Research. European Journal of Women's Studies 14(1):9-20. 
24. Lagro-Janssen T (2008). De geneeskunde is niet genderneutraal: invloed van de sekse van de dokter op de medische zorg. [Medicine is not gender-neutral: influence of physician sex on medical care]. Nederlands Tijdschrift voor de Geneeskunde 152(20):1141-1145.

25. Grol R, Buchan H (2006). Clinical guidelines: what can we do to increase their use? The Medical Journal of Australia 185(6):301-302.

26. McGlynn EA, Asch SM, Adams J, Keesey J, Hicks J, DeCristofaro A, Kerr EA (2003). Clinical guidelines: what can we do to increase their use? Stratgeis to close the gap between development and implementation of guidelines. The New England Journal of Medicine 348:2635-2645.

27. Celik H, Klinge I (2005). Mainstreaming gender en diversiteit in de gezondheidszorg. Zijn we op weg naar een diversiteitsbewuste gezondheidszorg? [Mainstreaming gender and diversity. Are we moving toward a diversity competent Health Care]. Tijdschrift voor Genderstudies, 8(5):12-22. 



\title{
Chapter 6
}

\section{Process evaluation of a diversity training programme: the value of a mixed method strategy}

\author{
H. Celik \\ T.A. Abma \\ I. Klinge \\ G.A.M. Widdershoven
}




\begin{abstract}
A B S T R A C T
Patients' health and health needs are influenced by dimensions of diversity like gender, ethnic origin and socioeconomic state. This paper presents a process evaluation of a diversity sensitivity training program for healthcare professionals. The training was implemented in three healthcare practices (mental health, nursing home and hospital care). Mixed methods were used to monitor the implementation of the training and its effects after three years. Findings demonstrate that the training stimulated participants' awareness, knowledge and critical attitude towards diversity. The motivation and willingness to take action regarding diversity was also enhanced. Yet, these developments were less apparent among nursing home participants who felt less satisfied and did not develop a critical perspective on this issue. Qualitative data were helpful to explain differences between the settings. By means of the combination of quantitative and qualitative data, we can conclude that individual learning was not enough to guarantee a sensitive approach to diversity at the organizational level.
\end{abstract}




\section{INTRODUCTION}

In healthcare delivery, patients' experiences and needs are often reduced to a set of signs and symptoms within a biomedical framework. ${ }^{1}$ However, patients' symptoms are not purely biomedical., ${ }^{2,3}$ Patients' health and the way in which symptoms are presented are influenced by dimensions of diversity such as gender, ethnic origin, and socioeconomic state/class. ${ }^{4,5}$ These dimensions are shape patients' health needs. In order to account for the various dimensions that constitute the needs of an individual patient an 'intersectional' approach has been developed. ${ }^{6-10}$ While a holistic approach complements the purely biomedical model of illness with social and psychological needs, the intersectional approach goes a step further stressing the differences between individual patients by paying explicit attention to the interplay of the dimensions of gender, class and ethnicity. In this approach dimensions of diversity are not additive, but mutually constitutive.

In health care practices, however, the notion of diversity is just emerging among health professionals. ${ }^{11}$ There is, for instance, not much attention for the fact that a leg fracture is experienced differently by an athlete than by an office worker. A leg fracture will also lead to different challenges for women with caring tasks for children than for single men. Also the need for necessary medical treatment can differ among these patients. Some will prefer rest, while others, who do not have the opportunity to take sufficient rest, will choose for pain relief through medication and/or surgery, with its consequences. Diversity appropriate care is care in which professionals pay deliberate attention to the special needs of an individual patient following from the interplay between gender, class and ethnicity and other dimensions of difference.

To enhance awareness of the importance of diversity sensitivity in the provision of healthcare, health professionals should first be aware of the relation between diversity and patients' health and health demand. According to Pathman and colleagues awareness is the first criterion for change. ${ }^{12}$ To result in actions, awareness should be followed by acceptance, adoption and adherence. Therefore diversity should be in the scope of practice and an integral part of the repertoire of professionals. It is also important to attend to the professionals' enthusiasm for (or resistance to) change as well as barriers in the institutional context. ${ }^{13}$ Awareness about diversity in healthcare practices can be stimulated by providing health professionals with a diversity awareness training. ${ }^{14,15}$ Our aim in the paper is to investigate the extent to which diversity awareness training can promote diversity sensitivity among health professionals. In this article we present the results of a process evaluation conducted in three healthcare settings (mental health care, hospital care, and nursing home care) in the Netherlands. After a brief description of the intervention, we describe the process evaluation and the results. In the discussion we reflect on the limitations of our design and the limitations of the training program. Finally, the lessons learned in the evaluation of the training are discussed, followed by a conclusion. 


\section{INTERVENTION：A DIVERSITY TRAINING}

In cooperation with MOVISIE, the Dutch Centre for Social Development, a blueprint for a diversity awareness training was developed. ${ }^{16}$ The training was based on an intersectional approach to diversity (See Figure 1). This approach is characterized by a complex matrix of diversity in which different axes of differentiation and social hierarchies are combined and mutually construct each other.

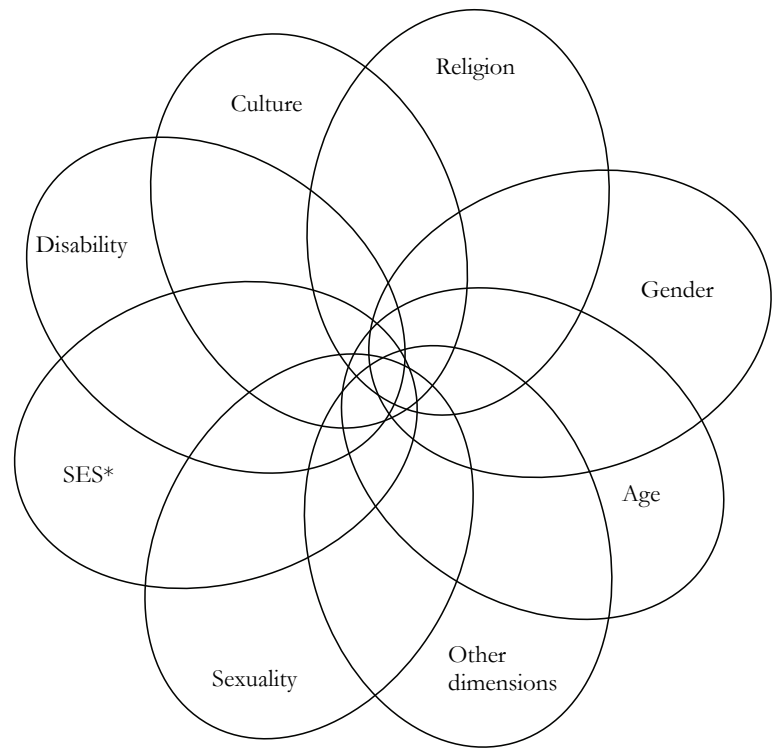

FIGURE 1 Diversity matrix

* SES means the Socio economic state/class of a patient

To fine tune the training to each of the three healthcare settings and to create favourable social conditions, informal talks with managers of the healthcare settings facilities were carried out. The resulting training program materials consisted of a manual for tutors' ${ }^{17}$ and a manual for participants' with a reader. ${ }^{18}$ The manuals consisted of four modules with relevant theoretical and practical information. The training was provided in four sessions of 4 hours by two trainees: Nico van Oosten (MOVISIE), an experienced trainer and the first author of this article.

\subsection{PARTICIPANTS OF THE TRAINING}

For the selection of the three healthcare practices (mental health, hospital, nursing home) the following criteria were used: 1) the willingness to take diversity into account (motivation); 2) a minimum of eight and a maximum of twelve participating health 
professionals; 3) no current mergers or intentions to merge the healthcare practice; 4) willingness to financially support the training (in terms of time for following the training during office hours). The training participants from the healthcare practices were selected by the programme manager of the healthcare practice. In total 31 nurses took part in the training: 8 participants from mental health practice; 12 from hospital practice; and 11 from nursing home practice. Overall one participant dropped out and four participants ( 2 of mental health care, 1 from the hospital, and 1 from the nursing home) missed 1 training module. From 2 participants we did not get complete pre and posttest data on.

\subsection{TRAINING CONTENT}

During the four training modules, participants carried out several exercises individually, in subgroups and plenary (See Table 1).

BOX 1. Example of group activity in mental health practice: 'Asking the other question'

The case of a patient using mental healthcare

P. has a history of psychiatric illness. After the death of P's partner, P. is admitted several times to a general hospital. The diagnosis is: depression with a psychotic character. P. also has a serious form of Parkinson's disease. Since 1998 P. has been living at the current address, but unfortunately it is not going well. Despite good intentions, P. disturbs the neighbours a great deal, especially due to the habit of cleaning the house in the middle of the night. Due to Parkinson's P. falls often. P. sustained a wound from a recent fall which is not healing well due to neglect.

\section{Participants responded to the following questions:}

Which dimension of diversity is dominant? Are there other important dimensions? How are these related? And are some dimensions underused? Participants' discussed whether the person in the case was male or female, whether gender mattered, how old the person was and why these things were not usually systematically accounted for in their work. 
The first module began with an exercise to introduce the concept of diversity. Participants finished the sentence: "To me, diversity means ...". The theoretical background of diversity was discussed, its dimensions and its relevance to the levels of the institution (individual, organizational) as well as the possible pitfalls of not considering diversity. ${ }^{19}$ This was followed by the method of 'Asking the other question', focussing on other than biomedical questions, in order to raise awareness of all relevant aspects of diversity (see Box 1). In the exercise 'Imagine being a patient' participants were asked to look at their organisation (interior, entrance of the building etcetera) through the eyes of patients. Additionally, participants critically reviewed a video fragment from the Dutch Heart Foundation about the impact of diversity on cardiovascular diseases.

In the second module participants brainstormed about how diverse they themselves were. They elaborated on the question: What could be better in my practice and for the patient? Furthermore implementation theories were provided and the pros and cons of changing routines and attitudes were discussed. ${ }^{20}$ In addition, the formal and informal managerial support required for an innovation was outlined. The strengths and weaknesses of a recent care innovation in the participants' ward were examined into possible opportunities and barriers for change.

The third module started with a theoretical discussion about mainstreaming gender. ${ }^{21}$ Mainstreaming, in this context, is a strategy to integrate gender related experiences, knowledge, and interests into the agenda at all levels of an healthcare institution. ${ }^{22}$ A Human Resource Department might, for example, adopt a diversity policy to work towards a more mixed composition of the staff. Strengths of the setting were articulated, such as politeness, empathy and team spirit, and their usefulness for practice improvement with regard to diversity sensitive care. Next, participants assessed the gaps (weaknesses) regarding diversity in their own setting and formulated short and long-term targets for improvement.

The third module started with a theoretical discussion about mainstreaming gender. ${ }^{21}$ Mainstreaming, in this context, is a strategy to integrate gender related experiences, knowledge, and interests into the agenda at all levels of an healthcare institution. ${ }^{22}$ A Human Resource Department might, for example, adopt a diversity policy to work towards a more mixed composition of the staff. Strengths of the setting were articulated, such as politeness, empathy and team spirit, and their usefulness for practice improvement with regard to diversity sensitive care. Next, participants assessed the gaps (weaknesses) regarding diversity in their own setting and formulated short and long-term targets for improvement.

In the last module participants evaluated policy documents, care protocols and guidelines used in their practice, by looking through 'Diversity glasses'. Participants were made conscious of the possible influence of diversity and evaluated these documents from a non-neutral perspective. Furthermore, the participants examined the pros and cons of these documents from a diversity perspective. Finally, the participants prepared a work plan for action using knowledge gained as a result of the training. 
TABLE 1 Content of the training modules

\begin{tabular}{|c|c|c|}
\hline Module & Aim & Content \\
\hline 1. General introduction & $\begin{array}{l}\text { Conceptualization of } \\
\text { diversity and achieving } \\
\text { individual engagement }\end{array}$ & $\begin{array}{l}\text { Introduction } \\
\text { Warming-up exercise: what is diversity? } \\
\text { Interactive theoretic discourse about the matrix of } \\
\text { diversity, and the levels of diversity: individual, } \\
\text { symbolic and institutional } \\
\text { Apply the 'Asking the other question' method to a } \\
\text { patient case (see Box 1) } \\
\text { Exercise 'Imagine being a patient' } \\
\text { Critically review a video consult } \\
\text { Evaluation of module } 1\end{array}$ \\
\hline $\begin{array}{l}\text { 2. Diversity and the } \\
\text { professional }\end{array}$ & $\begin{array}{l}\text { Identify the forces and } \\
\text { advantages of diversity for } \\
\text { professionals }\end{array}$ & $\begin{array}{l}\text { Association exercise: How diverse am I? } \\
\text { What could be better in my work? } \\
\text { What were the tensions for professionals in a } \\
\text { recent innovation? } \\
\text { Instructions for the assignment 'How do politics } \\
\text { work at the institutional level? } \\
\text { Evaluation of module } 2\end{array}$ \\
\hline 3. Diversity and the institution & $\begin{array}{l}\text { Knowing how to apply } \\
\text { diversity in practice. Analyz } \\
\text { ing the tensions for change. }\end{array}$ & $\begin{array}{l}\text { Interactive theoretic discussion about mainstream- } \\
\text {-ing gender } \\
\text { Short and long term aims and priorities } \\
\text { What are the strengths of this practice? } \\
\text { Exercise how to make the strengths useful for } \\
\text { implementing diversity? } \\
\text { Instructions for the assignmnt 'Diversity Glasses' } \\
\text { Evaluation of module } 3\end{array}$ \\
\hline 4. Work plan for action & $\begin{array}{l}\text { Making a work plan to } \\
\text { stimulate actions. The } \\
\text { results of module } 1 \text { to } 3 \\
\text { were used as input }\end{array}$ & $\begin{array}{l}\text { Looking through 'Diversity glasses' } \\
\text { Building a work plan for action } \\
\text { Evaluation of module } 4 \\
\text { Evaluation of training program }\end{array}$ \\
\hline
\end{tabular}

The training program was based on the Deming cycle for quality (of care) improvement. The original Deming cycle consists of four phases. ${ }^{23}$ For our purposes, we modified the cycle, expanding it from four to six phases (See Figure 2). The first extra phase is the no attention phase: there is no attention for diversity, either because health professionals do not recognize diversity factors or because they think these issues are irrelevant for their practice. The second extra phase is the (some) attention phase: participants have (some) awareness of diversity, however they do not put it into practice. These two phases were followed by the well-known phases of planning, doing, studying and acting. Planning is the intention to pay attention to diversity in practice, doing is the application of knowledge into practice, studying is systematically evaluating the results, and acting is making desired modifications, accordingly. 


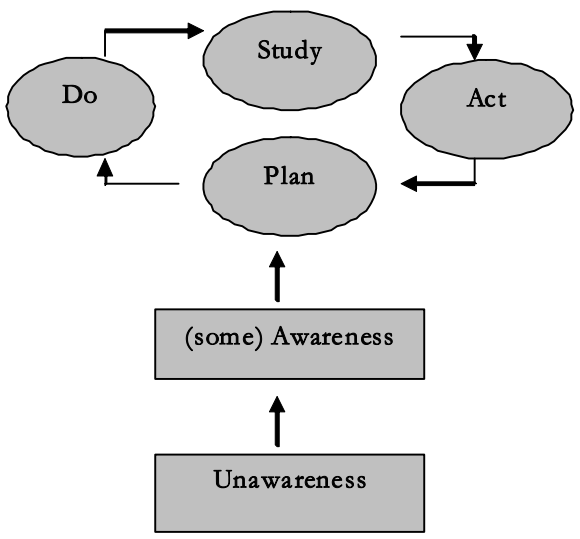

FIGURE 2 Modified Deming cycle

\section{EVALUATION DESIGN AND INSTRUMENTS}

This study can be seen as a process evaluation to monitor the implementation process of the diversity training. Process evaluation can be both formative and summative. ${ }^{24}$ This study had a summative goal aimed at evaluating whether our diversity training raised awareness and whether the training was implemented as planned. Our research design combined qualitative and quantitative methods. Greene and colleagues argue that mixed method approaches are more comprehensive, as they include different aspects and perspectives, and therefore yield results which provide more insight and deeper understandings of an issue..$^{25}$ A combination of various methods was used to monitor the implementation process of the training as well as to determine the extent to which the goals of the training had been realized (enhanced awareness, knowledge, motivation and willingness to take action in a diversity sensitive manner in the long and short run, see Table 1). Quantitative methods included a survey of participants' diversity awareness and self-reported knowledge (pre and post) and an assessment of the participants' satisfaction with a questionnaire. Qualitative methods included participant observations of all training sessions, oral group evaluations with participants during the training and semi-structured interviews with participants as well as managers. Details will be explained below. 


\subsection{QUANTITATIVE METHODS AND INSTRUMENTS}

The training was assessed through a survey for diversity awareness (See Table 2A). A quantitative pretest-posttest design with closed questions was used to evaluate the effects of the training on participants' diversity awareness and knowledge. We expected that the interpretation of these quantitative results would be difficult, since outcomes might be the result of combined effects of factors that are not directly related to the training such as shortage of staff, work pressure, changes in the patient population and organizational dynamics. With this in mind, the data were combined with qualitative results in order to elaborate on, enhance or illustrate the quantitative results. ${ }^{26}$

TABLE 2A Quantitative instruments

\begin{tabular}{|c|c|c|c|}
\hline Instrument & What & Content & When \\
\hline \multirow[t]{6}{*}{$\begin{array}{l}\text { Survey for diver- } \\
\text { sity awareness } \\
(\mathrm{N}=31)\end{array}$} & $\begin{array}{l}\text { General questions } \\
\text { regarding demo- } \\
\text { graphic data }\end{array}$ & $\begin{array}{l}\text { NameSex } \\
\text { Educational background } \\
\text { Job function }\end{array}$ & $\begin{array}{l}\text { Before and } \\
\text { after training } \\
\text { program }\end{array}$ \\
\hline & $\begin{array}{l}\text { Diversity sensitive } \\
\text { statements }\end{array}$ & $\begin{array}{l}\text { 1. In general, if attention is paid to gender, health } \\
\text { supply will be better accommodated to specific } \\
\text { health problems; } 2 \text {. Striving for (cultural) diversity } \\
\text { among employees has a surplus value when the } \\
\text { patient population is diverse as well; } 3 \text {. It is not } \\
\text { relevant to consider diversity issues in pol- } \\
\text { icy(documents); } 4 \text {. To appoint a diversity expert as } \\
\text { staff member or coordinator is superfluous; etc. }\end{array}$ & $\begin{array}{l}\text { Before and } \\
\text { after training } \\
\text { program }\end{array}$ \\
\hline & $\begin{array}{l}\text { Participant opinion } \\
\text { about diversity in } \\
\text { their healthcare } \\
\text { practice }\end{array}$ & $\begin{array}{l}\text { Deming PDCA cycle; Possible answers: 'could be } \\
\text { much better', 'could be better', 'good', or 'excel- } \\
\text { lent'. }\end{array}$ & $\begin{array}{l}\text { Before and } \\
\text { after training } \\
\text { program }\end{array}$ \\
\hline & $\begin{array}{l}\text { Self assessment of } \\
\text { the knowledge }\end{array}$ & $\begin{array}{l}\text { Determine/assess your knowledge before and after } \\
\text { the training (on a 1-10 scale). }\end{array}$ & $\begin{array}{l}\text { After the } \\
\text { programme }\end{array}$ \\
\hline & $\begin{array}{l}\text { Participants self } \\
\text { reported attitude } \\
\text { for diversity }\end{array}$ & Deming PDCA cycle & $\begin{array}{l}\text { Before and } \\
\text { after training } \\
\text { program }\end{array}$ \\
\hline & $\begin{array}{l}\text { Participants read } \\
\text { the literature in the } \\
\text { reader? }\end{array}$ & Read the literature in reader: YES/NO & $\begin{array}{l}\text { After the } \\
\text { programme }\end{array}$ \\
\hline $\begin{array}{l}\text { Questionnaire for } \\
\text { Satisfaction } \\
(\mathrm{N}=31)\end{array}$ & $\begin{array}{l}\text { Program Satisfac- } \\
\text { tion }\end{array}$ & $\begin{array}{l}\text { Were participants' course objectives met? Were } \\
\text { individual lectures and workshops presented effec- } \\
\text { tively? Did the training provide new insights? Did } \\
\text { the training provide practical and applicable knowl- } \\
\text { edge? Were methods of the training adequate? }\end{array}$ & $\begin{array}{l}\text { After the } \\
\text { training }\end{array}$ \\
\hline
\end{tabular}


The satisfaction of the participants was assessed by a questionnaire filled out at the conclusion of the training. The participants were asked to evaluate the training by giving grades from 1 to 10 and to provide an explanation for the grade in terms of the extent to which the program fulfilled their expectations and whether their course objectives were met. Furthermore, the participants were asked to indicate whether the program content was presented effectively and whether the training provided new insights. They also evaluated the practical applicability of their knowledge and the training method. Finally we measured to what extend the participants read the reader with study material.

\subsection{QUALITATIVE METHODS AND INSTRUMENTS}

Nine semi-structured interviews (three in each setting) were held before the training to gain an understanding of the participants' expectations from the training and to get an idea of their prior experiences (See Table 2B). The topic list for these interviews with nurses and (nurse) managers were developed on the basis of existing literature on diversity and the implementation of innovations in healthcare from recent research. ${ }^{27}$ Topics included respondents' characterizations of their institutions and treatment plans; behaviours and decisions of respondents regarding diversity; factors that enable or obstruct attention paid to diversity and diversity orientation. We asked the program coordinator to select a variety of respondents to gain a broad range of experiences and meanings. The interviews, which lasted between 40 and 60 minutes, were tape-recorded and transcribed verbatim. Field notes were taken of contextual information, impressions during interviews and from the informal talks after the interviews. ${ }^{28}$

Participant observations were made during 12 sessions of the training program and during informal conversations with participants and managers after the sessions. During all modules observation notes were recorded by one of the trainers, designated as the observer, while the other was teaching the module. The roles of the trainers (observer and moderator) alternated for practical reasons. Notes of the informal conversations were made in retrospect by the first author. The notes included interpretative comments on the intentions or attitudes which might underlie the various observed behaviours. There are two major limitations to making observational notes. First, two observers will (selectivity) see, hear and record different things. This weakness was limited by the trainer and the observer spending time discussing the notes with each other. The second drawback to this method is if an observer has prior information, observer bias can occur. This potential bias can be detected when two persons record what happened. In our case, a discussion between the trainer as moderator and observer helped to illuminate differences in the observation of a session. For the most part, the observations were complementary. The advantage of making observational notes was that we also gained extra information from observing the unobtrusive actions 
and interventions, which are signs that indicate a kind of behaviour (pattern), while it was not explicitly meant to do so. ${ }^{29}$

At the end of the session every module was orally evaluated by a discussion about the value of the module as perceived by the participants and its impact on them in terms of what they have learned. At the end of Module 1 we asked participants to imagine that they would encounter a colleague later that day, who had not participated in the training. The colleague is in a hurry, but asks your opinion about the training. What would you say (in short) to this colleague? After module 2 participants gave a score to the session using a standard 0-100 'thermometer' scale, after which we discussed participants' experiences and feelings. Module 3 was evaluated by an open discussion started by asking the participants: How do you feel about this session? Directly after completing the whole programme, an open group discussion was held in order to evaluate the training. The discussion started with the following question: To what extent do you feel that the objectives of this training have been fulfilled? We ended this group discussion with the following question: Do you have suggestions for improving the training for future purposes? Notes were taken of all oral evaluations by both the trainer and observer, and discussed afterwards.

To gain insight into the long-term results we assessed the experiences three years after the last session, by means of three interviews with the same program managers/coordinators of the healthcare practices. These open interviews were guided by the following topics: interpretation of the quantitative results of the training; long term experiences and initiatives; suggestions for improving future training for maximal effect. These interviews were tape-recorded and completely transcribed.

TABLE 2B Qualitative instruments

\begin{tabular}{|c|c|c|c|}
\hline Instrument & What & Content & When \\
\hline $\begin{array}{l}\text { Interviews } \\
\mathrm{N}=9\end{array}$ & $\begin{array}{l}\text { Semi-structured } \\
\text { interviews with } \\
\text { nurses and (nurse) } \\
\text { managers }\end{array}$ & $\begin{array}{l}\text { Interview topics: How respondents characterize } \\
\text { their institutions and their treatment plans; behav- } \\
\text { iours and decisions; diversity orientation }\end{array}$ & $\begin{array}{l}\text { Before the } \\
\text { training }\end{array}$ \\
\hline $\begin{array}{l}\text { Participative } \\
\text { observation } \\
\mathrm{N}=12(3 * 4)\end{array}$ & $\begin{array}{l}\text { Observation } \\
\text { participants during } \\
\text { training }\end{array}$ & Direct observation & $\begin{array}{l}\text { During all } 12 \\
\text { sessions of } \\
\text { the training }\end{array}$ \\
\hline $\begin{array}{l}\text { Oral (Process) } \\
\text { Evaluation } \\
\mathrm{N}=12\left(3^{*} 4\right)\end{array}$ & $\begin{array}{l}\text { Module } 1 \text { to } 4 \text { and } \\
\text { groups discussion } \\
\text { of the training }\end{array}$ & $\begin{array}{l}\text { Strengths and limitations of the modules and the } \\
\text { training and what could be better. }\end{array}$ & $\begin{array}{l}\text { After every } \\
\text { module }\end{array}$ \\
\hline $\begin{array}{l}\text { Follow-up } \\
\text { interviews } \\
\mathrm{N}=3\end{array}$ & $\begin{array}{l}\text { Open interviews } \\
\text { with program } \\
\text { coordinators }\end{array}$ & $\begin{array}{l}\text { Interview topics: interpretation of the quantitative } \\
\text { results of the training, long term experiences and } \\
\text { initiatives, suggestions for improving the training } \\
\text { and its effects for future purposes. }\end{array}$ & $\begin{array}{l}3 \text { years after } \\
\text { the training }\end{array}$ \\
\hline
\end{tabular}




\subsection{ANALYSis AND integRATION OF DATA}

Statistical comparisons of the changes in the self-reported awareness and knowledge of diversity as measured by the survey were made using the Wilcoxon signed rank test for 2 related non-parametric samples. The change has been reported as significant if $\mathrm{p}<0.05$. The statements component of the survey was rated with 'strong agreement', agreement', 'disagreement' or 'strong disagreement'. For each question the answer representing the highest awareness was coded with 4 and the answer representing the lowest awareness with 1. Participants' opinion regarding diversity dimensions was coded with 'could be much better'; 'could be better'; 'good'; and 'excellent'. The statements with a pre-post comparison were analysed using a t-test for paired samples. The change was found to be significant if $\mathrm{p}<0.05$. All statistical data were processed using SPSS. The pre and post-test of the participants and the degree of satisfaction with the diversity training were scored by giving grades from minimum 1 to maximum 10 to the evaluation questions. Average scores were compared.

The analysis of the qualitative interviews was done by the first author, and the second author gave feedback on the analyses in terms of questions regarding the credibility/robustness of the categories/themes and the link between the raw data and the interpretations. After reading the field notes, to get a general impression of the data, the interview contents were characterised and classified. The preordained topics served as a framework for the content analysis. ${ }^{30}$ After analysing seven interviews, conceptual saturation occurred. The remaining interviews and field notes were used to confirm the analyses and concept definitions.

The qualitative and quantitative data analyses were not just complementary. Greene's mixed method approach goes beyond accumulation of the different facets or dimensions of the same complex phenomenon. ${ }^{31}$ We were gathering data from a multiplicity of sources (triangulation) and integrated these to illuminate the complexity of the diversity training and to get a more insightful and comprehensive 'picture' of the phenomenon under study. We performed 'crossover track' analysis, ${ }^{32}$ which means that the results from one method are clustered, summarized, or transformed and integrated with the other method.

\section{RESULTS}

The modules were provided as planned in the mental health institution and hospital. In the nursing home didactic adjustments were needed, because these participants had difficulty with the diversity concept, the training program content and the academic language used by the trainers. In all settings the background of participating health professionals and managers varied. However, the educational level of the nursing home participants was lower (intermediate vocational education) than that of the other mental 
health and hospital practice participants (academic and higher vocational education). In this section the findings will be presented. The structure of this section is based on the main themes relating to the improvement of diversity sensitivity among professionals in the three settings.

\subsection{AWARENESS AND KNOWLEDGE}

Awareness and knowledge are required to recognize the relevance of diversity for one's practice and to develop plans for implementing diversity sensitive care. Diversity awareness was assessed by a survey before (baseline) and after the training (outcome). Awareness improved significantly for the mental health $(\mathrm{p}=.026)$ and for the hospital $(\mathrm{p}<0.005)$, which suggests that the training was effective for this outcome. In the nursing home practice there were no significant changes $(\mathrm{p}=.749)$. Self reported knowledge concerning diversity also increased as a result of the training. Participants from the mental health institution rated their own knowledge on average as 6.3 (SD: 1.71) on a scale of 1 to 10 before the training and on average as 8.1 (SD: .86) after the training (See Table 3). The reported knowledge of the participants at the hospital showed an even greater increase from 4.1 (SD: 1.30) to 7.4 (SD: .70). The increase in self reported knowledge was the lowest among nursing home participants: from average 5.9 (.99) to 7.3 (.67), in relative terms.

TABLE 3 Self reported knowledge of the participants $(\mathrm{N}=31)$ graded on a scale of 1 to 10 before (pre) and after (post) the training.

\begin{tabular}{|c|c|c|c|c|c|}
\hline \multicolumn{2}{|c|}{$\begin{array}{l}\text { Mental Health practice } \\
N=8\end{array}$} & \multicolumn{2}{|c|}{$\begin{array}{l}\text { Hospital practice } \\
\mathrm{N}=12\end{array}$} & \multicolumn{2}{|c|}{$\begin{array}{l}\text { Nursing Home practice } \\
N=11\end{array}$} \\
\hline Pre & Post & Pre & Post & Pre & Post \\
\hline Mean (SD) & Mean (SD) & Mean (SD) & Mean (SD) & Mean (SD) & Mean (SD) \\
\hline $6.3(1.71)$ & $8.1(.86)^{*}$ & $4.1(1.30)$ & $7.4(.70)^{*}$ & $5.9(.99)$ & $7.3(.67)^{*}$ \\
\hline
\end{tabular}

*Knowledge improved after the program

We provided all participants with a document containing general information on diversity as well as specific diversity literature related to their field. This reader was read by $63 \%, 58 \%$ and $36 \%$ of the participants in the mental health practice, hospital practice and nursing home practice, respectively.

Mental health participants were already familiar with the notion of diversity before the training. The highest self reported knowledge at baseline was (see Table 3) for mental health practitioners (6.3 versus 4.1 among hospital and 5.9 among nursing home participants) and can be understood in the light of the gender specific educational programs implemented in this sector some time before our diversity training. Although participants stated that some exercises were too simple given their foreknowledge, they 
reported that the training helped them to further acquire know-how regarding diversity; they began to see that gender was only one dimension of diversity, and that various dimensions of diversity (age, ethic background and SES) interrelate. As one of the participants aptly notices:

The client does not exist and is more than a diagnosis. (Mental Health, Participants)

Participants mentioned that they became more critical about a neutral approach to diversity; and that they felt empowered to question organizational routines, as a result of the training. In addition, they started to realize that diversity sensitivity should be part of the whole organization (mainstreaming) and not just a dimension of the professional-client interaction.

I have learned that I need to continue to ask questions, at all organizational levels, about what is obvious. (Mental Health, Evaluation).

The baseline situation at the hospital was quite different. Participants reported that they had no background knowledge (self reported knowledge score at baseline: 4.1) and mentioned that diversity was not considered to be relevant for care giving before the training. The following reflects this:

No, everyone gets the same treatment. I do not anything with it. The care given when someone walks in is not dependent on diversity characteristics. (Hospital, Interview, nurse HT)

The self reported diversity knowledge and awareness score indicates that participants acknowledged the limits of their expertise. They thought they could learn something and felt motivated to follow the training program. During the training participants reported that they started to realize that diversity was important in their work. They began to perceive patients differently and to recognize various diversity dimensions and their interrelatedness. It also became clear to them that every patient is unique and has a specific health demand.

You have differences between a man and a woman, but also among men you have many different men. What is important is to get an eye for these differences. We work with people. You can standardize work processes, but not their application to the patient. (Hospital, Follow-up, FE)

The survey data suggest that the training in the hospital was effective, and the most effective of the three settings in increasing the level of awareness and knowledge among participants (see Table 3). This knowledge and awareness was also sustained over a longer period, as will be pointed out later.

Nursing home participants also reported increasing their awareness and knowledge concerning diversity, but to a lesser extent compared to the other settings. This modest outcome is underscored by the qualitative data. We observed that during the last module a Babel-like 'confusion of tongues' occurred. Participants complained about the complexity of the concept and felt that they were back to where they started. The con- 
fusion, they said, was the result of the fast pace and the high academic level of the training. The training could be improved, from their perspective, by tailoring it to the cognitive level of the participants. They also suggested giving the participants more time to assimilate the material.

To improve the training we need more leeway to understand the concept of diversity and to make it less difficult (Nursing bome practice, Participants, Process Evaluation)

The responses from nursing home participants generally indicated that they did not feel the training process was completed successfully since the participants had just started to understand the complexity of the notion of diversity.

\subsection{CRITICAL ATTITUDE}

In this context, critical attitude is attained once health professionals have the ability to see the blind spots of a neutral approach to diversity. They will also be less likely to be neutral themselves and conscious of the possible influence of diversity in health care delivery. The initial opinion of the participants in all practices was that the attention paid to diversity issues was good. After the training the opinion(s) about diversity among mental health and hospital participants was that it could be better (see Table 4). The participants indicate that more attention to this concept is desirable. The obtained qualitative data indicate that mental health and hospital participants did become more aware of the shortcomings of their standard, neutral approach. Mental health participants mentioned, for example, that the provision of their care is not adequately adapted to a culturally diverse population.

In the future, it is expected that the target group will change, particularly in that there will be more non-native Dutch patients. Changes made within the institution should take this target group into account. (Mental Health, Participants, Imagine being a patient)

TABLE 4 Opinion participants $(\mathrm{N}=31)$ regarding the attention for diversity before and after the training

\begin{tabular}{|c|c|c|c|c|c|}
\hline \multicolumn{2}{|c|}{$\begin{array}{l}\text { Mental Health practice } \\
\mathrm{N}=8\end{array}$} & \multicolumn{2}{|c|}{$\begin{array}{l}\text { Hospital practice } \\
\mathrm{N}=12\end{array}$} & \multicolumn{2}{|c|}{ Nursing Home practice } \\
\hline Pre & Post & Pre & Post & Pre & Post \\
\hline Good & Could be better & Good & Could be better & Good & Good \\
\hline
\end{tabular}

In the mental health setting this critical attitude towards diversity is still present several years after the training according to the study follow-up. Program coordinators promoting diversity sensitivity point out how difficult it is to implement the complex notion of diversity, but they do not give up.

The difficulty (...) is that, on the one hand, gender issues are already accepted by some who take these issues into account and apply them without being noticed and, on the other hand, (...) others 
are much less focused on gender and, therefore, it is much less in their mind and approach. And if you add diversity factors to this it only becomes more complex. (Mental Health, Follow-up, CA 37)

Hospital participants also became more critical during the training. They mentioned, for instance, that older patients might feel disoriented or on unfamiliar ground due to the poor signs (small lettering, not clearly placed, and not well recognizable) in the organization.

The clinic is not in the clinic building and the signs are bad or a bindrance. The signs should be more visible, clear and recognizable. (Hospital, participants, 'Asking the other question')

The follow-up interview with the hospital program coordinator reveals that there still is a sense of urgency to improve the quality of care. She critically reflects on the actual situation, as the next quote illustrates:

The stance is: the doctor knows what is good for the patient. (...). One looks in a particular way at the patient. (...) Do you see the wound or the patient? (...) The point is that we need to recognize that things are different. (Hospital, Follow-up, FE)

While mental health and hospital participants see ways to further improve the quality of care taking into account diversity ('could be better'), the nursing home participants appeared to remain constant in their opinion that enough attention is paid to diversity in their setting ('good'). There is less development in their attitude as compared to other participants. This can be explained by an examination of the qualitative data. The nursing home participants reported that they already take diversity into account, though their view on diversity is somewhat simplistic.

With regard to sex, we maintain a segregated policy for male and female residents (...). Once in a while it happens that a room is mixed, but that is really sporadic. We try as much as possible to take different customs into consideration from people from different ethnic origins. With regard to age, we specialize in the elderly. With regard to handicapped residents, we stimulate them to their potential. (...) With regard to socioeconomic status, we adjust our communication to the appropriate level. (Nursing home, Interview, CdO, 107)

The development of a critical attitude among mental health and hospital participants is fostered by an enhanced awareness and knowledge in these settings; if one understands what diversity means and why it is important, then it is easier to be critical of one's practice. The development of a critical outlook was not found among nursing home participants. 


\subsection{WILLINGNESS TO TAKE ACTIONS}

Willingness means a readiness among professionals to take actions to promote diversity sensitive care giving. The pre (before) and post (after) training results of the participants' attitude towards diversity are shown in Table 5. The classifications are based on the Deming cycle (see Figure 2).

TABLE 5 Participants attitude $(\mathrm{N}=31)$ in Deming's cycle (no/some attention-plan-do-study-act.) for diversity before (pre) and after (post) the training

\begin{tabular}{|c|c|c|c|c|c|}
\hline \multicolumn{2}{|c|}{$\begin{array}{l}\text { Mental Health } \\
\mathrm{N}=8\end{array}$} & \multicolumn{2}{|l|}{$\begin{array}{l}\text { Hospital } \\
\mathrm{N}=12\end{array}$} & \multicolumn{2}{|c|}{ Nursing Home } \\
\hline Pre & Post & Pre & Post & Pre & Post \\
\hline Plan & Do* & Not aware & Plan* & Do & Do \\
\hline
\end{tabular}

*attitude improved after the training

We found that mental health participants developed a willingness to put diversity into practice. At baseline, participants indicated that they were motivated to pay attention to diversity characteristics in practice. They were in the plan-phase of the Deming cycle. After the training, the participants reported in the interviews that they started with putting their intentions into practice. On the basis of these data we decided the participants progressed to Deming's do-phase. Such a development can also be seen among hospital participants, who progressed from the 'not aware' to the 'plan' phase. Nursing home participants did not report a change in their willingness to take actions; they remained in the 'do' phase, with no significant change in their care giving. This score was 'higher' on the Deming cycle, and therefore seemed to be better than that of the other two. However, this was not the case, since the qualitative data indicated that a motivation for change was lacking.

During the training the mental health participants started to develop a working plan, and intended to establish a diversity study group at their institution. This group planned to make a thorough inventory of whether the treatments took the concepts of diversity into consideration. It turned out that the study group was established, but disbanded after a year. One of the reasons was that the study team was not fully integrated into the management team which weakens the link to potential policy changes. The person who embraced diversity left and the new manager did not have the willingness to invest in the diversity team.

The project Group which we had was discontinued (...) stopped also because it was not sufficiently imbedded in the management of the organization. It is disconcerting that in an organization where there are three signatures from a management level supporting this group, that one person can stop it after a change of just one staff member. (Mental Health, Follow-up, CA 104) 
Despite this setback, since the team had the willingness to carry on with the integration of diversity in the institution, they made new plans. The team currently organizes an annual symposium on gender and also presents an annual gender award to the health professional with special competencies for addressing gender issues in healthcare delivery. Additionally, they intended to make diversity part of the core values of their institution. Recently, their Board of Directors was contacted and it reacted positively to the group's plans to integrate diversity at all levels.

In the hospital practice, participants were in the no awareness phase at baseline. After the training, the participants had progressed to the plan phase. During the training, participants made an inventory of their own information material for patients. They found that the current information for patients was not up to standard when evaluated according to diversity sensitivity criteria, such as that the information should be assessable and understandable for each and every patient. The information was not attuned to the elderly and certainly not to non-Dutch speaking patients, for example.

After a cursory inventory of our patient information pamphlets it became clear that we did not have information, of any kind, available in any language other than Dutch. This was also the case for supplementary audio-visual materials. Illiterate and non- (or poor) Dutch speakers/ readers lack this sort of information. (Hospital, Participants 'Building a work plan')

After the last session of the training, several encouraging initiatives in the hospital practice were taken such as mentioning the subject in annual reports and organizing training programs. These initiatives helped to trigger professionals continuously to consider diversity in practice and to see the rewards for patients and professionals.

A lot has happened since you left (...). We continued with the thought that the quality of care will be good if the quality of the approach is good. (...) You see the patient and the differences between patients, attributed to cultural background. For that reason, we have organized work conferences for nearly 700 co-workers. (Hospital, Follow-up, FE)

These initiatives are grounded in a vision of quality care that finds support among managers at the top-level, as indicated in the follow-up interview.

The participants in the nursing home practice remain in the do phase. This corresponds with the other qualitative information. There has almost been no progression in their thinking. Although participants said they understood the notion of diversity, they later experienced difficulties in designing a work plan for action.

During the previous module we understood the concept of diversity, but now we feel we are back where we started. It is very complex. (Nursing home, participants, Module 4 'Building a work plan for action')

The follow-up indicates that the readiness to take action is not only hindered by lack of know how, but is also impeded by organizational constraints, such as restricted time due to the heavy workload, bureaucracy, structural shortage of personnel and lack of 
support. If caregivers, with a low degree of training, feel they cannot even give the basic care to the residents and clients, it seems impractical expect them to implement diversity sensitive care.

\subsection{SATISFACTION}

When assessing participants' satisfaction at the end of the training we found that participants were positive about the training (see Table 6). The level of satisfaction among nursing home participants was; however, significantly lower than that among those in the mental health and hospital practice.

TABLE 6 Program satisfaction of participants' $(\mathrm{N}=31)$

\begin{tabular}{|c|c|c|c|}
\hline & $\begin{array}{l}\text { Mental health } \\
\text { Mean (sd) } \\
\mathrm{N}=8\end{array}$ & $\begin{array}{l}\text { Hospital } \\
\text { Mean (sd) } \\
\mathrm{N}=12\end{array}$ & $\begin{array}{l}\text { Nursing Home } \\
\text { Mean (sd) } \\
\mathrm{N}=11\end{array}$ \\
\hline Were participants' course objectives met? & $7.0(1.5)$ & $7.6(0.8)$ & $5.9(0.6)$ \\
\hline $\begin{array}{l}\text { Were individual lectures and workshops } \\
\text { presented effectively? }\end{array}$ & $7.3(1.6)$ & $7.8(0.7)$ & $6,1(1.0)$ \\
\hline Did the training provide new insights? & $7.7(1.8)$ & $8.3(0.8)$ & $6.5(1.1)$ \\
\hline $\begin{array}{l}\text { Did the training provide practical and } \\
\text { applicable knowledge? }\end{array}$ & $7.6(1.5)$ & $7.1(0.8)$ & $6.2(1.2)$ \\
\hline Were methods of the training adequate? & $7.6(1.2)$ & $8.0(0.5)$ & $6.3(0.9)$ \\
\hline
\end{tabular}

Some mental health participants said that their appreciation of the training was positively influenced by their previous knowledge about gender sensitivity in care giving. Others said that the training had an additional value, as diversity encompasses more than just gender.

I was already inspired by an earlier course on sex-specific care giving. (...) I am especially satisfied due to the primacy of diversity over its dimensions such as gender. (Mental Health, Participants, Evaluation)

Hospital participants reported that they felt inspired by the training, as it was connected to social questions.

The gathering was interesting and inspiring. The subject is connected to social issues. (Hospital, Participants, Evaluation)

The nursing home participants were less positive; they had difficulty with the intensive training and grasping the concept of diversity given their educational level and limited previous training. 


\section{DISCUSSION}

The objective of the present study was to investigate the extent to which a diversity training program can enhance the sensitivity for diversity among health professionals. Our study indicates that the interface between gender, age, culture, social economic state, disability and other concepts is difficult to grasp for individual health professionals. Perhaps the intersectionist model as visualized in Figure 1 is too complicated. This was especially clear in the nursing home practice where the participants were less educated. Most likely, the training and the literature provided were too difficult for them. This is indicative of a 'program failure' which means, ${ }^{24}$ in this instance, that the training did not activate the causal process (more awareness and knowledge) that would potentially culminate in the intended goals (readiness for action). In the case of the nursing home practice the training was not fully appropriate and, therefore, relatively ineffective. The responses of the nursing home participants therefore require us to rethink the training for those with lower educational levels. However, the basic underlying assumption, that training is an appropriate tool to affect positive change toward diversity sensitive health care, remains tenable.

In line with this observation is the suggestion that diversity training for individual professionals is a prerequisite, but not enough to ensure action being taken for diversity sensitive care giving at the organizational level. Despite the participants' increased insight into diversity, there were still many constraints on implementing the diversity concept. This was not due to a lack of enthusiasm at the individual level. Participants were motivated and had a particular interest in new ideas. According to Rogers, this is a prerequisite for innovations. ${ }^{33}$ Participants also felt a 'sense of urgency' to change their practice, which in the literature are also seen as an element necessary for organizational transformations. ${ }^{13}$ Yet, their sense of urgency was not automatically shared with other stakeholders in the organization. As a result, diversity remained the sole responsibility of a small group of well-trained health professionals, and was not embraced by the other health disciplines and managers. In order to bring about institutional changes an adjusted policy is required which takes into account the need for mainstreaming diversity at all organizational levels and among all stakeholders (compare: Grol \& Grimshaw and Yano). 34,35

Critics may question the status of the self-reported knowledge on which this study is based. From a post-positivistic paradigm self-reported knowledge is indeed subjective and biased. Working from an interpretive or constructivist paradigm, this kind of knowledge is not necessarily negative. It provides an understanding (versus explanation) of the insiders' perspective on what they have learned about diversity in the training. In combination with the qualitative data from the interviews this helps to gain an insight in the experiences of the participants and the meaning and value they endow to these experiences. The data, for instance, helped to illuminate how participants wrestle with the diversity concept and the application of diversity in practice. 
Another related question concerns the reliability and the internal validity of the study, since the evaluator herself is the most important instrument in the study. Within the interpretive paradigm trustworthiness criteria and procedures have been developed to assess the quality/goodness of the interpretations. ${ }^{36}$ Credibility refers to the degree by which participants in the evaluation can identify themselves with the analysis and interpretations. In our study we checked the credibility frequently using the 'member check' procedure: respondents were asked whether they recognized the analyses of the interviews. In the follow-up interviews after three years we deliberately checked whether the coordinators of the training program on diversity could approve our analysis of the settings. Furthermore, the combination of methods (triangulation) helped to sort out various dimensions and perspectives on the effects and implementation of the training. Since the evaluator was engaged in all the four training modules with the three groups of participants for a longer period of time and visited the sites after three years it was possible to monitor the development of the participants (procedures of prolonged engagement and persistent observation). During the study the evaluator (first author) gained systematic feedback from her external supervisors (co-authors), who acted as peer-debriefers.

The external validity of the study can be questioned since the selection of the settings was based on pragmatic grounds. Generalization beyond these settings to the broader health care practice is problematic for that reasons. Yet, from an interpretive paradigm knowledge is always context-bound. A convenience sample is less troublesome, and requires a detailed description of the studied settings in order to allow readers (versus the evaluator) to transfer knowledge from the studied to their own context. This is called a naturalistic generalization. ${ }^{37}$

\section{LESSONS}

The design of this study was given in by practical considerations. We were happy to find three settings willing to join our diversity training program, and chose not to have any type of comparison group and to use a convenience sample. Since we could not find validated instruments to measure diversity sensitivity, we developed our own instruments in combination with the semi-structured interviews. When designing the evaluation we did, however, not deliberately intend to conduct a process evaluation. It was more a coincidence that the evaluators were also engaged in the provision of the training, which enabled them to monitor the process from beginning to end. Initially the participant observations were not even labeled as data (but reduced to personal observations). Only later on in the study, we began to acknowledge and more systematically record the observations during the training. The field notes could have been carried out more systematically if we had formulated clear defined questions in advance. Another lesson concerns the follow-up interviews after three years. These were initially 
not planned. Yet, when we analyzed all the data, we felt the need to check our overall interpretations. Furthermore, we were dissatisfied with the short turn outcomes of the training. The follow-up interviews provided a lot of information and were efficient.

Another lesson concerns the combination of quantitative and qualitative data. The large set of methods and instruments, provided various sorts of data which quite surprisingly resulted in complementary and more comprehensive results. Many quantitative outcomes could be better understood and explained with the help of the qualitative data. Quantitative data helped to visualize trends which were not so obvious from the qualitative data, for instance, that the training was not beneficial for nursing home participants' progress. Quantitative data further articulated the differences between the settings. What the evaluators had sensed, but had ignored initially as being a personal observation, became much clearer. We found also differences between sorts of data, for example, that mental health participants were quite satisfied. The qualitative data suggested, however, that the training was sometimes too easy given the previous knowledge among participants in mental health care. It is, thus, the combination of qualitative and quantitative data (and not just the accumulation) that has shed more light on this issue. Yet, we also feel that there is a trade off between breath and depth when combining various sorts of methods. Our qualitative methods were quite crude and did not reach the depth of understanding that is realized when one only uses qualitative methods, like a Grounded Theory approach. This isn't necessarily problematic, but should be deliberately considered when choosing for a mixed methods strategy.

In retrospect we are quite dissatisfied with the results among participants within the nursing home. It seems quite obvious that the training was too academic for them, and that the organizational circumstances were limiting. A formative process evaluation would have been more appropriate to support the desired improvement of this practice; data from the evaluation could then have been used to adjust the training program to the organizational constraints and the educational needs of these participants.

\section{CONCLUSION}

A summative process evaluation of a diversity training in three health care settings demonstrated that such a program can increase the awareness, critical attitude, knowledge and willingness to take action among participants. Yet, the degree of improved understanding among participants varies across the settings. The training had a greater impact on the participants from the mental health institution and hospital compared to those from the nursing home. Qualitative data related to the complexity of the diversity concept, the cognitive level of the training, pre-understandings of participants and organizational constraints (case load; work pressure) were all helpful in explaining the quantitative differences found between the three settings in this study. 
The responses of the nursing home practice urge us to rethink the training for those with lower educational level in a constraining organizational context. The responsibility for the implementation of a complex concept like diversity can and should not be placed upon the shoulders of those with the lowest degree of education. Diversity sensitive care is first of all the responsibility of highly qualified professionals, including management and staff. They can act as role models and support others to practice diversity sensitive care.

We recommend further research on this subject to gain more insight into the effects of promoting diversity sensitivity in the multi-level and multi-actor context of healthcare practices. These studies should take a few additional outcomes into account, such as the adoption of the diversity concept and behavioral change. There is also a need to foster inter-organizational learning. Learning networks of participants from various organizations working on one highly complicated issue are particularly helpful to jointly discuss problems, to question routines, to pass on creative solutions and to find inspiration and energy for long-term changes in the direction of diversity sensitive care. 


\section{REFERENCES}

1. Mead N, Bower P (2000). Patient centeredness: a conceptual framework and review of the empirical literature. Social Science \& Medicine 51:1087-1110.

2. Hoffman E (2000). Women's health and complexity science. Academic Medicine, 75(11):1102-1106.

3. Bird CE, Rieker PP (1999). Gender matters: an integrated model for understanding men's and women's health. Social Science \& Medicine 48(6):745-755.

4. Street RL (2002). Gender differences in health care provider-patient communication: are they due to style, stereotypes, or accommodation? Patient Education \& Counseling 48:201-206.

5. Crenshaw KW (1994). Mapping the Margins: Intersectionality, Identity Politics, and Violence against Women of Color. In F. N. Albertson and R. Mykitiuk (Eds.), The Public Nature of Private Violence (pp. 93-118). New York: Routledge.

6. Wekker G (2001). Van monocultuur naar caleidoscoop. Humanistiek 6:26-33.

7. Van Mens-Verhulst J (2001). 'Diversiteit in theorie en praktijk: een bericht uit de feministische hulpverlening. [Diversity in theory and practice: a message from the feminist care]. Tijdschrift voor Humanistiek 2(2) 7-17.

8. Pinn VW (2003). Sex and gender factors in medical studies. Implications for health and clinical practice. Journal of the American Medical Association 289(4):397-400.

9. Bekker MHJ (2003). Investigating gender within health research is more than sex disaggregation of data: a multi-facet gender $\&$ health model. Psychology Health \& Medicine 2:231-243.

10. Moser I (2006). Sociotechnical Practices and Difference: On the Interferences between Disability, Gender, and Class. Science Technology Human Values 31:537-564.

11. Celik H, Klinge I (2005). Mainstreaming gender en diversiteit in de gezondheidszorg. Tijdschrift voor Genderstudies 2:12-22.

12. Pathman DE, Konrad TR, Freed GL, Freeman VA, Koch GG (1996). The awareness-to adherence model of the steps to clinical guideline compliance: the case of pediatric vaccine recommendations. Medical Care 34:873-889.

13. Kotter JP, Cohen DS (2002). The heart of change. Real life stories of how people change their organizations. Harvard: Harvard Business School Press.

14. Celik H, Lagro-Janssen T, Klinge I, van der Weijden T, Widdershoven G (2008). Maintaining Gender Sensitivity in the Family Practice: Facilitators and Barriers. Journal of Evaluation in Clinical Practice (In Press).

15. Verdonk P, Benschop YWM, De Haes JCJM, Lagro-Janssen ALM (2008). Making a gender difference: Case studies of gender mainstreaming in medical education. Medical Teacher 30:e194-e201.

16. Celik H, van Oosten N (2004). Blueprint training 'Gender, diversity and quality Assurance in healthcare practices. Maastricht: Maastricht University.

17. Celik H, van Oosten N (2005). Mainstreaming diversity in healthcare practices. The training manual. Maastricht: Maastricht University.

18. Celik H, van Oosten N (2005). Mainstreaming diversity in healthcare practices. Participants' manual and reader. Maastricht: Maastricht University.

19. Health Canada (2000). Types of Gender Bias Problems. In Women's Health Bureau, Health Canada's Gender-based Analysis Policy. Ottawa: Health Canada.

20. Grol R, Wensing M, Eccles M (2005). Improving patients' care: the implementation of change in clinical practice. Edinburgh: Elsevier Butterwort Heinemann.

21. Rees T (2001). Mainstreaming gender equality in science in the European Union' Gender and Education 13(3):243-260.

22. Council of Europe (1998). Gender mainstreaming. Conceptual framework, methodology and presentation of good practices. Strasbourg: Council of Europe. 
23. Langley GL, Nolan KM, Nolan TW, Norman CL, Provost LP (1996). The Improvement Guide: A Practical Approach to Enhancing Organizational Performance. San Francisco, California: Jossey-Bass Publishers.

24. Linnan L, Steckler A (2002). Process evaluation for public health interventions and research: an overview. In Linnan L ,Steckler A (Eds.). Process Evaluation for Public Health Interventions and Research (pp.1-23). San Francisco, CA:Jossey- Bass.

25. Greene JC, Kreider H, Mayer E (2005). Combining qualitative and quantitative methods in social inquiry. In B. Somekh and C. Lewin (Ed). Research methods in the social sciences (pp. 274-281). Sage, London.

26. Greene JC, Caracelli VJ, Graham, WF (1989). Toward a conceptual framework for mixed method evaluation design. Educational Evaluation and Policy Analysis 11(3):255-274.

27. Celik H, Abma TA, Widdershoven GAM, van Wijmen FCB, Klinge I (2008). Implementation of diversity in healthcare practices: barriers and opportunities. Patient Education \& Counseling 71:65-71.

28. Miles MB, Huberman AM (1994). Qualitative data analysis: an expanded sourcebook. Thousands Oaks: Sage.

29. Lincoln Y, Guba E. (1985). Naturalistic inquiry. New York: Sage, pp. 92-109.

30. Hsieh HF, Shannon SE (2005). Three approaches to qualitative content analysis. Qualitative Health Research 15(9):1277-88.

31. Greene JC (2007). Mixed Methods in Social Inquiry. Jossey-Bass, San Francisco.

32. Greene J, Benjamin L, Goodyear L (2001). The Merits of Mixing Methods in Evaluation. Evaluation $7(1): 25-44$.

33. Rogers EM (2003). Diffusion of innovations. (5th ed.). New York: Free Press.

34. Grol R, Grimshaw J (2003) From best evidence to best practice: effective implementation of change in patients' care. The Lancet 632:1225-1230.

35. Yano E (2008). The role of organizational research in implementing evidence-based practice: QUERI Series. Implementation Science 3(1):29.

36. Guba E, Lincoln Y (1989). Fourth Generation Evaluation. Beverly Hills, CA: Sage.

37. Abma TA, Stake RE (2001). Stake's responsive evaluation. In: Greene, J. and T.A. 



\section{Chapter 7}

General discussion and conclusion 


\section{INTRODUCTION}

Within healthcare practices, professionals play an important role in facilitating or impeding gender sensitive healthcare. This thesis aimed to contribute to practice improvements in terms of more gender sensitive care through the development, application and evaluation of a training program for healthcare professionals. It provided a practically grounded and theoretically inspired understanding of the factors which are beneficial or hindering the implementation of gender sensitive healthcare. In this chapter we will present an overview of our main findings and the lessons learned during this project. Then we will discuss the limitations of the study, followed by recommendations for further research, and practical suggestions to promote gender sensitivity in medical education and health policy. We will end with a conclusion.

\section{MAIN FINDINGS}

The results of this research project have shown that a wide spectrum of factors determine to which extent a gender sensitive approach is satisfactorily implemented in healthcare practices. ${ }^{1}$ These range from factors related to the individual healthcare professional to factors related to the organization and health policy on national level.

The evaluation results of the educational initiatives demonstrate that training health professionals is a helpful tool to stimulate the sense of urgency and raise the awareness of the blind spots of a neutral one-size-fits-all approach. ${ }^{2,3}$ Yet, gender sensitivity is not an easy concept to grasp for individual professionals. Through the training, professionals' awareness and knowledge towards gender issues increased. They also became more critical about a neutral approach after a gender sensitivity training. Yet, a minority of the professionals indicated that they felt that the required conditions and their own 'empowerment' process to embrace gender sensitivity were not completed with a training program. ${ }^{4}$ Although some professionals only started to understand the complexity of the notion of gender sensitivity, our basic assumption that training is an appropriate tool to trigger positive changes towards gender sensitive healthcare, remains tenable. In addition, we showed that sensitivity heavily hinged on how professionals were generally professionalized. In order to successfully master gender issues, structural education is fundamental. ${ }^{5}$ In spite of this, medical training is still gender-biased as a consequence of a biomedical focus. ${ }^{6,7}$

It has been shown earlier on that clinicians' knowledge deteriorates gradually after graduation. ${ }^{8}$ Therefore in addition to academic education (a form of individual learning) gender sensitivity should also be facilitated by training and support on-the-job. Learning at the workplace is attractive for professionals when it is practically oriented and context-bound, and it also stimulated social learning with and from each other. ${ }^{1}$ Professionals will become more motivated by a continuous exposure to gender sensitive 
knowledge in their practice, as new knowledge must be repeated in order to be effective. ${ }^{9}$ Through repetition, motivation becomes stable and by that a habit for professionals. ${ }^{2,10}$ In our project in the general practice, GP's were more motivated by practicing their gender sensitive knowledge, as they realized its significance and impact on patients. In this process the exchange of creative experiences, for instance in educational team meetings at the workplace between couples of trainee general practitioners (mainly young professionals with theoretical luggage) and more advanced general practitioners acting as instructors (mainly experienced professionals) was highly rewarding. ${ }^{2}$ In dialogue health professionals can pass on creative solutions and foster mutual learning. ${ }^{11}$ In our study we noticed that gender sensitivity can also be boosted by the combination of a clearly designed training, practical recommendations, regular discussions between professionals, and feedback and support from researchers as critical friends (the study team). Critical friends do not judge or stand above a practice, but are engaged in a dialogue with professionals in practice. The experiential and working knowledge of professionals is acknowledged as a source of wisdom, and provides the basis for a balanced and ethical relation with practice. ${ }^{12}$

Although training and education of health professionals is a catalyst, even a prerequisite for gender sensitivity, we agree with Grol \& Grimshaw that changes in practice are only partly within health professionals' control. ${ }^{13}$ A sense of urgency and enthusiasm among professionals is necessary, but not enough to ensure action being taken for gender sensitive care in the professional-patient relationship. A common problem in healthcare practices, for instance in the general practice and nursing home practice in this study, is the heavy case- and workload. Certain patient-related activities are timeconsuming, especially when the particular activity is not a routine. Under these constraining circumstances changes in the direction of gender sensitive care are more complicated. The active involvement of key actors (top and middle management) in the process of organizational learning is required to support professionals and create the conditions to adopt gender sensitive actions in healthcare practices. ${ }^{14}$ Within the practices included in our project several 'ambassadors' took the role of inspiring stakeholders, creating positive conditions to bring gender sensitivity into practice. In the hospital practice and mental health practice these ambassadors were mainly women in strategic positions. This is in line with the results of our literature review, that women (clinicians, nurses) are more sensitive towards gender issues. ${ }^{1}$ Schiebinger also states that the participation of women is crucial for gendered innovations, as human knowledge - what we know, value, and consider important - may change dramatically as women become partners. ${ }^{15}$

To foster a gender sensitive health sector the political environment can create requirements to facilitate and trigger professionals and (research) organizations. For example political initiatives at the European and/or national level have stimulated and financed gender sensitive research. Klinge conducted successive research projects funded by the European Commission under the Fifth and Sixth Framework Pro- 
gramme (FP5 and FP6) for Research, which offered unique opportunities to take a significant step forward in translating gender expertise to research and to bring about a fundamental change in a biomedical and health research practices. ${ }^{16}$ Also initiatives at the national level can inspire changes regarding gender sensitivity in practice. For instance, in the eighties the Dutch government promoted and financially supported the integration of 'sex and gender specific care' into regular care. As a result gender sensitive initiatives were taken on board in mental health institutions. In the mental health practice the effects of these investments were still noticeable. ${ }^{4}$

\section{LESSONS LEARNED}

In this research project lessons have been learned to implement gender sensitivity in healthcare practices. The main lessons are about the factors affecting the uptake and application of gender sensitivity in healthcare practices. The process of bringing gender sensitivity into practice starts with raising awareness and building knowledge concerning gender issues among health professionals. Awareness and knowledge are a 'conditio sine qua non', indispensable ingredients for the enhancement of gender sensitivity among professionals in health care practices. This is in line with the model of diffusion of innovations; the most powerful motor for innovation change is that potential users see the potential advantage of an innovation. ${ }^{17,18}$ Other scholars refer to the necessity of a sense of urgency as the basic ingredient for organizational changes, indicating the need that things can and should be different in the future (i.e. not just a cognitive understanding). ${ }^{19}$ Our research project demonstrated that educational programs deliberately paying attention to the limitations of taken-for-granted routines (in this case, the neutral approach to health) are an appropriate tool to create a sense of urgency among professionals to adopt a gender sensitive approach to health, however to sustain gained knowledge and apply it in practice more is needed.

Even if individual professionals are gender sensitive and are willing to take actions, existing attitudes and established patterns of care giving are not easily changed. To promote gender sensitivity in healthcare practice continuous exposure to educational initiatives, seem to be supportive. ${ }^{5}$ Regarding the further implementation, 'ambassadors' in a particular practice can stimulate and promote the adoption of new ideas, particularly when they are belonging to the social network of the professional and can be seen as internal opinion leaders. The presence of these motivated ambassadors and leaders can help to cross existing boundaries and activate the uptake and implementation of gender sensitivity. According to West et al, social networks influence the behaviour of professionals and it is important in the process by which professionals adopt (or fail to adopt) new innovations in practice. ${ }^{20}$ In our experience, the daily exchange of experiences between couples of general practitioners in their practice were motivational triggers for these professionals. ${ }^{5}$ 
Besides the role of health professionals, healthcare organizations and the wider political environment are also important components in the uptake and dissemination of gender sensitivity. ${ }^{1}$ In general it is legitimate to state that in organizations with an absorptive capacity and a receptive culture towards new ideas, it is easier to accomplish innovations. ${ }^{21,22}$ In our project we noticed differences in the success of bringing gender sensitivity into practice between practices with a supportive environment convincing health professionals and promoting changes towards gender sensitivity (mental health practice and general practices) and practices where such support was lacking (nursing home practice). ${ }^{3,4}$ In the mental health practice we also noticed the influence of earlier political initiatives, that had been implemented before. If there is dedicated support for gender sensitivity and ongoing financial resources for its implementation, health practices are more enabled to become gender sensitive. More broadly, Pandey \& Wright suggest that certain types of political influence have an impact on organizations' goals and consequently on the individuals working in them..$^{23}$ They suggest to 'connect the dots' between the focus on individual level and the political context.

In this research project we gradually gained more insight in the relevant components for bringing gender sensitivity in practice. For best practices, comprehensive approaches covering the professional level, supported by healthcare practices and the policy in the wider environment are needed. This means mainstreaming gender as a policy strategy will be helpful in strengthening a gender perspective in practice. In line with Stratigaki, mainstreaming gender should be complementary, a 'twin track' approach, rather than a substitution (replacement) of existing gender equality strategies, like for example positive action measures, which are more practice oriented. ${ }^{24}$

There were also methodological lessons learned during this research project. Our study followed an open and iterative process, rather than a fixed model. Our emergent design gradually developed during the project with subsequent thoughts and inquiries. We started with an explorative qualitative study to gain in-depth insight in the opportunities and barriers to bring gender sensitivity in practice. The results showed that health professionals were not competent enough to bring gender into practice. We reacted to this by developing a gender sensitivity training for health professionals. To measure the effects of the training quantitative methods were used. The quantitative data raised new questions and necessitated the use of qualitative methods and a process evaluation in order to help to understand the world behind the numbers and the strong and weak aspects of the training. The combination of qualitative and quantitative data has shed more light on the factors that ultimately determine the extent to which a gender sensitive approach is practiced by health professionals. Due to this integrative and mixed methods approach, we were able to add in each phase another layer of understanding concerning bringing gender sensitivity in practice. 


\section{Limitations OF THE STUDY}

This research project has certain limitations that need to be taken into account when considering its results. This study has not focused on the further development of intersectionality, but used the concept as a source of inspiration and basis for the development of a practical intervention to increase gender sensitivity among healthcare professionals. Within an intersectional framework all dimensions of difference and their interplay are taken into account in order to understand individual experiences, to theorize identity, as a property of social structures and cultural discourses. ${ }^{25}$ Although the impact of several categories of difference can hardly be underestimated, gender does play a pivotal role within these social identifiers. ${ }^{26}$ The decision to concentrate on gender can be regarded as obvious for our study, as the fruitful concept of intersectionality is thoroughly in development and still has to take definite shape in health and health care. The first attempts to translate this concept to health care by Schulz and Mullings, can serve as a basis for further elaborations of intersectionality in health care practices. ${ }^{27}$

Several different healthcare practices were subject of our study. This brings forth a trade off between breadth and depth. It can be argued that a more thorough understanding could have been reached by in-depth analysis of one particular health care practice. However, the investigation of gender sensitivity in dissimilar health care practices resulted in a realm of insight in the different practices and their sensitivity to bring it in practice.

Another limitation of our research project is the absence of patients' perspectives. There are several ways incorporate the patient perspective in research initiatives to improve gender sensitivity in health care. Patients could have been invited in the development of the training intervention, giving feedback on the training and its elements. Patient could also have participated in the provision of the training, explaining to professionals what matters when it comes to being sensitive to gender issues. Furthermore their perspectives could have been taken into account when evaluating the training. The view of the patient as a consumer of health care, can reveal additional information about the success of a study. Is care gender sensitive and is it good care in their eyes? Finally, patients could have joined more actively in the research process, not as respondents, but as advisors or partners. ${ }^{28}$ It is argued that the involvement of patients in research will increase the relevance of research and the implementation of its results. ${ }^{29}$

\section{RECOMMENDATIONS AND CHALLENGES}

The lessons we have learned and the limitations in this project can provide recommendations for future research education, policy and practice. 


\subsection{FURTHER RESEARCH}

An important topic for further research is to translate and further develop an intersectional approach to health and healthcare by combining empirical and theoretical analyses of the basic premises of intersectionality. The results of these analyses need to be tested in health care practices and followed by practical research. Comprehensive approaches are needed to gain more insight into the effects of promoting gender sensitivity in the multi-level and multi-actor context of healthcare practices. These studies will yield more additional information about patients' needs if they incorporate the patients' perspective. In research, there is also a need to promote patient participation, as collaboration between researchers and patients will be helpful to gain a better understanding of patients' experiences and priorities. Active involvement of patients with experiential knowledge in research activities can enrich the research process and lead to more legitimate results and ideas for research and education.

To further elaborate best practices concerning gender sensitive health care, empirical research should go hand in hand with implementation research. While empirical research is important to analyze the role of the multiple dimensions of difference, a gender sensitive and/or intersectional approach should be implemented in health care to find out what works and to find solutions to problems in the field in dialogue with professionals.

\subsection{EDUCATION}

Education can facilitate gender sensitivity by disseminating gender sensitive knowledge and making health professionals from the very beginning aware of and competent to attend to gender issues in practice. To create a gender sensitive attitude among health professionals, gender issues should not be ignored, but rather become an inclusive part of (post) medical education. The need for gender sensitive education has been widely advocated and supported by research, however a gender sensitive approach has not structurally entered (medical) education. There are specific challenges to embed gender issues in medical education and train professionals structurally on-the-job to create a gender sensitive atmosphere. In embedding gender issues in medical curricula it is more promising to start in interdisciplinary case-based curricula than in traditional lecture based biomedical curricula. To be successful on-the-job, professional development needs to be supported and guided by (academic) experts as critical friends and communicative change agents. Professionals in the field should have free entrance to use available (electronic) educational materials about gender issues at academic centers. This will also result in an advantage in time spend in a busy work environment of health professionals. 


\section{3. PRACTICE AND POLICY}

Best practices can be distributed by workplace learning (work based learning) and in inter-organizational learning networks (collective learning). On the workplace and in networks professionals can jointly discuss problems, question routines, pass on creative solutions and find inspiration and energy for long-term changes in the direction of gender sensitive care.

To develop and deliver gender sensitive health care, gender sensitive research should be further promoted at European and national level. At both levels we recommend (research) policy makers to introduce a gender-oriented perspective from the very beginning in policy, planning, implementation and evaluation of research. Clinical guideline organizations should pay systematic attention to gender sensitive issues in the process of guideline development. A policy of mainstreaming gender sensitivity is complementary to practical initiatives and can support processes of raising awareness, which make institutional learning possible, and in turn induces further processes of change.

\section{CONCLUSION}

Successful implementation of gender sensitivity in health care practices can be facilitated by initiatives at the individual professional level, the organization level and the wider political level. Best practices include continuous exposure of potential users to gender sensitive knowledge (professional education and workplace learning), organizations with an absorptive capacity and a receptive culture towards new ideas (active involvement of organizational key actors, especially women in strategic positions), and deliberate and ongoing (financial and political) support from the wider political environment. The lessons we have learned can be a motor to promote the uptake and dissemination of gender sensitivity in health care practices. 


\section{REFERENCES}

1. Celik H, Lagro-Janssen ALM, Klinge I, Widdershoven GAM, Abma TA. Bringing Gender Sensitivity into Practice: a Systematic Review (Submitted)

2. Celik H, Klinge I, van der Weijden T, Widdershoven GAM, Lagro-Janssen ALM (2008). Gender sensitivity among general practitioners: Results of a training programme. BMC Medical Education 8(36).

3. Celik H, Abma TA, Klinge I, Widdershoven GAM. Process Evaluation of a Diversity Training Program: the Value of a Mixed Method Strategy. (Submitted).

4. Celik H, Abma TA, Widdershoven GA, van Wijmen FCB, Klinge I (2008). Implementation of diversity in healthcare practices: barriers and opportunities. Patient Education \& Counseling 71(1):65-71.

5. Celik H, Lagro-Janssen T, Klinge I, van der Weijden T, Widdershoven G. Maintaining Gender Sensitivity in the Family Practice: Facilitators and Barriers. Journal of Evaluation in Clinical Practice (In press).

6. Verdonk P, Mans LJL, Lagro-Janssen ALM (2005). Integrating gender into a basic curriculum. Medical Education 39:1118-1125.

7. Verdonk P, Benschop YWM, De Haes JCJM, Lagro-Janssen ALM (2008). Making a gender difference: case studies of gender mainstreaming in medical education. Medical Teacher 30:e194-201.

8. Ramsey PG, Carline JD, Inui TS et al (1991). Changes over time in the knowledge base of practicing internists. Journal of the American Medical Association 266:1103-1107.

9. Sutton S (1993) The past predicts the future: Interpreting behaviour relationships in social-psychological models of health behaviours. In D. R. Rutter \& L. Quine (Eds), Social psychology and health: European perspectives (pp.71-88). Aldershot: Avesbury.

10. Sheeran P, Orbell S (1999). Implementation intentions and repeated behaviour: augmenting the predictive validity of the theory of planned behaviour. European Journal of Social Psychology 29:349-369.

11. Abma TA (2003). Learning by Telling. Storytelling Workshops as an organizational Learning Intervention. Management Learning 34(2):221-240.

12. Abma TA, Widdershoven GAM, Frederiks BJM, van Hooren RH van Wijmen F, Curfs PLMG (2008). Dialogical nursing ethics. The quality of freedom restrictions. Nursing Ethics 15(6):789-802.

13. Grol R, Grimshaw J (2003). From best evidence to best practice: effective implementation of change in patients' care. The Lancet 362:1225-1230.

14. Yano E (2008). The role of organizational research in implementing evidence-based practice: QUERI Series. Implementation Science 3(1): 29.

15. Schiebinger L (2008). Gendered Innovations in Science and Engineering. Stanford University Press, Stanford, California.

16. Klinge I (2007). Bringing Gender Expertise to Biomedical and Health-Related Research. Gender Medicine 4(2): S59-S63.

17. Berwick M (2003). Dissemination innovations in Health Care. JAMA 289(15):1969-1975.

18. Rogers EM (1995). Diffusion of Innovations. New York: Free Press.

19. Kotter JP, Cohen DS (2002). The heart of change. Real life stories of how people change their organizations. Harvard: Harvard Business School Press.

20. West W, Barron DN, Dowsett J, Newton JN (1999). Hierarchies and cliques in the social networks of health care professionals: implications for the design of dissemination strategies. Social, Science \& Medicine 48:633-646.

21. Barnsley J, Lemieux-Charles L, McKinney MM (1998). Integrating Learning into Integrated Delivery Systems. Health Care Management Review 23(1):18-28.

22. Pettigrew AM, McKnee L (1992). Shaping Strategic Change. Making Change in Large Organisations. London: Sage.

23. Pandey SK \& Wright BE (2006). Connecting the Dots in Public Management: Political Environment, Organizational Goal Ambiguity, and the Public Manager's Role Ambiguity. Journal of Public Administration Research and Theory, 16(4): 511-532. 
24. Stratigaki M (2005). Gender Mainstreaming vs Positive Action. European Journal of Women's Studies 12(2):165-186.

25. Davis K (2008). Intersectionlity as buzzword: A sociology of science perspective on what makes a feminist theory successful. Feminist Theory 9(1):67-85.

26. Lagro-Janssen T, Lo Fo Wong S, van den Muijsenbergh M (2008). The importance of gender in health problems. European Journal of General Practice 14:836-838.

27. Schulz AJ, Mullings L (2006). Gender, Race, Class, and Health: Intersectional Approaches. San Francisco: Jossey-Bass.

28. Abma TA, Nierse CJ, Widdershoven GAM (2009). Patients as partners in responsive research: Methodological notions for collaborations in mixed research teams. Qualitative Health Research. (in press).

29. Oliver S, Gray J (2006). A bibliography of research reports about patients', clinicians' and researchers' priorities for new research. London: James Lind Alliance. 
Summary 
That sex and gender matter in health and health care has been demonstrated in a high number of studies about gender and health. It has been shown in the scientific arena that there are differences in epidemiology, presentation and course of diseases, as well as in treatment effectiveness and prognosis. At present, we have increasing knowledge about the influences of sex and gender on health and how disparities between the sexes in health prevail to exist. However, this growing body of knowledge does not automatically mean that gender sensitivity has been implemented in healthcare practices. We need to identify not only the differences in patients' needs themselves, but also the constraints that healthcare practices and professionals face in trying to meet patients' needs. Thus far, we seem to lack best practices and ways for successful implementation of gender related knowledge in health care. To promote the uptake and dissemination of gender sensitivity in practice, best practices can be vehicles to apply knowledge, improve it and share the lessons learned with health professionals. Therefore we first investigate in chapter 2 the state of art concerning the provision of gender sensitivity in health care practices and in chapter 3 we provide a literature review focused on gender sensitivity.

\section{CHAPTER 2}

The aim of this chapter is to investigate to which extent diversity is part of current healthcare practices and to explore opportunities and barriers in the implementation of diversity dimensions in health care practices. Nine in-depth, semi-structured interviews and three focus groups were conducted in three healthcare settings (mental health, hospital, nursing home care). The results demonstrate that (the potential of) diversity is an ambiguous issue; diversity is said to be important, but this has not led to adjustments of the neutral, disease-oriented approach of patients. If recognized at all, diversity is reduced to one dimension (sex). Barriers in the implementation of diversity relate to: (a) lacking awareness and knowledge of diversity, (b) poor information and communication, and (c) organizational constraints. Opportunities to implement diversity in healthcare include: (d) an emerging sense of urgency to attend to diversity, (e) the development of good practices, and (f) the political climate. We conclude that various barriers and some opportunities for the implementation of diversity in healthcare practices exist in the practices under study. There is ambiguity in how professionals deal with diversity. As a result, a neutral approach remains dominant in practice and policy. In order to raise awareness and enhance the competence of professionals, educational programmes and learning networks are required. 


\section{CHAPTER 3}

In this chapter a systematic review is provided regarding the implementation of gender sensitivity in healthcare. Literature was identified from CINAHL, PsycINFO, Medline, EBSCO and Cochrane (1998-2008) and the reference lists of relevant articles. The quality and relevance of 752 articles were assessed. Based on a three-step inclusion process: (1) selection based on title/abstracts; (2) selection based on full text; and (3) citation tracking, 11 empirical studies involving opportunities and barriers for the implementation of gender sensitivity in healthcare practices were included. Our results demonstrate that the implementation of gender sensitivity includes factors related to the professional, organizational and the policy level. Yet, the majority of studies focus solely on behavioural change of professionals by education or on the organizational culture. Development of comprehensive interventions to implement gender and their evaluation are needed to improve gender sensitivity in healthcare. These interventions should take into account the forming of a core group with committed key players in an institution, developing an appealing vision for the future, training and educating professionals, sharing successes by good and best practices and providing feasible solutions to the main obstacles experienced by the key actors in the process of change.

We continue the state of art concerning gender sensitivity in theory and practice with the uptake and dissemination of gender sensitivity in practice. In chapter 4 we investigate the effects of a training programme in primary health care practices (General Practice) and in chapter 5 we identify facilitators and barriers perceived by General Practitioner's (GPs) to maintain gender sensitivity in practice. In chapter 6 we present a process evaluation of a gender sensitive training in secondary health care practices: mental health practice, a hospital practice and nursing home practice.

\section{CHAPTER 4}

In this chapter we aimed to investigate whether GPs' gender sensitivity can be stimulated by a training programme. The focus was on three diseases: angina pectoris, depression and urinary incontinence. This chapter had a quantitative, explorative and descriptive design. By means of a training programme 18 GPs were trained to focus on gender-sensitive recommendations for the three diseases. With standardised registration forms, data were collected during a 6-month period. During the registration period, the GPs were visited by the study team to discuss the process of data collection. The GPs filled in registration forms for 100 patients: 39 with angina pectoris (31 women and 8 men), 40 with depression (26 women and 14 men), and 21 with urinary incontinence (20 women and 1 man). The results show that gender sensitivity can be stimulated among trained professionals. The combination of the training programme, clear and 
practical recommendations, daily discussion of relevant cases between GP couples, feedback and support during registration by the study team contributed to the outcome. We conclude that GPs' gender sensitivity was stimulated by the training programme and the supporting visits. Ideally, structural attention could be realised by embedding gender issues in existing organisational structures of general practices.

\section{CHAPTER 5}

This chapter aims to identify the facilitators and barriers perceived by GPs to maintain a gender perspective in family practice. Therefore, nine semi-structured interviews were conducted among nine pairs of GPs. The data were analysed by means of deductive content analysis using theory-based methods to generate facilitators and barriers to gender sensitivity. Our results show that gender sensitivity in family practice can be influenced by several factors which ultimately determine the extent to which a gender sensitive approach is satisfactorily practiced by GPs in the doctor-patient relationship. Gender awareness, repetition and reminders, motivation triggers, and professional standards were found to facilitate gender sensitivity. On the other hand: lacking skills and routines, scepticism, heavy workload, and the timing of implementation were found to be barriers to gender sensitivity. We conclude that while the potential effect of each factor affecting gender sensitivity in family practice has been elucidated, the effects of the interplay between these factors still need to be determined.

\section{CHAPTER 6}

This chapter presents a process evaluation of a diversity sensitivity training program for healthcare professionals. The training was implemented in three health care practices (mental health, nursing home and hospital care). Mixed methods were used to monitor the implementation of the training and its effects after three years. Findings demonstrate that the training stimulated participants' awareness, knowledge and critical attitude towards diversity. The motivation and willingness to take action regarding diversity was also enhanced. Yet, these developments were less apparent among nursing home participants who felt less satisfied and did not develop a critical perspective on this issue. Qualitative data were helpful to explain differences between the settings. By means of the combination of quantitative and qualitative data, we can conclude that individual learning was not enough to guarantee a sensitive approach to diversity at the organizational level. 


\section{CHAPTER 7}

Successful implementation of gender sensitivity in health care practices can be facilitated by initiatives at the individual professional level, the organization level and the wider political level. Best practices include continuous exposure of potential users to gender sensitive knowledge (professional education and workplace learning), organizations with an absorptive capacity and a receptive culture towards new ideas (active involvement of organizational key actors, especially women in strategic positions), and dedicated and ongoing (financial and political) support from the wider political environment. The lessons we have learned in this project can be a vehicle to promote the uptake and dissemination of gender sensitivity in health care practices. 

Samenvatting 
Dat verschillen als gevolg van sekse en gender van invloed zijn op ziekte en gezondheid is inmiddels uitgebreid aangetoond in wetenschappelijke literatuur. Genderverschillen bestaan op het gebied van epidemiologie, klachtenpresentatie en betekenisgeving, ziekteverloop, diagnosestelling, behandeling en preventie. Echter, de groeiende hoeveelheid literatuur betekent niet automatisch dat professionals in de gezondheidszorg sensitiever zijn geworden voor gender en dat waardevolle inzichten en werkwijzen over genderverschillen in gezondheidspraktijken zijn geïmplementeerd. Daartoe is het niet alleen nodig om verschillen tussen patiënten te duiden, maar vooral ook om de obstakels en positieve ervaringen waar gezondheidspraktijken en professionals tegenaan lopen bij de implementatie van gender sensitiviteit te identificeren. Tot op heden ontbreken systematische beschrijvingen van gender sensitieve 'best practices' en inzichten in de belemmeringen en mogelijkheden om gender gerelateerde veranderingen in gezondheidspraktijken te implementeren. Deze dissertatie wil hieraan een bijdrage leveren door een analyse van de huidige praktijk en kennis over de implementatie van gender sensitiviteit, en de evaluatie van trainingsprogramma's voor gender sensitiviteit en diversiteit in de $1^{\mathrm{e}}$ en $2^{\mathrm{e}}$ lijn.

In deze dissertatie bespreken we allereerst in hoofdstuk 2 de stand van zaken in gezondheidspraktijken betreffende de sensitiviteit van professionals voor verschillen, waarna we in hoofdstuk 3 een literatuuroverzicht geven over gender sensitiviteit.

Dit hoofdstuk heeft tot doel het onderzoeken van de mate waarin aandacht voor verschillen tussen patiënten een onderdeel is van huidige gezondheidspraktijken. Ook wordt in dit hoofdstuk behandeld welke mogelijkheden en beperkingen er zijn om aandacht voor verschillen in gezondheidspraktijken te implementeren. Daartoe zijn negen semi-gestructureerde diepte-interviews en drie focusgroepen gehouden in drie gezondheidspraktijken (geestelijke gezondheidszorg, ziekenhuis en verpleeghuis). De resultaten van dit onderzoek hebben aangetoond dat diversiteit een ambigu concept is; diversiteit wordt als belangrijk gepresenteerd, maar dit heeft in de praktijk (nog) niet tot zichtbare veranderingen van de neutrale ziektegeoriënteerde benadering geleid. Als diversiteit al herkend wordt, dan is de aandacht beperkt tot één dimensie ervan (sekse), terwijl vanuit een intersectionele benadering ook andere dimensies van verschil (waaronder leeftijd, sociaal economische status, etniciteit) en de wederzijdse beïnvloeding daartussen, verschillen bepalen. Barrières om diversiteit in de praktijk te implementeren zijn het gevolg van (a) een gebrek aan bewustzijn van en kennis over diversiteit, (b) tekortschietende informatie en communicatie, en (c) organisatorische beperkingen. Het implementeren van diversiteit in gezondheidspraktijken wordt juist gestimuleerd door (d) een stijgende sensitiviteit voor het belang van diversiteit, (e) het ontwikkelen van 
goede praktijkvoorbeelden en een stimulerend politiek klimaat. We concluderen dat verschillende barrières en mogelijkheden een rol spelen bij het implementatieproces van diversiteit in gezondheidspraktijken. Bovendien gedragen professionals zich paradoxaal met betrekking tot diversiteit. Als gevolg daarvan, blijft een neutrale benadering de praktijk en het beleid daarvan domineren. Om het bewustzijn van professionals te verbeteren en hen competenter te maken zijn gerichte opleidingsprogramma's en lerende netwerken vereist.

\section{HOOFDSTU 3}

In dit hoofdstuk wordt een systematisch literatuuroverzicht met betrekking tot de obstakels en mogelijkheden bij de implementatie van gender sensitiviteit in gezondheidspraktijken gepresenteerd. Voor het identificeren van literatuur werden de databases CINAHL, PsycINFO, Medline, EBSCO en Cochrane (1998-2008) gebruikt. Daarnaast werden de referentielijsten van de relevante artikelen doorlopen. De kwaliteit en de relevantie van 752 artikelen werd beoordeeld. In totaal werden 11 empirische studies geïncludeerd via een 3-staps selectietechniek: (1) selectie op basis van titel/abstract, (2) selectie op basis van volledige tekst; en (3) selectie op basis van referentielijsten. Uit de resultaten blijkt dat de aandacht voor gender en de implementatie daarvan in de praktijk afhankelijk is van verschillende factoren die op drie niveaus een rol spelen: het professionele niveau, het organisatieniveau en het beleidsniveau. Opvallend is dat de meerderheid van de studies zich ofwel uitsluitend beperkt tot een gedragsverandering van professionals middels opleiding ofwel tot een verandering van de organisatiecultuur. Het is nodig om interventieprogramma's te ontwikkelen om gender op meerdere niveaus te implementeren en te evalueren teneinde gezondheidspraktijken gender sensitiever te maken. Voor het slagen van deze brede interventies zijn van belang: betrokken sleutelfiguren binnen de organisatie, training en opleiding van professionals, delen van succes middels 'goede praktijken' en het bieden van oplossingen voor de belangrijkste ervaren obstakels in het veranderingsproces. Ten slotte zouden organisaties die succesvol zijn bij het implementeren van gender sensitiviteit beleidsmatig ondersteund moeten worden in de vorm van positieve publiciteit, middelen en mankracht.

$\mathrm{Na}$ deze stand van zaken betreffende gender sensitiviteit in theorie en praktijk wordt deze dissertatie voortgezet met het oppakken en verspreiden van gender sensitiviteit in gezondheidspraktijken. In hoofdstuk 4 onderzoeken we de effecten van een trainingsprogramma voor het verhogen van gender sensitiviteit bij professionals dat in de eerste lijn (huisartsenpraktijken) is uitgezet. In hoofdstuk 5 beschrijven we de factoren die deze huisartsen in de praktijk faciliteren dan wel belemmeren bij het in de praktijk brengen van de gender gerelateerde kennis, die zij middels het trainingsprogramma hebben opgedaan. In hoofdstuk 6 bespreken wij een procesevaluatie van een compe- 
tentieprogramma voor gender gerelateerde onderwerpen in de tweedelijns gezondheidszorg (GGZ, ziekenhuis, verpleeghuis).

\section{HOOFDSTK 4}

Dit hoofdstuk stelt zich ten doel te onderzoeken of de gender sensitiviteit van huisartsen middels een trainingsprogramma gestimuleerd kan worden. Het onderzoek waarover wordt gerapporteerd heeft een kwantitatief, exploratief en beschrijvend design. Het trainingsprogramma focust op drie ziektebeelden (angina pectoris, depressie en urine incontinentie) en werd uitgezet onder negen huisartsenkoppels. Middels gestandaardiseerde registratieformulieren, werd data verzameld gedurende zes maanden. Tijdens de registratieperiode werden de huisartsen bezocht door het studieteam om het proces van dataverzameling te bespreken. In totaal zijn 100 registratieformulieren ingevuld: 39 voor angina pectoris ( 31 vrouwen, 8 mannen), 40 voor depressie (26 vrouwen, 14 mannen) en 14 voor urine-incontinentie (20 vrouwen, 1 man). De resultaten laten zien dat gender sensitiviteit onder getrainde professionals bevorderend kan worden. De combinatie van een trainingsprogramma, duidelijke en praktische aanbevelingen, dagelijkse besprekingen van relevante casussen tussen de huisartsenkoppels, feedback en ondersteuning vanuit de onderzoeksteam, lijken bij te hebben gedragen aan het positieve resultaat. We concluderen dat de aandacht voor gender in de praktijk gestimuleerd kan worden dankzij de combinatie van een trainingsprogramma en ondersteunende bezoeken in de praktijk. Idealiter zou structurele aandacht kunnen worden gerealiseerd door gender gerelateerde onderwerpen in bestaande organisatiestructuren van huisartsenpraktijken in te bedden.

\section{HOOFDSUK 5}

Dit hoofdstuk beoogt de factoren te identificeren die huisartsen als beperkend dan wel als bevorderend ervaren bij het behouden van een gender perspectief in de huisartsenpraktijk. Daartoe zijn negen semi-gestructureerde interviews gehouden onder negen koppels van huisartsen. Data werd geanalyseerd door middel van de deductieve content analyse, waarbij 'theory-based' methoden zijn gebruikt om bevorderende en belemmerende factoren te genereren. De resultaten laten zien dat gender sensitiviteit in huisartsenpraktijken beïnvloed kan worden door een verscheidenheid van factoren. Deze factoren zijn uiteindelijk bepalend voor de mate waarin een gender sensitieve benadering in de arts-patiënt relatie wordt gepraktiseerd. Gender bewustzijn, repetitie, geheugensteuntjes, motiverende 'triggers' en professionele standaarden zijn factoren die gender sensitiviteit in de praktijk kunnen bevorderen. Aan de andere kant kunnen factoren als gebrek aan vaardigheden en routines, een sceptische houding, hoge werkdruk en de 
slechte timing van de implementatie als beperkend werken voor het behouden van gender sensitiviteit in de praktijk. We concluderen dat, terwijl het potentiële effect van de verschillende factoren op gender sensitiviteit in dit hoofdstuk wordt opgehelderd, de effecten van de wisselwerking tussen deze factoren op elkaar nog verder onderzocht dienen te worden.

\section{HOOFDSTU 6}

In dit hoofdstuk wordt een procesevaluatie beschreven van een diversiteitscompetentietraining voor professionals in de gezondheidszorg. De training is geïmplementeerd in drie gezondheidspraktijken: GGZ, ziekenhuis en verpleeghuis. Een mixed method strategie is gebruikt om de implementatie van de training en zijn effecten (na drie jaar) te monitoren. De resultaten laten zien dat de training het bewustzijn, kennis en kritische attitude van de deelnemers met betrekking tot diversiteit heeft bevorderd. De motivatie en de bereidwilligheid tot het nemen van gerichte acties stimuleerden eveneens de aandacht voor diversiteit in de praktijk. Deze ontwikkeling was echter minder duidelijk onder de deelnemers in het verpleeghuis. $\mathrm{Zij}$ waren minder tevreden en ontwikkelden niet een kritisch vermogen met betrekking tot diversiteit. Onze kwalitatieve data waren nuttig om de verschillen tussen de settingen te duiden. Dankzij de combinatie van kwalitatieve en kwantitatieve data kunnen we concluderen dat 'individual learning' niet voldoende is om aandacht voor diversiteit op organisatieniveau te garanderen.

\section{HOOFDSUK 7}

Succesvolle implementatie van gender sensitiviteit in gezondheidspraktijken kan worden gefaciliteerd door initiatieven op het individuele professionele niveau, het organisatieniveau en het politieke omgevingsniveau. Voor een 'goede praktijk' is het nodig dat potentiële gebruikers structureel worden blootgesteld aan gender sensitieve kennis (professionele opleiding en leren op de werkvloer), dat de organisatie en de organisatiecultuur ontvankelijk zijn richting nieuwe ideeën (actieve betrokkenheid van sleutelfiguren) en dat er structurele (financiële en politieke) steun is vanuit de politieke omgeving. De lessen uit deze dissertatie kunnen behulpzaam zijn bij het promoten van het oppakken en verspreiden van gender sensitiviteit in gezondheidspraktijken. 



\section{Dankwoord}

De afronding van dit proefschrift is een mijlpaal die ik niet had kunnen bereiken zonder de inzet, betrokkenheid en steun van een groep mensen. Deze mensen ben ik een bijzonder woord van dank verschuldigd.

\section{Guy Widdershoven}

Beste Guy, je bent een promotor die goed is in het realiseren van een intellectueel klimaat en het doorhakken van moeilijke knopen. Ik wil je bedanken voor de mogelijkheden die je me hebt gegeven en je steun en vertrouwen die een bepalende rol hebben gespeeld bij het tot stand komen van dit proefschrift.

\section{Toine Lagro-Janssen}

Beste Toine, je bent een bron van positieve energie. Toen ik vastliep in mijn promotietraject, werd ik door jou met open armen ontvangen. In onze gesprekken was je erg betrokken en had je altijd oog voor het geheel. Ook je interesse voor mijn thuisfront heb ik altijd zeer gewaardeerd. Dankzij jouw steun ligt mijn proefschrift er, waar jij vanaf het begin al je vertrouwen over uitsprak.

\section{Tineke Abma}

Beste Tineke, juist omdat je later betrokken werd in mijn promotietraject, was jouw kijk extra verfrissend. Zonder jouw bijdrage had dit proefschrift er zeker anders uitgezien. Jouw stimulerende begeleiding en je sterke analytische vermogen waren voor mij een grote steun.

\section{Ineke Klinge}

Beste Ineke, ik ben je erkentelijk voor al je inspanningen en je bereidheid om snel en kritisch mijn manuscripten van commentaar te voorzien. Daar heb ik van geleerd! Als expert op het gebied van gender/diversiteit en gezondheid, hield je me altijd bij de les.

\section{Frans van Wijmen}

Beste Frans, ik zat bij jou aan tafel toen ik bijna klaar was met mijn master Gezondheidswetenschappen en aangaf dat ik wilde promoveren. Al vanaf dat eerste uur was je erg betrokken. Die betrokkenheid strekte verder dan alleen mijn project. Ik ben je erg dankbaar voor je steun. 


\title{
Vivianne Baur \& Christi Nierse
}

De afgelopen jaren heb ik het geluk gehad kamer 3.544 te mogen delen met Vief en Christi. Toch hebben jullie veel meer voor me betekend dan alleen het zijn van een prettige kamergenoot. Bij jullie kon ik onvoorwaardelijk terecht. Op moeilijke momenten wisten jullie heel goed te relativeren en bij successen hadden we altijd een extra reden voor een 'feest'. Met veel plezier zal ik terugkijken naar de tijd die we samen doorbrachten. Heel veel succes met de afronding van jullie proefschrift. Ik zal jullie echt missen!

\begin{abstract}
Albine Moser
Ik maakte kennis met je toen je bij mij thuis kwam om je artikel te 'verdedigen' bij de Aio-soepers. Ik was gelijk onder de indruk van je kwaliteiten als wetenschapper en wist dat ik daar veel van kon leren. Ik ben je dankbaar voor je 'lessen' over kwalitatieve data analyse en je bereidheid om mijn manuscripten van een methodologische reflectie te voorzien. Al snel kwam ik er achter dat je meer dan alleen wetenschappelijke kwaliteiten had. Voor de nodige ontspanning tussendoor was je altijd in voor een Latte Caramel in de huiskamer van de Douwe Egberts bar. Du bist eine super Freundin und eine fantastische Kollegin!
\end{abstract}

\section{Josy Ubachs}

Dankzij jouw aanwezigheid bij Metamedica was het extra gezellig. Ik heb altijd uitgekeken naar een gezamenlijke werkdag. Onze levendige discussies over onze promotietrajecten en niet te vergeten over Kes, Sara en Selin, liepen soms toch wel een beetje uit de hand. Maar goed dat we werden onderbroken door telefoontjes of de tussenkomst van een welbekende collega.

\section{Andere collega's}

Een woord van dank gaat tevens uit naar mijn collega's: Rob Houtepen, Sandra van der Dam, Patricia Jaspers, Sandra Reijntjens, Margreet Stolper, Sander Welie, Elleke Landeweer, Annelien Bredenoord, Rankie ten Hoopen, Guido de Wert, Anja Krumeich, Ron Berghmans, Ireen Proot, Ine van Hoyweghen, Jenny Slatman, Arno Müller, Rein Vos, Angelique Heijnen, Arnold van Alphen, Loek Hollands, Petra Verdonk, Lim Lee Wei en Trudy van der Weijden. Hellen, bedankt voor je secretariële ondersteuning.

\section{Nico van Oosten}

Beste Nico, in het GDKZvv project hebben we samen trainingsmodules ontwikkeld en deze in gezondheidspraktijken uitgezet. Het was voor mij een uitdaging om met een ervaren trainer, professionals in gezondheidspraktijken bewust te maken van het belang van gender en diversiteit. Ik heb veel geleerd van je didactische vaardigheden en je probleemoplossend vermogen. 


\section{Bosiljka Djikanovic}

Dear Bosa, as your master thesis supervisor, it was valuable to experience your enthusiasm to improve gender sensitivity among professionals in a different environment. It is fantastic that together we wrote an article, based on the extensive data set which you have collected in Serbia. Our collaboration will continue and I am looking forward to the next manuscript. I wish you all the best in finishing your $\mathrm{PhD}$ thesis.

\section{Wim van der Minne}

Als onderzoeksteam reisden we samen van de ene huisartsenpraktijk naar de andere. Als huisarts kon je me veel vertellen over de praktijk. Ik ben je ook dankbaar, omdat ik een kijk in de keuken van jouw huisartsenpraktijk mocht nemen.

\section{Deelnemende praktijken}

Dankzij de deelname van GGZ Altrecht (Zeist), Isala Klinieken (Zwolle), Antonius IJsselmonde (Rotterdam) en de huisartsenpraktijken was het mogelijk om mijn onderzoek te doen. In het bijzonder ben ik dankbaar voor de steun en bijdrage van Corrie Arts, Marlies Groeneveld en Fenna Eefting. Jullie hebben de deuren van jullie praktijk voor me opengezet en als sleutelfiguren een belangrijke rol gespeeld bij het tot stand komen en de afronding van het project. Ik ben ook alle deelnemers dankbaar voor hun bereidwilligheid en de ervaringen die ze met me wilde delen.

\section{Oudercommissie Sterre}

De leden van de Oudercommissie Sterre: Annelien Duits, Chantal Buurman, Leontine de Vlieger, Gabriela van Gemert-Gunther, Wendy Kieboom, Koen Matthijssen, Martine van Duiseldorp en Karin Verstraeten wil ik graag bedanken voor de urenlange gezellige vergaderingen en voor jullie interesse voor mijn proefschrift.

\section{Tulay Ilhan-Koksu}

Lieve Tulay, in Maastricht ben jij mijn maatje in de privésfeer. Samen zijn we vaak gezellig in de weer met onze kinderen en dan hebben we echt geen tijd om aan werkgerelateerde activiteiten te denken. Ik ben blij dat kleine Salih en mijn kinderen samen heerlijk kunnen spelen en op een gezonde manier ruzie kunnen maken.

\section{Andere vriendinnen}

Een bijzondere groep van vriendinnen wil ik graag bedanken voor hun vriendschap, steun en interesse bij het schrijven van mijn proefschrift: Sinem Bulut-Yazir, Derya Kunt, Sibel Aydin-Güven, Pearl Gumbs, Esin Zorlu-Kement, Sahure Seymen, Sinem Güven, Mediha Bahadir, Nediye Baydar, Hatice Turkoglu, Marloes van der Laan, Marianne Hollestelle, Belianne de Kock-Versluis, Kim Minanon-Heijnen, Yasemin Durmus, Reyhan Nergiz, Elvira Besselink, Ayten Elvan-Taspinar, Franca Driessen-Hoeke en Petra Wolfs-Loehr. 


\section{Inga Swane-van Gelein Vitringa}

Lieve Tante Inga, ik leerde je kennen op mijn eerste onderwijsbijeenkomst aan de rechtenfaculteit. Het klikte gelijk. De afgelopen jaren hebben we veel met elkaar gedeeld. Ik bewonder hoe juist jij allerlei werkzaamheden combineert met een voltijd Masterstudie. Je bent een bijzonder mens en een geweldig voorbeeld voor me. Het is voor mij een grote eer dat jij mij op deze bijzondere dag wilt bijstaan als paranimf.

\section{Mijn schoonfamilie}

Lieve schoonouders, Yusuf Baba en Emine Anne, dankzij jullie liefdevolle zorgen voor onze kinderen, kon ik altijd met een gerust hart werken aan mijn proefschrift. Ik ben jullie zeer dankbaar daarvoor. Yasemin, mijn lieve schoonzus. Het is zo fijn dat ik met jou nog een zusje erbij heb. Bedankt voor je interesse voor mijn proefschrift. Lieve Sinan, met jou maken we vaak een kosten/baten analyse over van alles en nog wat. Recentelijk konden we ook praten over de zorgsector. Ik bewonder de manier waarop jij in de zakenwereld staat. Hasan ve Gülsen, doktorama göstermiş olduğunuz ilgiden dolayi teşekkür ederim.

\section{Broers en zussen}

Canim abilerim Lütfü, Murat ve Canim ablalarim Nuran ve Saniye, sizin ve degerli Sehriban yengemin, Seher yengemin, Ömer enistemin, Gurkan ensitemin ve Battal kardesimin sonsuz desteği benim için çok değerli. Ik weet dat ik altijd en onvoorwaardelijk op jullie steun kan rekenen en dat is een voorrecht. Saniye, ik wens jou heel veel succes bij het schrijven van je proefschrift over diversiteit binnen de politieorganisatie.

\section{Muserref Celik-Karakaya}

Lieve Musje, jij hebt een hele bijzondere plaats in mijn leven. Het is geweldig dat je mijn paranimf wilt zijn. Nu kunnen we na al onze carrièrepraatjes ook samen mijn proefschrift 'verdedigen'.

\section{Mijn ouders}

Canim Mustafa Babacim ve Lütfiye Annecim, bu yolumun basinda siz varsiniz. Özellikle sizin sonsuz sevginizi ve çok değerli desteğinizi hiçbir zaman eksik etmediğiniz için sizlere çok teşekkür borçluyum. Sizi çok seviyorum!

\section{Sara en Selin Temel}

Benim canim yavrularim. Jullie zijn mijn oogappeltjes, de kleur in mijn leven. Tussen alle drukte door, zijn jullie een geweldige afleiding voor mij en geven jullie mij een gevoel van intense rijkdom.

\section{Yasin Temel}

Birtanem, hayatımı güzelleştirdiğin icin ve desteğini hiçbir zaman eksik etmediğin icin sana cok teşekkür ederim. Jouw steun en vertrouwen op vele fronten is te omvangrijk om in woorden te vatten. Met jou kan ik de wereld aan! 


\section{Curriculum Vitae}

Halime Celik werd geboren op 12 juni 1978 te Heusden. Zij behaalde haar Mavo, Havo en VWO diploma in respectievelijk 1995, 1997, 1999 an het d'Oultremontcollege te Drunen. Van september 1999 tot maart 2003, volgde ze aan de Universiteit Maastricht (UM) de studie Gezondheidswetenschappen met als specialisatie Beleid en Management. Daarna werkte ze aan dezelfde universiteit gedurende een paar maanden als junior onderzoeker op de afdeling Beleid, Economie en Organisatie van de Zorg aan de UM. In september 2003 begon ze aan haar promotieonderzoek op de afdeling Health, Ethics \& Society (Metamedica). Parallel aan dit onderzoek heeft zij de studie Nederlands Recht (UM) gevolgd in deeltijd en in november 2009 haar diploma behaald.

Halime is in 2001 getrouwd met Yasin Temel. In 2006 werd zij moeder van Sara en in 2007 van Selin. 


\section{LIST OF PUBLICATIONS}

Celik H, Lagro-Janssen T, Klinge I, van der Weijden T, Widdershoven G. Maintaining Gender Sensitivity in the Family Practice: Facilitators and Barriers. Journal of Evaluation in Clinical Practice (In Press).

Djikanovic B, Celik H, Simic S, Matejic B, Cucic V. Health professionals' perceptions of intimate partner violence in Serbia: opportunities and barriers for response improvement. Patient Education and Counseling (In Press).

Celik H, Abma TA, Widdershoven GA, van Wijmen FCB, Klinge I (2008). Implementation of diversity in healthcare practices: barriers and opportunities. Patient Education \& Counseling 71:65-71.

Celik H, Klinge I, van der Weijden T, Widdershoven GAM, Lagro-Janssen ALM (2008). Gender sensitivity among general practitioners: Results of a training programme. BMC Medical Education 8(36).

Celik H., Klinge I. (2005) Mainstreaming gender en diversiteit in de gezondheidszorg. Zijn we op weg naar een diversiteitsbewuste gezondheidszorg? Tijdschrift voor genderstudies 2:12-22.

Visser-Vandewalle V, van der Linden C, Temel Y, Celik H., Ackermans L, Spincemaille GH, Camaert J (2005). Long-term effect of bilateral subthalamic stimulation in advanced Parkinson disease. Parkinsonism \& Related disorders 11 (3):157-165.

Temel Y, Ackermans L, Celik H, Spincemaille GH, van der Linden C, Walenkamp GH, van de Kar T, Visser-Vandewalle V (2004). Management of hardware infection following deep brain stimulation. Acta Neurochirurgica 146:355-361.

Visser-Vandewalle V, Van der Linden C, Temel Y, Celik H, Beuls E (2003) Long-term motor effect of unilateral pallidal stimulation in advanced Parkinson disease; a study of 26 patients. Journal of Neurosurgery 99(4):701-707.

Celik H, Abma T.A., Klinge I,. Widdershoven G.A.M. Process Evaluation of a Diversity Training Program: the Value of a Mixed Method Strategy. (Submitted).

Celik H, Lagro-Janssen ALM, Klinge I, Widdershoven GAM, Abma TA. Bringing Gender Sensitivity into Health Care Practice: a Systematic Review. (Submitted) 